\title{
Treatment decisions in elderly patients with end-stage renal disease
}

Citation for published version (APA):

Mulder, W. J. (2002). Treatment decisions in elderly patients with end-stage renal disease. [Doctoral Thesis, Maastricht University]. Datawyse / Universitaire Pers Maastricht.

https://doi.org/10.26481/dis.20020531wm

Document status and date:

Published: 01/01/2002

DOI:

10.26481/dis.20020531wm

Document Version:

Publisher's PDF, also known as Version of record

\section{Please check the document version of this publication:}

- A submitted manuscript is the version of the article upon submission and before peer-review. There can be important differences between the submitted version and the official published version of record.

People interested in the research are advised to contact the author for the final version of the publication, or visit the DOI to the publisher's website.

- The final author version and the galley proof are versions of the publication after peer review.

- The final published version features the final layout of the paper including the volume, issue and page numbers.

Link to publication

\footnotetext{
General rights rights.

- You may freely distribute the URL identifying the publication in the public portal. please follow below link for the End User Agreement:

www.umlib.nl/taverne-license

Take down policy

If you believe that this document breaches copyright please contact us at:

repository@maastrichtuniversity.nl

providing details and we will investigate your claim.
}

Copyright and moral rights for the publications made accessible in the public portal are retained by the authors and/or other copyright owners and it is a condition of accessing publications that users recognise and abide by the legal requirements associated with these

- Users may download and print one copy of any publication from the public portal for the purpose of private study or research.

- You may not further distribute the material or use it for any profit-making activity or commercial gain

If the publication is distributed under the terms of Article $25 \mathrm{fa}$ of the Dutch Copyright Act, indicated by the "Taverne" license above, 


\section{Treatment decisions in elderly}

patients with end-stage renal disease 
Wubbo Jan Mulder, Maastricht 2002

ISBN 9052783454

Cover design: B. Eggen

Layout: Tiny Woulers

Production: Datawyse | Universitaire Pers Maastricht

Parts of this study were financially supported by the GERON Foundation. Additional financial support by Byk, MSD, Pfizer, Eli Lilly, Astra Zeneca, BMS, Novartis, Merck and Bayer was gratefully aknowledged. 


\title{
Treatment decisions in elderly patients with end-stage renal disease
}

\author{
PROEFSCHRIFT \\ ter verkrijging van de graad van doctor \\ aan de Universiteit Maastricht, \\ op gezag van Prof. dr. A.C. Nieuwenhuijzen Kruseman, \\ rector magnificus, \\ volgens het besluit van het College van Decanen, \\ in het openbaar te verdedigen \\ op vrijdag 31 mei 2002 om 16.00 uur
}

door

Wubbo Mulder

geboren op 5 september 1952 te Amsterdam

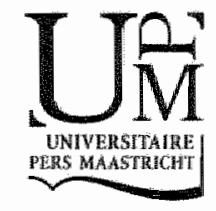




\section{Promotor}

Prof.dr. H.F.P. Hillen

Co-promotores

Prof.dr. K.M.L. Leunissen

Dr. J.F.B.M. Fiolet

\section{Beoordelingscommissie}

Prof.dr. J.A. Knottnerus (voorzitter)

Prof.dr. R.A.M.G. Donckerwolcke

Prof.dr. W.H.L. Hoefnagels (Katholieke Universiteit Nijmegen)

Prof.dr. R.Th. Krediet (Universiteit van Amsterdam)

Prof.dr. C. Spreeuwenberg 
What if a day or a month or a year

Crown thy delight with a thousand wished contentings,

Cannot the chance of a day or an hour

Fill thee again with as many sad tormentings

English Hymn

Wat (betekent het) als een dag of een maand of een jaar

Uw verrukking bekroont met duizend gewenste bevredigingen?

Kan niet het toeval van een dag of een uur

U niet opnieuw plagen met evenveel droeve kwellingen?

Engelse Psalm 



\section{Contents}

Abbreviations

Chapter 1 Intraduction, general outline and aims of the thesis

Chapter 2A Renal function and renal disease in the elderly

Chapter 2B Renal replacement therapy in the elderly

Chapter 3 Clinical characteristics of elderly patients with end-stage renal disease: a retrospective study in the Dutch population

Chapter 4 Treatment selection criteria and prognostic factors in elderly patients with end-stage renal disease

Chapter 5 The illness burden of end-stage renal disease in elderly patients

Chapter 6 General discussion: Rationing of renal replacement therapy in elderly patients with end-stage renal disease

Chapter 7 Summary

Chapter 8 Samenvatting

Dankwoord

Curriculum Vitae 


\section{Abbreviations}

\begin{tabular}{|c|c|c|}
\hline $\mathrm{ADL}$ & $=$ & Activities of daily living \\
\hline ACE & $=$ & Angiotensin converting enzyme \\
\hline ACTH & $=$ & Adreno cortico tropic hormone \\
\hline ARF & $=$ & Acute renal failure \\
\hline BOP & $=$ & $\begin{array}{l}\text { Beoardelingsschaal ouderen patiënten (Assessment scale } \\
\text { elderly patients) }\end{array}$ \\
\hline APD & $=$ & Continuous ambulatory peritoneal dialysis \\
\hline Cer & $=$ & Creatinine clearance rate \\
\hline $\mathrm{Cl}$ & $=$ & confidence interval \\
\hline CVD & $=$ & Cardiovascular disease \\
\hline EDTA & $=$ & European dialysis and transplant association \\
\hline ERA & $=$ & European renal association \\
\hline ERPF & $=$ & Effective renal plasma flow \\
\hline ESRD & $=$ & End-stage renal disease \\
\hline GFR & $=$ & Glomerular filtration rate \\
\hline HD & $=$ & Hemodialysis \\
\hline ICD-9-CM & $=$ & $\begin{array}{l}\text { International classification of diseases } 9 \text { th revision, clinical } \\
\text { modification }\end{array}$ \\
\hline IDDM & $=$ & Insulin-dependent diabetes mellitus \\
\hline MMSE & $=$ & Mini mental state examination \\
\hline MOF & $=$ & Multi organ failure \\
\hline NIDDM & $=$ & Non-insulin-dependent diabetes mellitus \\
\hline NSAIDs & $=$ & Nonsteroidal anti-inflammatory drugs \\
\hline PAH & $=$ & Para amino hippuric acid \\
\hline PD & $=$ & Peritoneal dialysis \\
\hline RAAS & $=$ & Renin angiotensin aldosterone system \\
\hline RRT & $=$ & Renal replacement therapy \\
\hline RPF & $=$ & Renal plasma flow \\
\hline SD & $=$ & Standard deviation \\
\hline SIP68 & $=$ & $\begin{array}{l}\text { Sickness impact profile (The Maastricht variant of the SIP } \\
\text { with } 68 \text { questions) }\end{array}$ \\
\hline USRDS & $=$ & United States renal data system \\
\hline
\end{tabular}




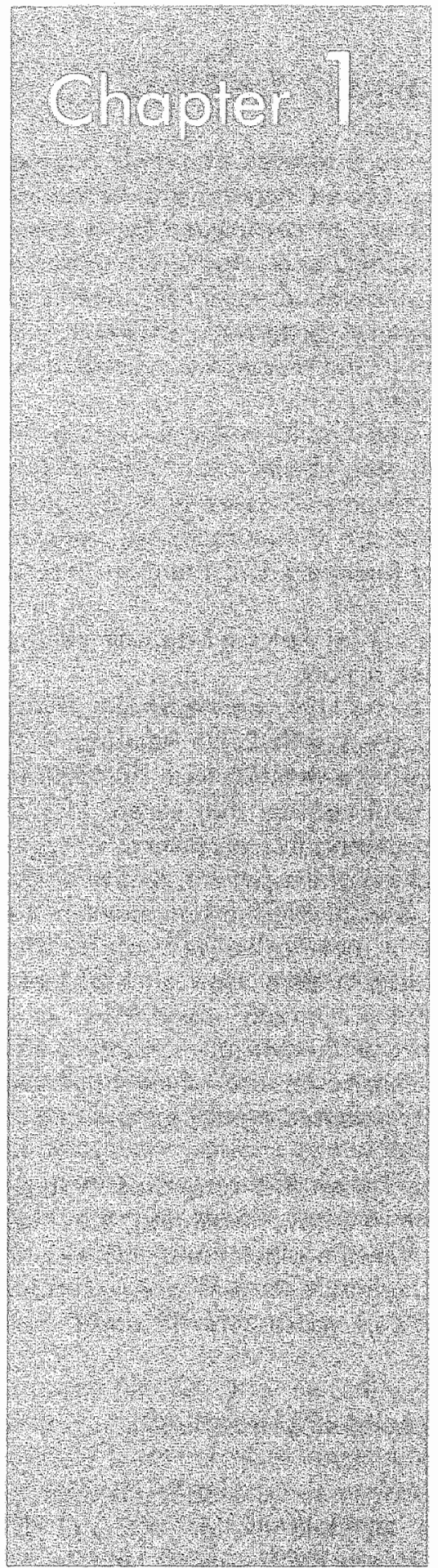

\section{Introduction, general outline and aims of the thesis}




\section{Introduction, general outline and aims of the thesis}

End stage renal disease (ESRD) is more and more a disease of elderly people. The progress of medical technology not only leads to an increase of average life expectancy, but also to a more effective treatment of cardiovascular disease. This results in a growing number of patients with ESRD as a late manifestation of wascular disease. Mareover, medical progress enables us to enroll patients at advanced age in renal dialysis and transplantation programs, whereas until recently the decline of physiology and function in the elderly were considered contraindicative for renal replacement therapy (RRT).

RRT is a heavy burden for the elderly patient, who has to undergo therapy for many hours a week and has to withstand many side effects and complications. Elderly patients on dialysis often have more chronic illnesses and are more debilitated than those without renal failure and are therefore more prone to complications. RRT is a very expensive form of treatment and therefore also a heawy burden for society.

For elderly patients, RRT (dialysis, mostly passive center dialysis) is mostly lifelong therapy, because renal transplantation is a scarce option.

In most West-European countries, as well as in the USA, and Australia, some form of selection is applied for the elderly patients with ESRD entering RRTprograms. Hardly any data can be found in literature which criteria are used to carry out this selection. Although there is general consent that severe loss of cognitive function is a selection criteria for not entering RRT programs, whereas age itself is not. Other factors like general condition of the patient, co-morbidity, but also socioeconomic status, social activity, and finally the limitation in the health care resources, probably all play a roll in making the decision to offer renal replacement therapy in the individual elderly patient. How each of these and perhaps other factors influence patient selection is largely unknown.

Dialysis therapy is no cure for ESRD, but a therapeutic measure to sustain life. The ESRD patient on diallysis is a patient with a chronic disease, which influences many aspects of his life. A number of studies demonstrate significant changes in the quality of life of almast every patient on $\operatorname{RRT}^{1,2,3}$.

In the USA, with probably less patients excluded from RRT programs, a large percentage of elderly patients withdraw from therapy, indicating the high demands of dialysis on the individual patient. On the other hand, there is an indication that some elderly patients are able to adjust to stressful events such as $\mathrm{RRT}^{4}$. So in many respects it is useful to find the best match between patient and therapy.

In this thesis we will try to find an answer to a number of questions concerning this subject (Figure 1.1).

First of all we undertook a retrospective study to answer the question whether there is selection of elderly patients in the Netherlands for entering RRT programs and to determine the percentage of elderly ESRD patients who do not receilve RRT. 
Retrospective study

Chapler 2

Chopter 3

-Clinical cherocteristics

- Sopotientus entering RRT

Chapler 4

Medicall characteristics

- Biological charoc ter istices:

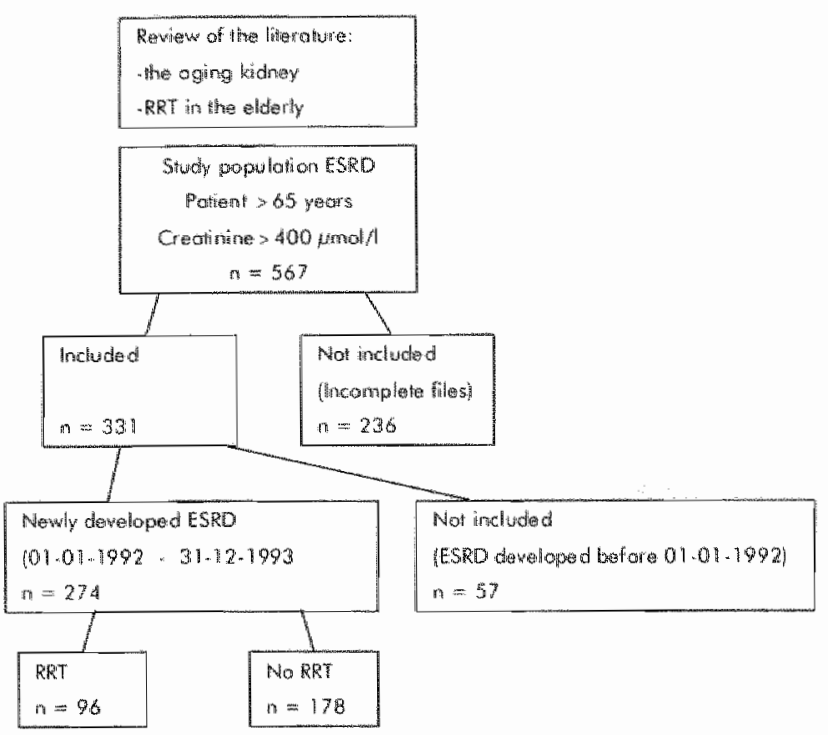

Cross-sectional sludy

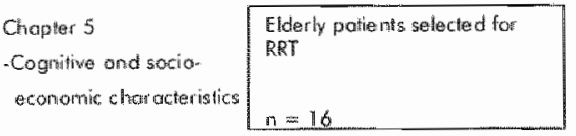

Thapter 5

econpmbs choriacteristic

Chapter \&

Proposed olgorith m for trestrment detsion in alderly ESRD potians
Eiderly patienis stoble on RRT Elderly patients: control grous no renal dystunction $n=59$

Figure 1.1 General outline of the thesis

Secondly we wanted to find out which criteria can be used to identify those elderly patients with ESRD who will respond best on RRT.

In an elderly population sickness is more often one of the problems contributing to a complex problem of multimorbidity and functional loss, than a single entity. Therefore, our investigations focused on somatic, biological, aspects as on social, non-biological, factors.

A question of equal importance was whether the elderly ESRD patient benefits from RRT. Is chronic dialysis just adding time to life or offers it the patient an opportunity for a meaningful continuation of his life?

In chapter 2A the literature is reviewed concerning morphological and functional changes of the aging kidney, as well as the pathological conditions leading to loss of renal function in the elderly.

In chapter $2 \mathrm{~B}$ a literature review is performed on renal replacement therapy in elderly patients, differentiated to the respective treatment modalities, with inclusion of data on renal transplantation in this population. 
In chapter 3 a retrospective study is presented in which epidemiological data are collected of elderly patients with ESRD in 1992 and 1993, seen in four hospitals with dialysis facilities in the southern part of the Netherlands. Patient selection was performed by a survey in the laboratory records of the four participating hospitals. Elderly patients age 65 years and over, with a serum creatinine of $400 \mu \mathrm{mol} / \mathrm{I}$, as an arbitrary measure of ESRD, were selected. In this woy we found 567 patients. The medical files of 331 patients revealed sufficient data for data collection on baseline characteristics, socioeconomic status, functional status, medical history, primary renal diagnosis, comorbidity, medical interventions, and clinical course. Of special interest in this study is the fact that data are collected not only from patients who were actually treated for ESRD, but also those patients are taken in account who, based on their laboratory results were potentially candidates for RRT, but did not receive dialysis treatment. In this way a rather accurate estimation was possible of the size of the problem of ESRD in the elderly. The focus in this chapter is on the clinical characteristics of elderly patients with end-stage renal disease.

In chapter 4 a retrospective study is presented on the medical and biological characteristics of the same population. However in this study only data of 277 elderly patients who developed ESRD in 1992 and 1993 were collected. A comparison is made between patients who underwent RRT and patients who did not. Apart from a survival analysis between both groups, an attempt is made to find out which biological and non-biological criteria were decisive in the treatment decision.

In chapter 5 biological and non-biological characteristics of elderly patients with ESRD are studied in a cross-sectional study. A comparison is made between patients with end-stage renal disease but not yet on RRT, patients stable on RRT and elderly patients with no apparent renal dysfunction. In this chapter the hypothesis is tested that RRT is improving the condition and the feeling of well being of elderly patients with ESRD. Also the question is posed whether, and if so in which respect, patients stable on RRT still differ in their assessment of sickness from elderly patients with no renal impairment.

In this chapter non-biological characteristics are central issues. Assessment of the cognitive function and the socio-economic status was performed in a crosssectional study. In a retrospective investigation measuring of cognitive function and social activity is not good feasible, so a transversal investigation was necessary. A comparison was made between 16 elderly patients with ESRD before undergoing RRT, 107 patients stable on RRT and 59 consecutive patients, without important renal impairment and in no need for langstanding chronic therapy referred to the outdoor geriatric department. Beside cognitive function, measured by the Mini Mental State Examination (MMSE), and functional status using the Katz's scale of basic activities and the Barthell index, quality of life was registered with the aid of the Maastricht variant of the Sickness Impact Profile, the SIP68 in this study. 
Two questions are addressed in this chapter. First, are cognitive function, socioeconomic status, social activity, and patients self-estimation of quality of live, factors in patient selection for RRT; and, secondly, are patients on RRT improving on these factors during RRT. The geriatric outdoor population is here used as a control group to assess the basic functional and socio-economic parameters in a ellderly population for comparison.

In chapter 6 we discuss the ethical implications of selection of elderly patients for treatment by renal function replacement therapy. Secondly we propose an algorithm, which can be used to perform this selection.

In chapter 7 a summary is given of the studies in this thesis.

Chapter 8 is a summary in Dutch.

In summary, the main questions of this thesis are:

1. What is the incidence and prevalence of ESRD in elderly patients? (Chapter 3)

2. What is the extent of patient selection for renal replacement therapy in the group elderly patients with ESRD? (Chapter 3 )

3. Are there biological and/or non-biological determinants on which this selection is based? (Chapter 4)

4. What is the outcome of RRT in elderly patients, in comparison with the patients not treated with RRT? (Chapter 3)

5. What are the biological characteristics of elderly patients with ESRD at the start of treatment? (Chapter 5)

6. Is RRT in elderly patients leading to improvement of quality of life and social activity? (Chapter 5)

7. Is it possible to make recommendations for future patient selection? (Chapter 6) 


\section{Literature}

1. Bhl $M$, Ferrans $C$. Powers $M$. Coparing stressors and quality of life of dialysis patients. ANNA Journal 1988; 15(1):27-36.

2. Denour $A$, Shannon J. Qualify of life of dialysis and transplanted patients. Nephron $1980 ; 25: 117-120$.

3. Jahnson J, McCauley C, Copely J. The quality of life of hemodialysis and ransplant patients. Kidney International 1982;22:286-291.

4. Morgan B. The relationship between chronological age and perceived quality of life of hemodialysis patients. ANNA Joumal 1990;17(1):63-66. 


\section{Renal function and renal disease in the elderly}

WلMulder, Hillen HFP

European Journal of Internal Medicine $2001 ; 12: 86-97$ 


\section{Abstract}

In all industrialized countries, life expectancy has risen in the past 100 years. The number of elderly patienis reaching end-stage renal disease (ESRD) and requiring renal replacement therapy has also increased. During the past few decades, the pattern of ESRD has changed significantly with the emerging predominance of elderly patients. The causes of this phenomenon are manifold and include an increasing number of chronic diseases Aypical of the "third age", such as type 2 diabetes and vascular disease. In many species, a consequence of aging includes deterioration of renal function, partly due to structural alterations, and partly as the result of a diminishing blood flow. Im humans, the aging kidney is characterized by modifications resulting from organic and functional disturbances. In particular, type 2 diabetes mellitus has emerged as an important condition, the microvascular and macrovascular complications of which are a common cause of morbidity and mortality in older patients. In part 1 of this review, the marphological and functional changes of the aging kidney will be reviewed, as well as the pathological conditions leading to the loss of renal function in the elderly. 


\section{The aging kidney}

\section{1. hroduction}

Today, the treatment of renal diseases reflects a changing situation with an aging population. The proportion of the population made up of elderly persons in the western world is steadly increasing. In 1900 , only $4 \%$ of the population in the Netherlands was 65 years of age or older. In 2000, the percentage of persons 65 years or older has uncreosed to 13.5 , representing 2.1 mitition inhabitants. Moreover, $2.3 \%$ of the Dutch population is 80 years of age and older."

The growing elderly population is a consequence of increased longevily in our society. The life expectancy for men was 70.8 years in 1972 ; this increased to 75.2 years in 1997 . For women, was 76.8 years in 1972 and 80.6 years in $1997^{2}$

Longevity and an increasing elderly society have several implications for the delivery and costs of heolth care in patients with renal disease. Elderly persons use health care services at a greater rate than young persons do. Heath care and the costs associated with it increose with age. ${ }^{3,4}$ The mojor reason for this increase is the improvement in medical fechnology which allows effective treatment for elderly patients. Age itself is no longer a contraindication for even complex medicat treatments such as hemodialysis and renal transplantation.

Since the 1980s, senal replacement therapy is technically avallable to older patients. Since then an increase is seen in renal replacement theropy in elderly patients due to a liberalisation of acceptance criterio for dialysis in combination whth the age-reloted increase in the incidence of chronic rencl failure. ${ }^{5}$ However, in dally practice, rend replacement freatment is anly performed in approximately $40 \%$ of elderly patients with renal failure..$^{6-12}$ Comorbidity, impaired mobility and impaired cognitive functions are the main medical criteria for selecting elderly patients for renal replacement therapy. ${ }^{13,14}$ Yet, ageism and different opinions of patients, of primary care physicians and of specialists are involved in the selection process. ${ }^{15,16}$

Giving the important implications of age on health care for elderly patients with renal disease, we reviewed the main aspects of the pathophysiology of the aging kidney, the epidemiology of renal failure at old age, and the application of renal replacement therapy in the elderly.

\subsection{The aging kidney}

Aging is accompanied by a substantial reduction in renal function. Yet, the function of the senescent kidney is still sufficient under normal circumstances at older age. Changes in renal function reduce the capacity of elderly persons to respond to physiological and pathological stress. In fact, a number of serious 
characteristic morphological and functional disturbonces often characterize the aging kidney.

\subsection{Morphological changes}

\subsubsection{Macroscopic changes}

The weight of the human kidneys remains fairly constant until the fifth decade of life and then slowly decreases to less than $300 \mathrm{~g}$ in the ninth decade of life. ${ }^{17.19}$ There is a more substantial loss of tissue in the cortical than in the medullar region. ${ }^{20,21}$ In the medulla an increase is seen in the interstitial tissue, accompanied by fibrosis and increase of fat content af the level of the renal sinus. Renal length may diminish as much as $2 \mathrm{~cm}$ between the fitth and eight decade, which represents a loss in volume of $40 \%{ }^{22}$ This reduction correlates with the degree of sclerosis of the intrarenal arteries, suggesting that these agerelated changes are related to atherosclerosis.

In elderly persons without apparent renal disease, over $50 \%$ of the kidneys autopsied are smooth or manifest only a fine granularity at the surface. Only about 12 to $14 \%$ of the kidneys are coarsely scarred. ${ }^{23.24}$ This scarring is ubiquitously distributed aver the kidney. Studies of hypertensive subjects have shown similar results.

Simple cysts are common in the aging kidney, especially along the distal nephron. They increase in frequency and size after the fifth decade. ${ }^{25}$

As the cortex becomes thinner, glomeruli tend to crowd together. ${ }^{26}$ The medulla shows a marked increase in interstitial fibrosis after the age of $70 .{ }^{27}$

A reduced concentration of acid mucopolysaccharides in the medulla is mentioned as a cause of this medullar fibrosis. In the cortex, these concentrations remain unchanged. ${ }^{28}$

\subsubsection{Microscopic changes}

\subsubsection{The glomeruli}

The number of glomeruli decreases with age. Moore found that the mature adult kidney contains between 600.000 and 1.2 million glomeruli. ${ }^{29}$ in subjects dying in the seventh decade of their lives the number of glomeruli was half or twothirds of that at a younger age. After the third decade, glomerular sclerosis begins to appear, eventually leading to collapse of glomeruli, which are finally replaced by hyaline material. The proportion of hyalinized, obliterated glomeruli in the adult kidney tends to increase with age, especially in men. In an autopsy study, Kasiske showed that glomerulosclerosis correlates with the extend of intrarenal vascular changes. ${ }^{30}$ Both age and the extend of atherosclerotic vascular changes correlated independently with the number of hyalinized glomeruli in the cortex as well in the medulla. In subjects over the age of 50 , this proportion ranges from 1 to $30 \%$ and is unrelated to the total number of glomeruli 26,27 . While the number of glomerular tufts, as well as the number of glomerular and tubular cells decreases, the size of the individual cells 
increases. ${ }^{3 i}$ In juxtaglomerular nephrons this obliteration leads to a direct continuity between afferent and efferent arterioles. ${ }^{32}$ In the more peripherally sited nephrons, obliteration of the glomeruli is accompanied by an obliteration of the vasa afferentia.

In rats, the earliest changes in glomerular sclerosis include thickening of the mesangium and of the glomerular basal membrane. Changes in the number of mesangial cells and in the contents of glomerular cells lead to obliteration of the urinary space, adhesion of the capillary loops, hyalinisation and, finally, sclerosis. ${ }^{33}$ The glomeruli of aging rats contain $\lg M$, but these deposits do not seem to produce the renal lesions. ${ }^{34}$ The appearance of these deposits coincides with the development of proteinuria and the frequency of both increases with age. In humans, the glomerular basement membrane thickens only until the fourth decade. ${ }^{35}$ After the age of 60 , the surface area of the glomerular basement membrane decreases again and shows wrinkling, followed by deposition of hyaline material. With the reduction in the number of glomeruli, hyperperfusion and hyperfiltration of the remaining glomeruli develop. ${ }^{36}$ Hyperfiltration leads to disruption of the capillary membranes contributing to progression of the sclerosis of the glomeruli.

\subsubsection{The distal nephron}

The tubuli show marked changes with increasing age: thickening of the basement membrane, focal cellular necrosis, irregular cell height, and morphological cell alterations, all eventually leading to a decrease in the proximal tubular volume.

Collecting tubules dilate and resemble diverticuli, many of which contain bacteria and may be the source of recurrent urinary tract infections in the elderly. ${ }^{37}$ These ectasia and diverticuli from distal and convoluted tubules become more common with age. From one single nephron up to 20 may arise and probably result in the weakening of the tubular basement membrane. Many contain histological evidence of casts, epithelial debris and organisms, leading some authors to suspect that they are responsible for recurrent urinary tract infections. ${ }^{38}$ In biopsies drawn from over 100 patients - from newborn to very ald subjects - a strong correlation was found between glomerular and tubular dimensions. The volume of glomeruli and proximal tubuli diminished at the same rate. Oliver, however, stated that in later life there is little correlation between the size of glomeruli and tubuli. Thus the tubule does not constantly degenerate after glomerular destruction. ${ }^{39} \mathrm{He}$ described hypertrophy with hyperplasia of proximal tubules of glomeruli that were normal in size, atrophied, or even destroyed. More distal parts of the nephron were much less affected.

\subsubsection{Risk factors}

It is still a matter of debate whether the loss of nephrons is the result of aging alone or an effect of concomitant pathological conditions such as hypertension, diabetes mellitus type I as well as type II, recurrent infections of the urinary tract, hyperlipidemia, and atherasclerosis. ${ }^{40}$ Cigarette smoking increases both in type I and in type II diabetes mellitus the risk of development of nephropathy and 
nearly doubles the progression to end-stage renal failure. ${ }^{41,42}$ But also in patients with a primary renal disease smoking is an independant risk factor for progression to renal failure. ${ }^{43}$ The pathogenesis is thought to be vascular, with intra- en extrarenal hemadynamic changes, and non-vascular, toxic, with damage of the renal and particularly glomerular microvasculature as a result of its effects on platelet function, thromboxane metabolism and endothelial cell function. ${ }^{44}$

Renal irradiation and thyroid or androgen supplements are mentioned to accelerate age-related glomerular sclerosis. ${ }^{45.47}$

The process of glomerulosclerosis may be influenced to some extend by therapies aiming at decreasing glomerular and systemic hypertension, reducing hyperfiltration by decreasing protein load and preventing secondary hyperparathyraidism. ${ }^{48,49}$

\subsection{Vascular changes and renal plasma flow}

\subsubsection{Vascular changes}

Renal blood flow per gram decreases progressively after the fourth decade..$^{50}$ Cortical flow decreases to a greater extend than medullary flow. This decline is not attributable to a reduced cardiac output, but due to an increased renal vascular resistance. ${ }^{51}$

The small arteries of the kidney show an age-related progressive thickening of the intima, mainly consisting of elastic tissue, associated with atrophy of the

In the terminal arteries and in the arterioles, intimal thickening is caused by subendothelial deposition of hyaline material and callagen fibers. Changes appear in small arteries as early as the second decade but become more pronounced after the age of 30 . By the age of 50 all arteries are involved. ${ }^{52}$ The question remains whether these changes are the result of aging alone or (partly) of hypertension and atherosclerosis. In a micro-angiographic examination of the aging normotensive kidney, Ljungquist and Lagergren, who recorded increasing tortuosity of the afferent arterioles, did not find a difference
between the ages of 60 and 79.53

Postmortem angiographic examination of kidneys of normotensive subjects showed the most severe changes in the most peripheral arteries, particularly those at the renal poles. However, no correlation was found between age and severity of vascular changes above the age of 50 . Only a comparison between young and elderly subjects gave significant differences. ${ }^{23,54}$ Aging also has its influence on the endothelium function in the renal circulation. Intravenously administrated L-Arginine induces a much smaller increase in renal plasma flow and plasma cGMP in hypertensive patients than in normotensives. ${ }^{5.5}$ Multivariate analysis however showed that aging besides hypertension may independently impair endothelium-dependent renovascular dilatation. This effect production. 


\subsubsection{Renal plasma flow}

Ageing is accompanied by a decrease of renal plasma flow (RPF) and renal blood flow. ${ }^{56}$ Renal plasma flow (RPF), measured by para-amino-hippuric acid(PAH-) clearances, decreases with age at a greater rate than inulin clearance, from a mean of $649 \mathrm{ml} / \mathrm{min}$ in the fourth decade to a mean of $289 \mathrm{ml} / \mathrm{min}$ in the ninth decade. The increment of the RPF on an acute oral protein load $(1 \mathrm{~g} / \mathrm{kg}$ body weight) is also reduced in elderly (>60 years) patients. ${ }^{57}$ McDonald and colleagues found that elderly subjects were capable of a greater vasodilatation (and a greater increase in PAH) than younger subjects. ${ }^{5 \mathrm{~B}}$

They suggested that renal vasculature in elderly people showed a relatively higher state of vasoconstriction. The decrease in RPF, they stated, was, therefore, the result of an enhanced renal vascular resistance. Later investigations, however, showed a greater baseline vasodilatation in the renal vasculature of the elderly. ${ }^{59}$ This postulates a diminished blood flow to the renal vessels due to intraluminal changes (atherosclerosis). The rise in blood pressure with age and the high-protein 'western' diet are mentioned as possible contributors to the progressive fall in renal perfusion and function with increasing age. However a comparison between 29 inhabitants of Boston (USA) (age range 19- 79 years, mean: 52.4) and 16 indian inhabitants of an isolated Panamanian island (age range 18-86 years mean: 51.6 ) with no tendency of blood pressure rise with age and on a low protein diet, does not support this hypothesis. ${ }^{60}$ Renal plasma flow and filtration fraction (GFR/effective RPF) rose with age in both populations and even steeper in the indian population. GFR however, was higher at any age in the island inhabitants.

The cortical blood flow decreases more rapidly than the mean blood flow, sparing the juxtamedullary nephrons. These nephrons have a higher filtration fraction. This seems to explain why the filtration fraction in the elderly is often increased. ${ }^{61}$ However, this can also indicate an increased postglomerular vascular resistance.

\subsection{Functional changes in aging}

\subsubsection{Glomerular filtration rate}

Glomerular filtration rate (GFR) is low at birth, reaches normal (adult) values before the end of the second year of life, and remains fairly constant until the age of $30 .{ }^{62}$ Early studies indicate thatt, thereafter, GFR shows a linear decline. As a result, the values in the eighth decade are only one-half to two-thirds of those measured in young adults. ${ }^{41,63}$

Later investigations suggest that the decline in GFR with increasing age shows more of a non-linear pattern. ${ }^{6.67}$ The decline of GFR in younger adults has an average rate of $4 \mathrm{ml} / \mathrm{min}$ per decade. In the period between 50 and 75 years of age, this ralle amounts to approximately $10 \mathrm{ml} / \mathrm{min}$ per decade. ${ }^{68}$ After the age of 75 , the rate of decline decreases again to a slower rate. ${ }^{69}$

Yet, while creatinine clearance decreases with age, often no increase in plasma creatinine is seen. ${ }^{70}$ Thus, serum creatinine concentration in the elderly conceals the physiological decrease in GFR. In renal disease, it is usually thought that the 
number of nephrons must be halved before function is affected, a reduction apparently unusual in the aging kidney. "The remaining nephrons probably undergo compensatory hypertrophy. ${ }^{72}$ Differences between kidneys in this capacity for hypertrophy, possibly depending on the condition of their vessels, could explain the large differences in glomerular dimensions found in the elderly. ${ }^{71}$ Comorbid conditions therefore, can confound renal function in the elderly. Fliser et al. performed a comparative study between young healthy normotensive subjects ( $\mathrm{n}=24$ mean age 26.3 years), elderly healthy normotensive subjects $(n=29$ mean age 68.7 years), elderly treated and untreated hypertensive patients $(n=25$ mean age 70.6 years), and elderly patients with compensated mild to moderate heart failure $(n=14$ mean age 69.6 years). ${ }^{73}$ Compared to the young subjects mean GFR was significantly lower in the elderly, despite similar mean plasma creation levels.

However, GFR was in normal range in the elderly normotensive and hypertensive subjects, but not in the elderly patients with heart failure. ERPF was significantly lower in the elderly hypertensive patients in comparison with the normotensive elderly and still lower in the heart failure patients. Mean renovascular resistance and filtration fraction were significantly higher in the elderly, particularly in hypertensive and heart failure patients as compared with the young.

Despite the decrease in GFR in the course of a person's life, renal reserve, defined as peak postprandial GFR minus basal GFR, remains unchanged with increasing age. ${ }^{7 / 4}$ Population studies demonstrate a $10 \%$ decrease in GFR per decade after the age of 40 , without a change in serum creatinine. ${ }^{75}$

Because of the limited use of serum creatinine to estimate the creatinine clearance $(\mathrm{Ccr})$ in the elderly, the Cockroft and Gault formula is often used to

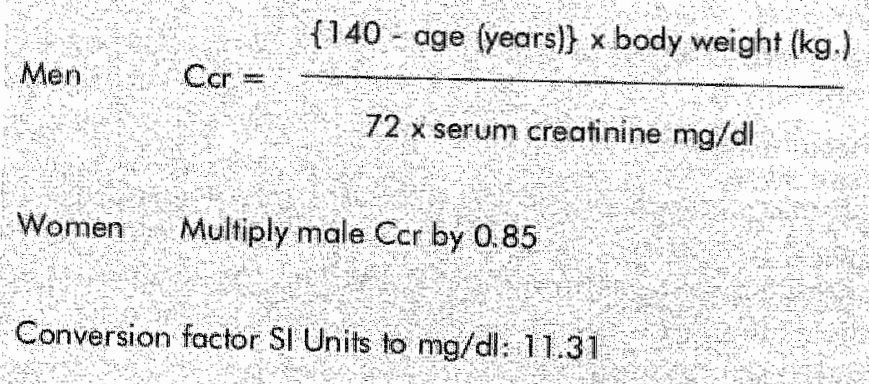

Although this formula is useful to estimate $\mathrm{Ccr}_{\text {r }}$ one must realize that it is not a substitute for careful clinical evaluation of the (elderly) patient. ${ }^{77}$ Gentric and colleagues found that the Cockroft and Gault formula underestimated GFR when compared to isotopic measurements in well-nourished patients with stable 
renal function who were $81-96$ years of age. ${ }^{78}$ A study using iothalamate clearance as the gold standard in 41 patients aged $65-85$ years found a poor correlation with the estimation of Cockroft and Gault. ${ }^{78}$

Longitudinal studies show a very large individual variance in the correllation between age and $\mathrm{Ccr}$. Lindeman et al. performed a long-term follow-up study of 446 persons, divided into three groups. Group 1 included 118 patients with some kind of renal disease - infection, hematuria, proteinuria, kidney stones, glomerulonephritis, or obstruction, group 2 consisted of 74 patients with hypertension, and group 3 included 254 healthy subjects. ${ }^{80}$ In all three groups, the mean decline in Cor was $0.87 \mathrm{ml} / \mathrm{min}$ per year: in group 1 it was 1.1 $\mathrm{ml} / \mathrm{min}$ per year, in group 2,0.92 $\mathrm{m} / / \mathrm{min}$ per year; and in group $3,0.75$ $\mathrm{ml} / \mathrm{min}$ per year.

Of these 446 persons, one-third (156) showed an increase in their GFR, suggesting that the decline in GFR often found in seemingly healthy persons is the result of an undetected pathological condition.

\subsubsection{Sodium and potassium metabolism}

With increasing age the capacity of the kidneys to conserve sodium becomes impaired. Frequently elderly patients have a high natriuresis and tend to sodium depletion, despite a decrease in GFR. ${ }^{81}$ Possible causes for renal sodium loss in healthy aged subjects include a low aldosterone level and a diminished reabsorption function of the ascending Henle's loop. ${ }^{82}$ Reduced Na-K-ATP-ase activity may also be involved. ${ }^{83}$ Acute sodium loading is associated with an enhancement of sodium excretion. In the elderly however, this reaction is delayed in comparison to younger subjects. ${ }^{84}$

Elderly persons have lower plasma renin activity. Basal renin, whether estimated by plasma renin concentration or renin activity, is diminished by $30 \%-50 \%$ in the elderly, despite normal levels of renin substrate. This basal difference between young and ald individuals is magnified by manoevres that augment renin secretion, eg salt restriction, diuretic administration and upright position. ${ }^{85}$

The lowered renin levels are associated with 30\%-50\% reductions in plasma concentrations of aldosterone, as well as with significant reductions in the clearance rate and the urinary aldosterone excretion, while on an unrestricted salt diet as well as after salf restriction. ${ }^{86,87}$ Plasma aldosterone and cortisol responses after ACTH stimulation are not impaired with advancing age, demonstrating that aldosterone deficiency in the elderly is a function of the coexisting renin deficiency and is not secondary to intrinsic adrenal changes. This probably accounts for the impaired salt restriction in elderly patients when challenged with a low-salt diet. Similarly it would account for the tendency of elderly subjects to develop hyperkalemia when placed on a low-salt diet. Agerelated alterations of the kidney (glomerulosclerosis, decreased number of functional mephrons) might account for the difference in the active to inactive plasma renin ratio. Also, a diminished synthesis of angiotensinogen by the liver can contribute to the decrease in the activity of the RAAS in aging. Furthermore, 
aging is associated with a reduced adrenal responsiveness to angiatensin II, resuling in a lower production of aldosterone.

The capacity to conserve potassium is also diminished in the elderly. Total body potassium is $20 \%$ lower than in younger subjects. ${ }^{3}$ On the other hand can the age-related decreases in renin and aldosterone contribute to an increased risk for hyperkalemia in the elderly in a variety of clinical settings. Through its action on the distal renal fubule, aldosterone increases $\mathrm{Na}^{+}$-reabsorption and facilitates the excretion of potassium. Aldosterone is therefore one of the major protective mechanisms in the prevention of hyperkalemia during potassium challenge. Since GFR (another major determinant of potassium excretion) is also impaired in older patients, serious elevations in plasma potassium are likely to develop, especially in the presence of $\mathrm{G}$ bleeding or when potassium salts are given intravenously. Moreover, the tendency to hyperkalemia is enhanced by any clinical setting associated with acidosis since the senescent kidney is rather slow in its reaction to acid loading, resulting in prolonged depression of serum $\mathrm{pH}$ and concomitant potassium elevation.

Potent antagonists of renal potassium excretion (e.g., spironolactone or friamterenel, as well as most nonsteroidal anti-inflammatory drugs (NSAIDs), Badrenergic blockers, and angiotensin-converting enzyme (ACE) inhibitors, which also inhibit potassium elimination, should be administered with caution in the elderly, and the concomitant administration of these agents and potassium should be avoided.

\subsubsection{Calcium and phosphate metabolism}

The serum levels of serum electrolytes, including calcium and phosphate remain relatively stable during life. The aging kidney, however, has a reduced capacity to deal with drastic changes in the serum levels of different electrolytes. ${ }^{91}$ For example, in the elderly, the reaction to immobilization, particularly when due to paralysis or a fracture, is exaggerated and may rapidly produce urinary calcium excretion in excess of $500 \mathrm{mg} / 24 \mathrm{~h}$ and lead to calcium stone formation.

It is customary to find relatively lower normal serum levels of calcium and higher serum levels of phosphate in the elderly as compared to young adults. In the aged, hypocalciuria and hyperphosphaturia are often found, the result of functional renal impairment. ${ }^{92}$

In addition, it should be noted that the elderly can suffer from a variety primary and secondary renal diseases that profoundly influence the remal metabolism of calcium and phosphate: e.g. Paget's disease, hypenthyroidism, malignancies, vitamin D deficiency, hyperparathyroidism, and diabetes mellitus. ${ }^{93,94}$

\subsection{Risk factors}

\subsubsection{Díabetes mellitus}

Over the past two decades, patients with diabetic renal disease, have comprised a steadily increasing segment of the population with end-stage renal disease (ESRD). ${ }^{95}$ In diabetes mellitus type I, increased capillary pressure and permeability are believed to play an important role in the pathogenesis of 
diabetic microangiopathy. ${ }^{96}$ Several authors have pointed out that in various organs, including the kidney, blood flow is increased. ${ }^{96.97}$ In early diabetes, this leads to renal hypertrophy with enlargement of the glomeruli, both generally and in the amount of basement membrane substance. Later on, the kidneys of a diabetic are at risk from a specific lesion typified by the nodular glomerulosclerosis, the Kimmelstiel-Wilson-lesion. In patients with type Il diabetes and micro-albuminuria, advanced structural changes in the glomerular basement membrane are seen. ${ }^{98}$ Typically ESRD occurs in type I diabetes some 15-30 years after diagnosis of diabetes, usually within $2-3$ years of onset of the nephrotic syndrome. ${ }^{99}$

Not very lang ago, type 11 diabetes mellitus was believed to be a benign condition, especially in elderly patients, with respect to life expectoncy and renal function. ${ }^{100}$

Now it is accepted that the rate of renal disease is equivalent in non-insulindependent diabetes mellitus (NIDDM) and insulin-dependent diabetes mellitus (IDDM). ${ }^{101.104}$ Nowadays, because of the greater prevalence of diabetes type II, patients with NIDDM account for most of the diabetics on dialysis. ${ }^{105,106}$

A number of patients with type II diabetes have the classic Kimmelstiel-Wilson lesions in their kidneys. Others, however, have non-specific vascular and interstitial lesions with few glomerular changes or none at all. ${ }^{107}$ A kidney afflicted with glomerulosclerosis may be more susceptible to diminished mesangial clearance function or immunologically mediated damage. Membranous and IgA nephropathies, focal segmental glomerulosclerosis and mesangiocapillary and extracapillary glomerulonephritis have been described in association with diabetes. ${ }^{108}$ Biopsy studies carried out in subjects with proteinuria, but with a glomerular filtration fraction in the normal range have found low prevalences (between 10 and $20 \%$ ) of glomerulonephritis. ${ }^{109,110}$

Improved glycemic control is known to slow the onset and progression of microvascular complications, but its effect on atherosclerotic disease has not been conclusively demonstrated."

Nephropathy in NIDDM is strongly determined by genetics. ${ }^{106,112,113}$ In clinical practice, the finding of a positive family history of cardiovascular events is a simple but powerful indicator for renal risk in NIDDM patients.

Non-insulin-dependent diabetics who develop nephropathy do so usually within 5-10 years of the diagnosis of diabetes, and the older the diabetic is at onset of nephropathy, the more rapid is the progression to ESRD. ${ }^{114}$

\subsubsection{Hypertension}

In the Baltimore longitudinal study of aging, a statistically significant correlation was found between mean blood pressure and the increase in serum creatinine in 1000 male volunteers between the ages of 22 and $97 .{ }^{115}$ The overall conclusion was that the decline in renal function was independently carrelated with age and mean arterial blood pressure, and that these variables were independent of each other. Thus, hypertensive patients without clinically detectable renal disease will have a greater expected decline in renal function than normotensive subjects. ${ }^{116}$ Higher levels of both diastolic and systolic blood 
pressure increase progressively cardiowascular morbidity and mortality. ${ }^{17.118}$ Systolic blood pressure however, is a more powerful risk factor for cardiovascular diseases than diastolic bloodpressure in elderly. The Multiple Risk Factor Intervention trial showed that a systolic bload pressure of $160 \mathrm{mmHg}$ was more closely associated with mortality than a diastolic bload pressure of 95 mintg. ${ }^{119}$ In the SHEP study the percentage of elderly (older than 60 years) with isolated hypentension was found to be over $10 \%$. 20

Untreated primary hypertension is very likely to cause renal damage. "The aging kidney's diminished functional reserve place it at risk for the progression of hypertensive arteriolar nephrosclersosis and also predispose to vulnerability related to reductions in blood flow and tissue oxygenation associated with transient decreases in intravascular volume and bload pressure. ${ }^{122}$

Many authors consider the prognosis of treated essential hypertension to be very good. They estimate that a small percentage $(<2 \%)$ will develop chronic renal failure. ${ }^{123,124}$ Others, however, do not share this optimism.

They point out that in the United States, one in 13 persons $(7.7 \%)$ with hypertension will develop hypercreatinemia, and $4 \%-16 \%$ of treated hypertensive patients have proteinuria. ${ }^{125,126}$ Several authors report a progression in the decline of the renal function. ${ }^{78,127,128}$

\subsubsection{Other risk factors}

Hyperlipidemia and race are other risk factors for declining renal function over time. ${ }^{129}$ McCord first reported that hypentensive black patients were more likely to acquire renal failure due to nephrosclerosis than Caucasian patients. ${ }^{130}$ Later studies confirmed this finding. 131.135

While hypertension has a greater prevalence in black patients than in white patients, this difference alone cannot account for the increased incidence of ESRD in Afro-Americans. ${ }^{1.36}$

Lipid abnormalities are major contributors to cardiovascular disease (CVD) in elderly. ${ }^{137}$ This is especially true in elderly diabetics.

Patients with hypertension and glucose intolerance have lower GFR's than ather persons of the same age. Glucose intolerance in combination with hyperuricemia, results in even lower GFRs. ${ }^{13 \%}$ In hypertensive patients with nephrosclerosis and normal fasting glucose, an oral glucose tolerance test revealed a type 11 diabetes mellitus in $52 \%$. "40

in women, there is an increase in prevalence of hypertension postmenopausal. ${ }^{14}$ Estradiol decreases vasoconstriction and mediates vasorelaxation by stimulating vascular production of vasodilators as nitric oxide and prostaglandins. 142 In elderly women the reduction of estradiol production in combination with a diminished expression of vascular estradiol receptors increase the risk of hypertension. ${ }^{122}$ 


\section{Renal disease in the elderly}

\subsection{Acute renal failure}

\subsubsection{Introduction}

Elderly patients are at greater risk of developing acute renal failure (ARF) than younger patients due to their diminished renal reserve capacity.

The ability of the kidneys to withstand acute insults to renal function is compromised. The percentage of patients with ARF who require dialysis ranges from $20 \%-60 \%$. 143,144

It is useful to categorize ARF according to prerenal, renal and postrenal causes. ${ }^{145}$ In Table 2.1, we categorize the main causes of ARF in elderly patients in this way. An increased incidence of ARF is demonstrated in the elderly, particularly in those receiving aminoglycoside antibiotics or after cardiovascular surgery. In a comparative study of 218 elderly patients (>60 years) and 816 younger patients $(<60$ yearsi, Glickman et al. found ARF as the second most common clinical diagnosis, accurring three times as often in the elderly patients $(14.2 \%$ vs. $3.9 \%) .{ }^{146}$ This may be related to a higher incidence of multiple organ failure in the elderly as well as to the progressive renal impairment seen with normal aging. ${ }^{147.149}$ A depression of the antioxidant system is present in critical ill patients with multiple organ failure (MOF). In patients with MOF and associated ARF this depression is even more pronounced, suggesting an additional effect on the antioxidative potential due to renal dysfunction. ${ }^{150}$ Prognosis and survival are mainly related to comorbidity rather than to age. ${ }^{151}$.

${ }^{154}$ Acute renal failure secondary to sepsis is associated with a very high mortality - up to $90 \% .^{121}$ Elderly patients who survive ARF need more time to recover and often do not regain full renal function. ${ }^{155}$

\subsubsection{Prerenal renal failure}

Prerenal azotemia is the most common cause of ARF in the elderly. ${ }^{150}$ Elderly patients are highly susceptible to ARF due to their predisposition to volume depletion as a result of their reduced capability to conserve sodium. An agerelated decline in renal function and the high prevalence of atherosclerosis with consequences for renal blood flow are contributing factors. ${ }^{157}$ Vomiting, diarrhoea, gastra-intestinal blood loss, the use of diuretics, often in combination with poor fluid intake, and congestive heart failure are all very common contributing factors in the elderly population. 
Table 2A 1 Couses of acule renal failure in elderly pafients

\begin{tabular}{|c|c|}
\hline Kolume depletion & $\begin{array}{l}\text { Elood loss, } \\
\text { Gastro intestinal loss, vomiting, diarthoea } \\
\text { Durefics, glycosuna, NSADD, ACE inhibitors }\end{array}$ \\
\hline Decreased effecive anterisil volume & $\begin{array}{l}\text { Decreased cardior oulput, congestive heart foilun } \\
\text { Myocordial infarction, cardioc arrhythmi } \\
\text { Hepatic disease cirthasis } \\
\text { Hypoalbumenio nephrotic syndiome } \\
\text { Sepsis }\end{array}$ \\
\hline nol Cous & \\
\hline Glomerular & $\begin{array}{l}\text { Acute glomerulonephritis } \\
\text { Yasculitis }\end{array}$ \\
\hline Tubulor & \\
\hline Tubular necrosis & $\begin{array}{l}\text { Ischemic (shock, sepsis) } \\
\text { Toxic e,g, aminoglycosides, radiocontrast agents. } \\
\text { amphiotericin B }\end{array}$ \\
\hline Tubulo- interstiol nephritis & $\begin{array}{l}\text { Infectious } \\
\text { NSAIDs, penicilin, thiazides sul hha compounds }\end{array}$ \\
\hline Pbstruglion & $\begin{array}{l}\text { Myoglobulin, hemioglobin, Bence Jones proteinurio, } \\
\text { unate. }\end{array}$ \\
\hline & $\begin{array}{l}\text { Vasculitis, quto unmune diseases } \\
\text { Malighant hypertension }\end{array}$ \\
\hline Postrenal raus: & \\
\hline Upper tract & $\begin{array}{l}\text { Stones } \\
\text { Malignangy } \\
\text { Papillary necrosis }\end{array}$ \\
\hline Lower tract & $\begin{array}{l}\text { Benign prostate hypertrophy } \\
\text { Prostate, bladder, ar pelvic carcinoma } \\
\text { Stinctures, yolves }\end{array}$ \\
\hline
\end{tabular}

The use of nonsteroidal anti-inflammatory drugs (NSAIDs) is of special interest in the aged. First of all, gastroduodenal damage is seen in $20 \%-40 \%$ of people who take these drugs, with high risks of peptic ulcers, and this may result in bleeding and even death. ${ }^{158}$ Secondly, the risk of NSAID-related nephrotoxicity increases with age. ${ }^{159}$ In situations where systernic circulation and/or renal perfusion is compromised, prostaglandin synthesis is increased, leading to vasodilatation, necessary to minimize renal ischemia. The use of NSAIDs under these conditions blocks vasodilatation with an inhibiting effect on renal blood flow and the risk of developing renal failure. 160

The use of angiotensin-converting enzyme (ACE) inhibitors can also be associated with hemadynamically mediated ARF. Again, a state of reduced renal blood flow due to low intake or excessive diuresis forms the major risk factor for this complication. This complication can occur not only in patients with bilateral 
renal artery stenosis, but also in patients with atherosclerosis of the smaller vessels of the kidney. ${ }^{161,162}$

\subsubsection{Parenchymal renal failure}

Acute tubular necrosis is the result of ischemic or toxic injury. Any prolonged cause of prerenal failure can evolve into acute tubular necrosis. Second to ischaemia, toxins are the most common cause of ARF. Drugs can damage the kidney by several mechanisms.

Damage resulting from decreased renal perfusion brought on by, for example, the use of NSAIDs and ACE inhibitors has already been mentioned. Direct toxicity to the tubuli has been described for aminoglycosides, radiocontrast agents, cyclosporine, cisplatin, tacrolimus, amphotericin B, methotrexate, foscarnet, pentamidine, and heavy metals. Cocaine, ethanol, and lovastatin can induce rhabdamyolysis resulting in damage to the tubuli. Intratubular obstruction can be the result of the use of sulphonamides, ethylene glycol (formation of calcium oxalate crystals), and chemotherapeutics (formation of uric acid crystals as a result of tumor lysis). Allergic interstitial nephritis has been described as a side effect of a number of drugs such as penicillins, cephalosporins, sulfonamides, rifampicin, NSAIDs, furosemide, thiazide diuretics, cimetidine, phenytoin, and allopurinol. A number of drugs (cyclosporine, tacrolimus, mitomycin, quinine, and conjugated estrogens) can also induce a hemolytic-uremic syndrome ${ }^{163}$

\subsubsection{Postrenal renal failure}

Obstruction of the urinary outflow tract can lead to ARF. It is important to detect such an obstruction in an early stage because removing of the obstruction increases the chance of recovery of renal function. Benign prostatic hypertrophy, carcinoma of the prostate, bladder, cervix, uterus, or rectum, or retroperitoneal malignancies are all important causes of postrenal obstruction, frequently seen in elderly patients. Ureteral stenting or percutaneous nephrostomy are possible options for removing the obstruction.

\subsection{Chronic renal failure}

Chronic renal failure is almost by definition a disease of the elderly. Reliable data on the incidence of chronic renal failure first became available when elderly patients were placed on renal replacement therapy (RRT). Glickman et al. report a rapidly increasing number of kidney biopsies in elderly patients after 1981. ${ }^{146}$ This coincides with the gradual acceptance of elderly patients for RRT. However, many reports on renal failure in elderly patients mention only a clinical diagnosis.

When discussing renal biopsies in these patients, only the primary renal diagnosis is mentioned; secondary causes of renal insufficiency are excluded. ${ }^{164}$ Secondary renal diseases caused, for example, by diabetes mellitus and hypertension, are likely to predominate in elderly patients. In the earlier mentioned study of Glickman et al. the most common clinical diagnosis 
nephrofic syndrome/proteinurio was equally distributed over young and elderly patients $\left(31.4 \%\right.$ versus $32.1 \%$ respectively) ${ }^{346}$ End-stage renal disease also occurred with almost equal frequencies in the two groups. Rapidly progressive glomerulonephritis was found to have a three times higher frequency in the elderly patient population. Thus it constitutes the third most common diagnosis in the elderly, whereas it is the ninth most common diagnosis in the younger age group. Diabetes and acute glomerulonephritis were equally distributed in both groups.

\subsubsection{Morphological diagnoses}

Nephrosclerosis is the most found morphological diagnosis in both elderly and younger patients. ${ }^{17}$ In the Glickman et al. study, membranous glomerulonephritis and crescentic glomerulonephritis were both more common in elderly patients. 117 The frequency of diabetic nephropathy, chronic glomerulonephritis, acule glomerulonephritis, focal glomerular absolescence, and fubular atrophy was approximately the same in both groups. Acute fubular necrosis was found in about $1 \%$ of each group. Other observers report a higher prevalence of nephrosclerosis, diabetes mellitus, obstructive uropathy, multiple myeloma, and amyloidosis in the elderly. ${ }^{165-168}$

The fact that renal disease in elderly patients has often more than one cause resulted in the diagnostic category labelled 'unknown'. Another reason for this high percentage may be the persistent reluctance to perform renal biopsies in elderly patients. A recent Dutch retrospective study of 122 elderly patients found the following primary diagnoses: tubula-interstitial nephritis (13\%), glomerulonephritis $(8 \%)$, renal vascular disease $(7 \%)$, diabetes mellitus $(7 \%)$, and polycystic kidney disease $(3 \%)$. In no less than 64 patients $(53 \%)$ was the primary diagnosis unknown. ${ }^{16 \%}$

A number of studies from different parts of the world report the cause of renal disease to be unknown at a rate varying from $10 \%$ to $24 \%$ (mean 24\%). ${ }^{170-175}$

In the 1118 patients older than 65 years of age who entered RRT in the period from 1990 to 1992 in the Netherlands, diabetes mellitus (types 1 and 11). glomerulonephritis, renal vascular causes, and polycystic kidney disease comprised $55 \%$ of the primary diagnoses. In 142 patients (13\%) the diagnosis was unknown $17 \%$ (Table 2A.2).

In the period from 1984 to 1992, the distribution over the listed diagnoses remained fairly constant with one exception: renal vascular disease. (Table 2A.2) This is most likely the result of the decreasing mortality secondary to acute cardiovascular disease. ${ }^{146}$ The number of patients who survive an acute cardiovascular event is still increasing.

This development, resulting in a longer life expectancy may be the cause of a higher percentage of subsequent complications of atherosclerasis such as renal insufficiency. Some authors also suggest a negative influence of our modern industrialized society on renal function resulting in a rising incidence of renal
failure. 77 
Table 2 A. 2 Clinical diagnoses in patients 65 years of age and older on renal replacement therapy

\begin{tabular}{|c|c|c|c|c|c|c|}
\hline & \multicolumn{2}{|c|}{19841986} & \multicolumn{2}{|c|}{$1987-1989$} & \multicolumn{2}{|c|}{$1990-1992$} \\
\hline Diabetes type I & 27 & $(5 \%)$ & 49 & $16 \% 1$ & 72 & $(6 \%)$ \\
\hline Diabetes type II & 28 & $(4 \%)$ & 43 & $(5 \%)$ & 62 & $(69)$ \\
\hline Glomerulonephritis & 70 & $(14 \%)$ & 78 & $(10 \%$ & 103 & $110 \%$ \\
\hline Pyelonephritis: & 78 & $(15 \%)$ & 94 & $(12 \%$ & 111 & $010 \%$ \\
\hline Renal vascular disease & 121 & $(24 \%)$ & 207 & (25\%) & 349 & $(31 \%)$ \\
\hline Polycystic kidney disease & 17 & $(3 \%)$ & 32 & $(4 \%)$ & 39 & $(3 \%)$ \\
\hline Other & 99 & $(19 \%)$ & 181 & $(22 \%)$ & 248 & $(21 \%)$ \\
\hline Unknown & 84 & $(16 \%)$ & 131 & $16 \%$ & 142 & $(13 \%$ \\
\hline Total & 514 & $(100 \%)$ & 815 & $(110 \%)$ & 1118 & $(100 \%)$ \\
\hline
\end{tabular}




\section{Literature}

1. Resultaten bevalkingsprognose 1992-2050 + kemcifers, 1950-2050. Centraal Bureau voor de Statistiliek Voorburg, Heerlen, 1992.

2. Perenboom $2 M_{i}$ v. Herten LM, Boshuizen HC, vd Woter HPA. Trends in de gezande levenswerwachting in Nederland, 1983-1994, met een verdeling naar ernst van ongezondheid. Leiden: TNO-rapport $97.009,1997$.

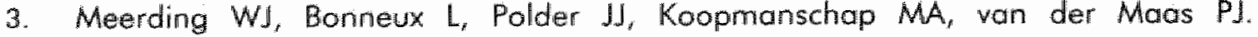
Demographic and epidemiological determinants of healthcare costs in Netherlands: cost of illness study. BMJ 1998;317:22-26.

4. Spillman BC, Lubitz J. The effect of longevity on spending for acute and long-term cone. NEJM 2000,342:1409-1415.

5. Raderic PJ, Ferris G, Feest TG. The provision of renal replacement therapy for adults in England and Wales: recent trends and future directions. QJM 1998;91:581-587.

6. Rotellar E, Lubelzar EA, Rotellar $C_{\text {, }}$ et al. Must patients over 65 years be hemodialyzed? Nephron 1985;41:152-156.

7. Kjallstrand $\mathrm{CM}$. Tyden $\mathrm{G}$. Inequalities in chronic dialysis and transplantation in Sweden. Acta Med Scand 1988;224:149-156.

8. Kjellstrand $C M$, Logan GM. Racial, sexual and age inequalities in chronic dialysis. Nephron 1987;45:257-263.

9. Rosansky 5J, Jackson K. Rate of change of end-stage renal disease trealment incidence, 1978-1987. Hos there been selection? J Am Soc Nephrol 1992;1502. 1506.

10. Moultan LH, Port FK, Wolfe RA, el al. Patterns of low incidence of of treated endstage renal disease among the elderly. Am J Kidney Dis 1992;55-62.

11. Kjellstrand CM, Maody H. Hemodialysis in Canada: a first-class medical crisis. Can Med Assoc J 1994;155:1067-1071.

12. Friedman EA. Rationing of uremia therapy. Artificial Organs 1992;16:90-97.

13. Farmery E, Milner $P$. Renal replacement therapy: purchasing review and recommendations. Devizes: Wiltshire Health Authority, 1997.

14. Chadna SM, Schulz J, Lawrence C, Greenwaod RN, Farrington. Is there a rationale for rationing chronic dialysis? A hospital based cohort study of factors affecting survival and morbidity. BMJ 1999,318:217-223.

15. Nissenson AR. Chronic peritoneal dialysis in the elderly. Geriatr Nephrol Urol $1991 ; 1: 3-12$

16. Holley JL, Foulks CJ, Moss AH. Nephrologist's reported attitudes about factors influencing recommandations to initiate or withdraw dialysis. I Am Soc Nephrol $1991 ; 1: 1284-1288$.

17. Roessle R, Roulet F. In: Mass und Zahl in der Pathologie, Berlin: Springer Verlag, 1932:63-66.

18. deleon W, Garcia A, dejesus PI. Normal weights of visceral organs in adult Filipinos. Philippine Journal of Science, 1933;52:111-127.

19. Wold H. Stereological principles for morphometry in electron microscopic cytology. International Review of Cytology, 1937;26:235-302. 
20. Dunnill RS, Halley W. Same observations on the quantitative anatomy of the kidney. J Pathology 1973;110:113-120.

21. Istrikawa I, Onouchi $Z_{*}$ Saito $Y$, Kitoda $H$, Shinoda $A$, Ushitani $K$, Tabuchi $M$, Suzuki M. Renal cortex wisualisation and analysis of dynamic CT curves of the kidney. I Computer Assisted Tomography 1981;5:695-701.

22. McLachlan MSF, Wasserman P. Changes in size and distensibility of the aging kidney. Br J Radiology 1981;54:488-491.

23. Mckeown F. Patholgy of the aged. London, Butterworths \& Co. (publ.) 1965:171. 204.

24. Giffiths GJ, Robinson KB, Cartwright GO, Mclachlan MSF. Loss of renal tissue in the elderly. Br J Radiology 1976,49:111-117

25. Laucks SP, McLachlan MSF. Aging and simple cysts of the kidney. Br J Radiology $1981 ; 54: 12-14$.

26. McLachian MSF, Gaunt A, Fulker MJ, Anderson CK. Estimation of glomerular size and number from radiographs of the kidney. Br J Radiology 1976;49:831-835.

27. McLachlan MSF. Anatomic, structural and vascular changes in the aging kidney. In: Nuñez JFM, Cameron JS, eds. Renal function and disease in the elderly" London Butterworths \& Co. (publ) 1987:3-26.

28. Inove $G$, Sawada $T$. Fuukunaga $Y$, Yoshikawa $M$. Levels of mucopolysaccharides in aging human kidneys. Gerontalogia, 1970;16:261-265.

29. Moore RA. The total number of glomeruli in the normal human kidney. Anatomical Record 1931; 48 153-168.

30. Kasiske BL. Relationship between wascular disease and age-associated changes in the human kidney. Kidney Int 1987;31:1153-1159.

31. Gayal VK. Changes with age in the human kidney. Exp Gerontol 1982,17:321-331.

32. Takazakura E, Sawabu N, Handa A, Takada A, Shindda A, Takeuchi J. Intrarenal vascular changes with age and disease. Kidney Int 1972;2:224-230.

33. Goldstein RS, Tarloff JB, Hook JB. Age-related nephropathy in laboratory rats. F A S E B J 1988;2:2241-2251.

34. Bolton, KW, Benton FR, MCLay JG, Sturgill BC. Spontaneous glomerular sclerosis in aging Sprague-Dwalley rats. Am J Path 1976;85:277-300.

35. Steffes MW, Barbosa J, Bagsen JM, Matas AJ, Mauer MW. Quantitative glomerular morphology the normal human kidney. Lab Invest 1983;49:82-86.

36. Brenner BM. Nephron adaptation to renal injury or ablation. Am I Physiol $1985,249, F 324-F 337$.

37. Keresztury, 5. Megyeri, L. Histology of renal pyramids with special regards 10 changes due to ageing. Acta Morphologica 1962;11, 205-215.

38. Darmady, EM. Offer, J. Woodhouse MA. The parameters of the ageing kidney. J Pathol 1973;109, 195-207.

39. Oliver, JR. In Cowdry's Problems of ageing, Baltimore; Williams \& Wilkins, 1952:631-655.

40. Levinson SP. Renal disease in the elderly: the role of renall biopsy. Am J Kidney Dis 1990; 16:300-306.

41. Sawicki PT, Didjurgeit $U$, Mühlhauser I, Bender $R$, Heineman $L$, Berger M. Smoking is associated with progression of diabetic nephropathy. Diabetes Care $1994 ; 17: 126-131$. 
42. Keller CK, Bergis KH, Fliser D, Ritz E. Renal findings in patients with type 2 diabetes. Am Soc Nephrol 1996;7:2627-2635.

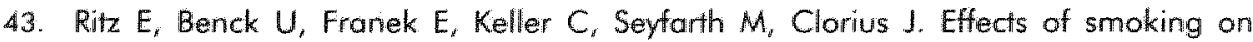
renal hemodynamics in healthy volunteers and in patients with glomerular disease. $J$ Am Soc Nephrol 1998;9:1798-1804

44. Orth SR. Smoking - A renal risk factor. Nephron 2000;86:12-26.

45. Anderson S, Meyer TW, Brenner BM. Mechanisms of age-associated glomerular sclerosis. In: Nunez JF, Cameron JS. eds. Renal function and disease in the Elderly. London, Butterworths \& Co. publ. 1987:49-66.

46. Rabbins ME, Bonsib SM. Radiation nephropathy: a review. Scanining Micrasc $1995,9(2): 535-560$.

47. Reckelhoff JF, Granger JP. Role of androgens in mediating hypertension and renal injury. Clin Exp Pharmacol Physial 1999;26(2):127-131.

48. Klahr S, Levey A, Beck G, Caggiula A, Hunsicker L, Kusek J, Striker G. for the Modification of Diet in Renal Disease Study Group. The effects of dietary pratein restriction and blood-pressure control on the progression of chronic renal disease. $N$ Engl I Med 1994;330:877-884.

49. Narins $R$, Cortes $P$. The role of dietary protein restriction in progressiwe azotemia. Editorial N Engl J Med 1994,330:929-930.

50. Lindeman RD, Goldman R. Anatomic and physiological age changes in the kidney. Exp Gerontol 1986;21:379-406.

51. Danziger RS, Tobin JD, Becker LC, Lakatta EG, Fleg JL. The age-associated decline in glomerular filtration in healthy normotensive volunteers: lack of relationship to cardiovascular performance. J Am Geriatr Soc 1990;38:11 $127-1132$.

52. Lakatla EG. Cardiovascular regulatory mechanisms in advanced age. Physialogical Reviews 1993:73(2):413-467.

53. Liungqvist $A$, Lgergren $C$. Normal intrarenal arterial pattern in adult and ageing human kidney. J Anatomy, London 1962;96:285-300.

54. Davidson AJ, Talmer LB, Downs M. A study of the angiographic appearances of the kidney in an aging normotensive population. Radiology 1969;92:975-983.

55. Higashi $Y$, Oshima T. Ozono R, Matsuura $H$, Kajiyama G. Aging and severity of hypertension attenuate endothelium-dependent renal vascular relaxation in humans. Hypertension 1997;30(2 pt 1):252-258.

56. Cohen MP, Ku L. Age-related changes in sulfation of base membrane glycosaminoglycans. Exp Gerontol 1983;18:447-450.

57. Drummond Pecly IM, Genelhu De Abreu Fagundes V. Francischetti EA. A definite role for the kallikrein-kinin system in the renal hemodynamic response to an oral pratein load during the aging process. Nephron 1999;83(4):308-313.

58. McDonald RF, Solomon DH, Shock NW. Aging as a factor in the renal hemodynamic changes induced by a standardized pyrogen. J Clin Inwest $1951 ; 5: 457-462$

59. Hollenberg NK, Solomon $\mathrm{DH}$, Shock NW. Senescence and the renal vasculature in normail men. Circ Res 1974;34:309-316.

60. Hollenberg NK, Rivera A, Meinking $T$, Martinez $G$, McCullough M, Passan D, Preston M, Taplin D, Viacaria-Clement M. Age, renal perfusion and function in islland-dwelling indigenous Kuna Amerinds of Panama. Nephron 1999,82(2):131. 138. 
61. Lindeman RD. Overview: Renal Physiology and Pathofysiology of Aging. Am J Kidney Dis 1990;4:275-282.

62. Davies DF, Shock NW. Age changes in glomerular filtration rate, effective renal plasma flow, and uubular excretory capacily in adult males. I Clin Inwest $1950,29: 496-507$.

63. Rowe JW, Andres R, Tobin JD, Nomis AH, Shock NW. The effect of aging on creatinine clearance in men: a cross sectional and longitudinal study. 1 Gerontol $1976,31: 155-163$

64. Epstein M, Hollemberg NK. Age as a determinant of renal sodium conservation in normal man. J Lab Clin Med 1976;87:411-417.

65. Friedmon SA, Raizner AE, Rosen H, Solomon NA, Sy W. Functional defects in the aging kidney. Ann Int Med 1972;76:41-45.

66. Luft FC, Fineberg NS, Miller JZ, Rankin CE, Weinberger MH. The effects of age, race and heredity on glomerular filtration rate following volume expansion and contraction in normal man. Am J Med Sci 1980;279:15-24.

67. Radico JL. Renal blood flow and glomerular filtration pate in the elderly. Therapeutic problems. High Blood pressure Cardiovasc Prevention 1992;1:151-155.

68. Graneus $G$, Aubell M. Technical notes. Reference values for ${ }^{57} \mathrm{Cr}$-EDTA clearance as a measure of glamerular filtration rate. J Clin Lab Invest 1981;41:61 1-616.

69. Larson M, Jagenburg $R$, Landahl S. Renal function in an elderly population. Scand J Clin Lab Invest 1986;46:593-598.

70. Frieman JR, Norman DC, Yoshikawa TT. Correlation of estimated renal function parameters versus 24-hour creatinine clearance in ambulatory elderly. J Am Geriatr Soc 1989;37:145-149.

71. Dunnil RS, Halley W. Some observations on the quantitative anatomy of the kidney. J Pathol 1973;110:113-120.

72. McLachlan MSF, Guthrie JC, Anderson CK, Fulkner MJ. Vascular and glomerular changes in the ageing kidney. J Pathol 1977;121:65-777

73. Fliser D, Franek $\mathbb{E}$, Joest M, Block S, Mutschler $E$, Ritz E. Renal function in the elderly: impact of hypertension and cardiac function. Kidney Int 1997;51 (4):1 196-1204.

74. De Santo $\mathbb{N} G$, Anastasio P. Coppola $S$, Barba $G$, Jadanza A, Capasso $G$. Age related changes in renal reserve and fubular function in healthy humans. Child Nephrol Urol 1991;11:33-40.

75. Rowe JW, Andres R, Tobin ID. Age adjusted normal standards for creatinine clearance in man. Ann Intern Med 1976;84:567-569.

76. Cocroft DW, Gault MH. Prediction of creatinine clearance from serum creatinune. Nephron 1976;16:31.34.

77. Brown WW, Davis BB, Spry LA, al. Aging and the kidney. Arch Intern Med $1986 ; 146: 1790-1796$

78. Gentric A, Legendre $\mathbb{A} M$, Cledes J. Validity of creatinine clearance from serum creatinine in subjects over 80 years old. Geriatr Nephrol Ural 1992;2:143-145.

79. Baracskay D, Jaroura A, Cugino A, et al. Geriatric renal function: estimating glomerular filtration in an ambulatory elderly population. Am 」 Kidney Dis $1997 ; 47: 222-228$.

80. Lindeman RD, Tobin J, Shack NW. Longitudinal studies on the rate of decline in renal function with age. J Am Geriatr Soc 1985;33:278-285. 
81. Epstein $M$, Hollenberg NK. Age as a determinant of renal sodium conservation in normal man. J of Laboratory and Clinical Medicine 1976,87,411-417

82. Macias-Nuñez JF, Roman AB, Commez JLR. Physiology and disorders of water balance and electrolytes in the elderly. In: Nuñez MUF, Cameron JS. eds. Renal function and disease in the elderly. London, Butterworths \& Co publ. 1987:67.

83. Katz Al. Renal Na-K-ATPase: its role in tubular sodium and potassium transport. Am J Physiol 1982;242:F207-F219.

84. Luff FC, Weinberger MH, Fineberg NS, Miller $J Z$, Grim CE. Effects of age on renal sodium homeostasis and its relevance to sodium sensitivity. Am J Med 1987;82 $(\$ .16): 9-15$

85. Laitinen T, Hartikainen J, Vanninen E, Niskonen L, Geelen G, Lansimies E. Age and gender dependency of baroreflex sensitivity in healthy subjects. I Appl Physiol $1998 ; 84(2): 576-583$.

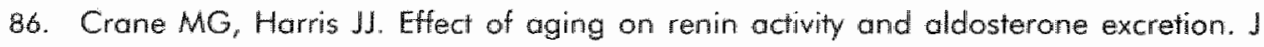
Lab Clin Med 1976;87:411-417.

87. Bover JH. Age-related changes in the remin-aldosterone system. Physiological effects and clinical implacations. Drugs Aging 1993,3(3);238-245.

88. Belmin J, Levy $B I$, Michel JB. Changes in the renin-angiotensin-aldosterone axis in later life. Drugs Aging 1994;5:391-400.

89. Cox JR, Shalaby WA. Potassium changes with age. Gerontology 1981;27:340-344.

90. Weir MR. Non-diuretic-based antihypertensive therapy and potassium homeostasis in elderly patients. Coronary Artery Disease 1997;8:499-504.

91. Bichet DG, Schrier RW. Renal function and diseases in the aged. In Schrier RW. Ed. Clinical Internal Medicine in the Aged. Saunders, Philadelphia, 1982;pp $211-221$

92. Galinsky D, Meller $Y$, Shany $S$. The aging kidney and callium-regulting hormones: vitamin D metabalites, parathyroid hormone and calcitonin. In Nuñez JFM, Cameron JS. Eds. Renal function and disease in the elderly. Butterworths, London, 1987; pp $121-142$.

93. Gregerman Rl, Bierman EL. Aging and hormones. In Williams RW. Ed. Textbook of Endocrinology. Philadelphia, Saunders 1981:1192:1212.

94. Heckel RH, Hofeldi FD. Endocrinolgy and metabolism in the elderly. In Schrier RW. Ed. Clinical internal medicine in the aged. Philadelphia Saunders, 1982:222-225.

95. Renal data system USRDS 1998 annual data reprort. Bethesda, Md.: National Institute of Diabeles and Digestive and Kidney Diseases, April 1998 (NIH publ.no.98-3176).

96. Tooke JE. Microvascular function in thuman diabetes; a physiological perspective. Diabetes 1995:44:721-726.

97. Patel V. Rassam S, Newsom R. Wiek J, Kohner E. Retinal blood flow in diabetic retinopathy. BMJ 1992;305:678-683.

98. Fioretto P. Steffes MW, Maver M. Glomerular structure in nonproteinuric IDDM patients with various levels of albuminuria. Diabetes 1994;43:1358-1364.

99. Miles AMV, Friedman EA. Diabetic dialysis patients. In Henrich WL. Principles and Practice of Dialysis Baltimore Williams \& Wilkins sec. edition, 1999:477-489.

100. Fabre J, Balant LP, Dayer PG, Fox HM, Vernet AT. The kidney in maturity onset diabetes mellitus: a elinical study of 510 patients. Kidney Int 1982,21:730-738.

10\%. Humphrey $L L$, Ballard DJ, Frohnert PP, ef al. Chronic renal failure in non-insulin dependent diabetes mellitus. Ann Intern Med 1989;111:788-796. 
102. Hasslacher $\mathrm{CH}_{d}$ Rith $\mathrm{E}$, Wahl P, et al. Similar risks of nephropathy in patients with type I and type II diabetes mellitus. Nephrol Dial Transplant 1989;4:859.863.

103. Nelson RG, Newman JM, Knowles WC, al. Incidence of end-stage renal disease in type 2 (non-insulin dependent) diabetes mellitus in Pima indians. Diabetalogia $1988 ; 31: 730-736$

104. Cowie CC, Port FK, Wolfe RA, et al. Disparities in incidence of diobetic end-stage renal disease according to race and to type of diabetes. NEJM 1989;321:10741079 .

105. Ritz E, Rychlik I, Lacatelli F, Halimi S. End-stage renal failure in type 2 diabetes - a medical catastrophe of worldwide dimensions. Am J Kidney Dis 1999;34(5):795808.

106. Ritz $E$, Orth SR. Nephropathy in patients with type 2 diabetes mellitus. NEJM: 1999,341:1127-1132.

107. Fioretto $P$, Maurer $M$, Bronco $E$, ef al. Patterns of renal injury in NIDDM patients with microalbuminuria. Diabetologia 1996;39:1569-1576.

108. Orfila C, Lepert JC, Medesto A, Pipy B, Suc JM. IgA nephropathy complicating diabetic glomerulosclerosis. Nephron 1998;79:279-287.

109. Olsen $S_{4}$ Mogensen CE. How often is type 2 diabetes complicated with non-diabetic renal disease? An analysis of renal biopsies and the literature. Diabelolpgia $1996 ; 67: 4411.443$.

110. Wirta $\mathrm{O}$, Helin $\mathrm{H}$, Mustonen J, Kuittinen $\mathrm{E}_{s}$ Savela $T$, Pasternak A. Renal findings and glomerular pathology in diabetic subjects. Nephron 2000;84:236-242.

111. UK Prospective Diabetes Study (UKPDS) Group. Intensive blood-glucose control with sulphomylureas or insulin compared with conventional treatment and risk of complications in patients with type 2 diabetes (UKPDS 33). Lancel 1998;352:837. 53 (Errotum, Lancet $1999: 354-602$ )

112. Pettil DJ, Saad MF, Bennet PH, Nelson RG, et al. Familial predisposition to renal disease in two generations of Pima Indians with type IInon-insulin-dependent) diabetes mellitus. Diabetologia 1990,33:438-443.

113. Strojek K, Grzeszczak W, Morawin Ex et al. Nephropathy of type ll diabetes: evidence for hereditary factors? Kidney Int 1997;51:1602*1607.

114. Nolph KD, Lundbilad AS, Novak JW. Current concepts: continuous ambulatory peritoneal dialysis. NEJM 1988;318:1595-1600.

115. Lindeman RD, Tobin JD, Shock NW. Hypertension and the kidney. Nephron $1987 ; 47(51): 62-67$.

116. Rosansky SJ, Hoover DR, King L, Gibson J. The association of blood pressure levels and change in renal function in hypertensive and nonhypertensive subjects. Arch int Med 1990;150:2073-2076.

117. Sowers $J \mathbb{R}$, Khoury $S$, Imam K. Therapeutic approach to hypertension in the elderly. Primary Care 1991;18:593-604.

118. Appelgate WB, Sowers JR. Elevated systalic blood pressure: increased cardiovascular risk and rationale for treatmaent. Am J Med 1996;100(suppl 3A]:S3-9.

119. Stamler J, Wenworth D, Neaton JD. Is the relationship behween serum cholesterol and risk of premature death from coronary heart disease continuous and graded? Findings in 356,222 primary screenees of the Mulfiple Risk. Factor Intervention Triall MRFIT. JAMA 186;256:2823-2828. 
120. Perry HM, Smith WM, MCDonald RH. Morbidity and mortality in the Systolic Hypertension in the Elderly Program (SHEP) pilot study. Stroke 189;20:4-13.

121. Perera GA. Hypertensive wascular disease: description and natural history. J Chronic Dis $1995 ; 1: 33-42$.

122. Sowers JR, Lester M. Hypertension, hormones, and aging. I Lab Clin Med 2000;135:379-386.

123. Weisstuch MM, Dworkin LD. Does essential hypertension cause end stage renal failure? Kidney int 1992:41/536):S33-\$37.

124. Madhaven $S$, Stockwell D, Cohen, Alderman MH. Renal function during anthypertensive treatment. Lancet 1995;345:749-751.

125. Perneger TV, Klag MJ, Feldman HI, Whelton PK. Projections of hypertension-related renal disease in middle-aged residents of the Uniled States. JAMA 1993;269:12721277.

126. Samuelson 0 . Hypertension in the middle-aged man: management and prognostic factors during long-term hypertensive care. Acta Med Scand 1985;702 (S):1-79.

127. Ruilope LM, Alcazar JM. Hernández E, Moreno F, Martinez MA, Rodica JL. Does adequate control of blood pressure protect the kidney in essential hypertension? J Hypertens 1990:8:525-532.

128. Rostand SG, Brown $G$, Kirk K, Rutsky EA, Dustan HP. Renal insufficiency in treated essential hypertension. N Engl J Med 1989;320:684-688.

129. Tierney WM, Harris LE, Copley JB, Luft FC. Effect of hypertension and type $\| 1$ diabetes on renal function in an urban population. Am J Hypertens 1990;3:69-75.

130. McCord $W$. Comparative blood creatinine levels in negro and white subjects. Tri State Med J 1941;13:2689-2699.

131. Easterling RE. Racial factors in the incidence and causation of end stage renal disease. Trans Am Soc Artif Intern 1977; Organs 23:28-32.

132. Rostand SG, Kirk K, Rutsky EA, Pate BA. Raciall differences in the incidence of treatment of end stage renal disease. N Engl J Med 1982;306:1276-1279.

133. Weller JM, Wu SCH, Ferguson CW, Hawthorne VM. End stage renal disease in Michigan. Am J Nephrol 1985;5:84*95.

134. Ferguson R, Grim CE, Openorth TJ. The epidemiology of end stage renal disease: The six year south-central Los Angeles experience, 1980-1985. Am J Public Health $1987: 77: 864-865$.

135. Walker WG, Neaton JD, Cutler JA, Neuwith R, Cohen JD. Renal function change in hypertensive nembers of the Multiple Risk Factor Intervention Trial: racial and treatment effects. The MRFIT Research Group. JAMA 1992;268:3085-3091.

136. McCellan W, Tuttle E, Issa A: Racial differences in the incidence of hypertensive end stage renal disease (ESRD) are not entirely explained by differences in the prevalence of hypertension. Am J Kidney Dis 1988;12:285-290.

137. Manolio TA, Pearson TA, Wenger NK, Barret-Connar E, Payne GH, Harlan WR. Cholesterol and Heart disease in older persons and women. Review of an NHLBI workshop. Ann Epidemiol 1992;(2):161-76.

138. Sowers JR. Diabetes mellitus and cardiovascular disease in women. Arch Int Med $1990 ; 158: 617-21$.

139. Branca GF, Satta A, Faedda R, soggia G, Olmea NA, Bartoli E. Risk factors for the progression of renal insufficiency in essential hypertension. Panminerva Med $1983 ; 25: 13-18$. 
140. Ruilope LM, Alcazar JM, Hernández E, Lahera V, GarciaRobles R, Villa E Metabolic alterations accompanying essential hypertension are associated with nephrosclerosis. J Hypertens: 1993:11(55):5475

141. Hanes DS, Weir MR, Sowers JR. Gender considerations in hypertension pathophysiology and treatment. Am J Med 1996;101(suppl 3A):10S-215.

142. Hayashi $T$, Yamada $K$, Esaki T. Estrogen increases endothelial nitric oxide by a receptor mediated system. Biochem Biophys Res Commun 1995;214:847-855.

143. Liano F, Carcia-Martin F, Gallego $A_{i}$ ef al. Easy and early pragnosis of acute tubular necrosis: a forward analysis of 228 cases. Nephron 1989;51:307-313.

144. Pascual J, Orotino L, Liano F, ey al. Incidence and prognosis of acute renal failure in older patients. I Am Geriatr Soc 1990;38:25-30.

145. Donker AJM, Gans ROB, Hoorntje SJ, Kootte AMM, ter Wee PM. Ziekten wan mieren en urinewegen. In: Meinders AE, Boogaerts MA, Donker AJM, Erkelens DW, Schalenkamp MADH, Vermeij P. Theropie in de interne geneeskunde. Utrecht Bunge publ 1992:692-696.

146. Glickman JL, Kaiser DL, Kline Bolton W. Aetlology and diagnosis of chronic renal insufficiency in the aged: The role of renal biopsy. In Macias Nunez JF, Cameron JS. eds. Real function and disease in the elderly. London Butterworths \& Co. publ 1987:484-508.

147. Pascual $\rfloor_{f}$ Orofino $L$, Liano $F$, ef al. Incidence and prognosis of acule renal failure in older patients. J Am Ger Soc 1990;38:25-30.

148. Pascual J, Orafino L, Burgos J. Acute renal failure in the elderly. Geriatr Nephral Urol 1992;2:51-61.

149. Lameire $N$, Verspeelt $\mathrm{d}$, Vanholder $\mathbb{R}$, Ringoir S. A review of the pathophysiology, causes and prognosis of acutte renal failure in the elderly. Geriatr Nephrol Urol $1991 ; 1: 77-91$.

150. Metnitz GH, Fischer M, Bartens $C$, Steltzer $H$, Lang T, Druml W. Impact of acute renal failure on antioxidant status in multiple organ failure. Acta Anaesthesiol Scand $2000 ; 44(3): 236-40$

151. Corwin $H L$, Bonwentre $J$. Factors influencing survival in acute renal failure. Semin Dial $1989 ; 2: 220-225$

152. Groeneveld ABJ, Tran DD, van der Meulen J, et al. Acute renal failure in the medical intensive care unit: predisposing, complicating factors and outcome. Nephron $1991: 59: 602-610$.

153. Sonnenblick M, Sloti IN, Friedlander $Y$, Kramer MR. Acule renal failure in the elderly treated by one-fime peritoneal dialysis. J Am Geriatr Soc 1988;36:1039.1044.

154. Spiegel DM, Ulliam ME, Zerbe GO, Berl T. Determinants of survival and recawery in acute renal failure patients dialyzed in intensive-care units. Am I Nephrol $1991 ; 11: 44-47$.

155. Oreopoulos DG, Yuan ZY. CAPD in Diabefics. Am Soc Nephrol Annual Meeting, Baltimore, now 1991.

156. Marcias-Nuñez JF, Lopez-Novoa JM, Martinez-Maldonado M.Acute renal failure in the aged. Semin Nephro: 1996;16:330-338.

157. Pascual J, Liano F, Ortano J. The elderly patient with acute renal failure. I Am Soc Nephrol 1995;6:144-153. 
158. Barrier $\mathrm{CH}$, Hirschowiz Bl. Controversies in the detection and management of nonsteroidal antinflammatory drug-induced side effects of the upper gastrointestinal fract. Arthritis Rheum 1989;32:926-932.

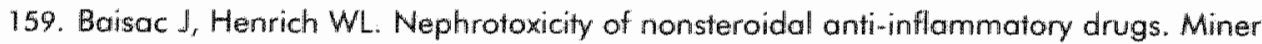
Electrolytie Metab 1994;20:187-1192.

160. Lash JP, Gardner C. Effects of aging and drugs use on normal renal function. Coronary Artery Dis 1997:8:489-494.

161. Hrick DE, Browning PJ, Kopelman R, Goorno WE, Madias NE, Dzau V. Captoprilinduced functional renal insufficiency in patients with bilateral renal-artery stenoses or renal-artery stenosis in a solitary kidney. N Engl J Med 1983;308:373-376.

162. Bridoux F, Hazzan $M$, Pallot $J L$ ef al. Acute renal failure after the use of angiotensinconverting-enzyme inthibitors in patients without renal artery stenosis. Nephrol Dial Transplant 1992;7:100-104.

163. Thadhani $R$, Pascual M, Bonventre JV. Acute renal failure. $N$ Engl I Med $1996: 22: 1448 \cdot 1460$.

164. Moorthy AV, Zimmerman SW. Renal disease in the elderly: clinicopathologic analysis of renal disease in elderly patients. Clin Nephrol 1980;14:223-229.

165. Eggers PW, Connerton $\mathbb{R}$, McMullan $M$. The Medicare experience with end-stagerenal disease: Trends in incidence prevalence and survival. Health Care Financing Review 1984;5:69-88.

166. Blagg CR. Chronic renal failure in the elderly. In: Oreopoulos DG ed. Geriatric nefrology. Boston, Martinus Nijhoff publ 1986:117-126.

167. Ponticelli $C$, Graziani $G$. Cantaluppi A, Moore R. Dialysis treatment of end-stage renal disease. In: Macias Nuñez JF, Cameron JS, eds. Renal function and disease in the elderly. London, Butterworths publ 1987:509-528.

168. Porush $J G$, Faubert FF. Chronic renal failure. In: Porush $J G$, Faubert FF. eds. Renal disease in the aged. Boston, Little Brown publ 1991:285-313.

169. Mandigers CMPW, de Jong W, van den Wall Bake AWL, Gerlag PGG. Renal replacement therapy in the elderly. Neth J Med 1996;49:135-142.

170. Walls J. Dialysis in the elderly. Some UK experience. Adv Perit Dial 1990, isuppl) $6: 82 \times 85$.

171. Segaloni GP, Salmone M. Piccoli GB. CAPD in the Elderly; Italian multicenter study experience. Adv Perit Dial 1990;(S) 6:41-46.

172. Posen GA, Fenton SA, Arbus GS, et al. The Canadian experience with peritoneal dialysis in the elderly. Adv Perit Dial 1990;(suppl) 6:47-50.

173. Diax-Buxo JA, Adcock A, Nelms M. Experience with continuous cyclic peritoneal dialysis in the geriatric patient. Adv Perif Dial 1990; (S) 6:61-64.

174. Piccoli $G$, Quarello $F$, Salomone $M$, ef al. Dialysis in the elderly: Comparison of different dialytic modalities. Adv Perit Dial 1990;(S) 6:72-81,

175. de Charro FTh, Geerlings W, Krediet RT, Ramsteiln PG, Tiandra YI. De ontwikkeling van het nievfunctie-vervangingsprogmma in Nederland. Statisch jaarverslag.

176. Port FK. Worldwide demagraphics and future trends in end stage renal disease. Kidney Int 43 1993;5 41:54-S7.

177. Steenland MK, Thun MJ. Fergusan CW, Port FK. Occupational and other exposures assaciated with end-stage renal disease: A case-control study. Am J Publ Health 


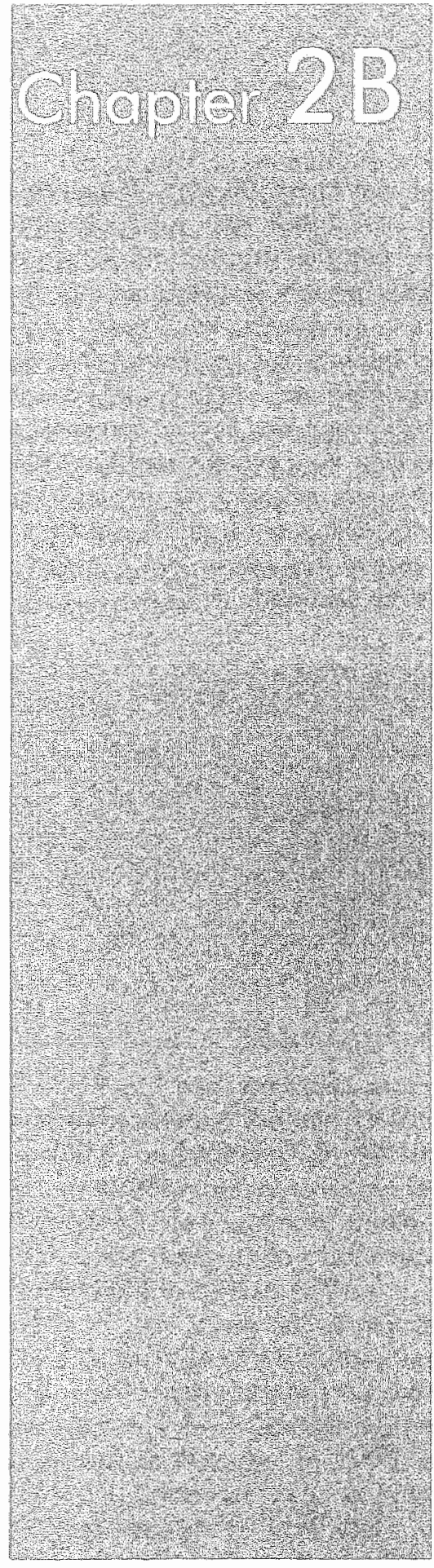

\section{Renal replacement therapy in the elderly}

WJ Mulder, HFP Hillen

European Journal of Internal Medicine

$2001 ; 12: 327-333$ 


\section{Abstract}

In all industrialized countries, life expectancy has risen in the past 100 years. The number of elderly patients reaching end-stage renal disease (ESRD) and requiring renal replacement therapy has dso increased. During the past few decades, the patfern of ESRD has changed significantly with the emerging predominance of elderly patierts. The causes of this phenomenon are manifold and include on increasing number of chronic diseases typical of the 'third age', such as type 2 diabetes and vascular disease. In many species, a consequence of aging includes deterioration of renal function, partly due to structural alterations, and partly as the result of a diminishing blood flow. In humans, the aging kidney is choracterized by modifications resulting from organic and functional disturbances. In particular, type 2 diabetes mellitus has emerged as an important condition, the microvascular and macrovascular complications of which are a common couse of marbidity and montality in older patients. In part II of this review, the specific aspects of renal replacement therapy in the elderly will be discussed. 


\section{Introduction}

In aimost all developed countries of the world, the elderly represent an increasing percentage of the patienis in renal replacement therapy (RRT) programs. In 1967, only $7 \%$ of the chronic dialysis population in the United States was 55 years or older.' In 1985, almost $60 \%$ of all new entrants in dialysis programs had a mean age of 55.5 years. ${ }^{2}$ In 1995 the median age of the patients who enrolled the the Medicare ESRD program was 64 years at start of the renal replacement therapy. ${ }^{3}$ In 1997, in the US, over 300,000 patients were receiving RRT; 194720 of them were aged 65 or over, comprising over $34 \%$ of the prevalent end-stage renal disease (ESRD) population. In the same year over 79000 patients were started on ESRD treatment. Patients aged 65-74 years had the highest recorded incidence rate; they were closely followed by those of 75 years of age and over. ${ }^{4}$ The United States Renal Data System (USRDS) also indicates a yearly rise in the incidence of treatment of elderly patients (Table 2B.1).

\section{Table 2B. 1 Treated Medicare ESRD Incidence Counts}

$\begin{array}{cccc}\text { Age } & \text { Count } & \text { \% of Total } & \text { Rate per Million } \\ 0-19 & 1,069 & 1,4 & 13 \\ 20-44 & 11,800 & 14.9 & 109 \\ 45-64 & 26,253 & 33,2 & 545 \\ 65-74 & 22,056 & 27,9 & 1296 \\ 75+ & 17,924 & 22,7 & 1292 \\ \text { Total } & 79,102 & 100 & 287\end{array}$

The same trend towards an increasing number of elderly patients in RRT programs starting the late 1970s and 1980s, can be seen in Canada, Europe, Australia, and Japan ${ }^{5.9}$ In the United Kingdom this trend was initially less steep due to the the country's budget restrictions for health care. ${ }^{10.11}$

Among all new patients starting renal-replacement therapy in England and Wales, the percentage of patients who were over 65 years increased from $11 \%$ in $1982-84$ to $39 \%$ in $1995 .^{12}$

What we see is not only that more elderly patients admitted to RRT programs, but also the age at which they were accepted gradually rose. During the 1980s, patients 75 years of age and older first enrolled RRT programs. ${ }^{13}$ Nowadays this age group showes almost the highest incidence among patients starting renal replacement therapy. ${ }^{4}$ In 1990, a questionnaire on the subject of treatment for elderly patients was sent to French nephrologists. The results showed that for patients younger than 90 years, age was no longer considered a good criterion for excluding patients from dialysis. ${ }^{14}$ Arguments for rationing dialysis by age, 
like poor survival expectancy, less quality of life and lower social abligations of elderly patients, and of course the high costs of renal replacement therapy, have been debated, leading gradually to the acceptance that age should not be a contraindication for RRT. ${ }^{1517}$

\section{Patient selection}

After disregarding chronological age as an exclusion criterion, the concept of biological age is sometimes used. ${ }^{18}$ However, such a judgment tends to be subjective, if not arbitrary. Nevertheless, selection does take place. ${ }^{19,20} \mathrm{~A}$ Swedish study reported that only $40 \%$ of all patients over 70 years of age with renal failure actually received treatment. ${ }^{21}$ A British survey reported that only 3 out of 37 patienis aged $70-100$ with end-stage renal failure underwent RRT. ${ }^{22}$ A survey of physicians in the United Kingdom revealed that a previously healthy octogemerian would not referred for dialysis by $68 \%$ of primary care physicians, or accepted for renal replacement therapy by $28 \%$ of nephrologists. ${ }^{23} \mathrm{~A}$ reluctance of family practioners to refer elderly patients for renal replacement therapy has been mentioned earlier. ${ }^{24}$

Yet, in the literature not very much evidence-based criteria can be found on which patient selection for RRT should be based. Severe dementia is a selection criterion commanly mentioned. Self-determination and autonomy are considered to be very important in this respect. ${ }^{25}$ In the above mentioned survey of French Nephrologists, $90 \%$ refused patients 75 years of age and older if they were not independent and did not have a supportive family. ${ }^{14}$ If the patient is truly campetent, then he or she should have the right to make a decision based on informed consent. ${ }^{26}$ However, decision making in this field is not always considered to be easy. ${ }^{27}$

In the United Kingdom criteria were published for the acceptance of patients on (local) renal replacement therapy programs. ${ }^{26}$ These criteria were based on potential life years to be gained from treatment, absence of significant comorbidity, and the capability of independent living. These recommandations showed to be a reasonable starting point following the results of a British hospital based cohort study. ${ }^{29}$ Over a four year period 292 patients with a mean age of 61.3 years starting planned or unplanned dialysis were defined on basis of age, comorbidity and functional status. Age, comorbidity and functional status were predictors of survival and morbidity. Age was heavily outweighed by the severity of comorbidity in predicting survival. The number of comorbid systems did not discriminate as well as the comorbidity severity score. Functional status (defined as the Karnowsky score) at the time of presentation, three months before presentation and the change in between all were usefull in predicting survival. The authors suggest that the question " how was the patient a few weeks ago before he or she became very unwell?" may be usefull in the treatment decision. The limited significance of age and the importance of comorbidity status was also found in the North Thames prospective cohort study. ${ }^{30}$ In this study a followup was made of 221 patients, aged 70 years and older, with end-stage renal disease. Mortality was significantly associated with age 80 years and older and 
peripheral vascular disease, but not with diabetes mellitus, ischemic heart disease, cerebrovascular disease, chronic obstructive airway disease, sex or treatment modality.

All these results clearly indicate that age alone should not be used as selection criterion for renal replacement therapy. However, the burden that renal disease and dialysis therapy imposes on elderly patients should not be underestimated. In the United States, probably the highest percentage of elderly patients are accepted for RRT. This lenient policy creates another problem: withdrawal from dialysis. Approximately one out of every five dialysis patients withdraws from dialysis before death. ${ }^{31}$ This does not include patients who have stopped dialysis because of restored of renal function. Patients are more likely to withdraw from dialysis if they are white, female, diabetic, older than 65 years, or living in nursing homes. ${ }^{32.33}$ Almost a quarter of all deaths in dialysis patients 65 years and older were preceded by withdrawal from dialysis in the period 1994 . $1996 .^{34}$

Accordingly, the decision to initiate renal replacement therapy in an elderly patient should be made after due consideration of the individual patients physical and medical status as well as his or hers psychlogical well-being.

\section{Treatment modalities}

\subsection{Hemodialysis}

The most common treatment modality in elderly patients is hemadialysis (HD). In the United States, around 80\% of the ESRD patients aged 65 years and over are treated with hemodialysis and only about $10 \%-12 \%$ of the patients 75 years and older are treated with peritoneal dialysis (PD) ${ }^{35,36}$ In Europe this percentage is similar, with the exception of the United Kingdom. Only in Australia and New Zealand is the distribution between $\mathrm{HD}$ and $\mathrm{PD}$ in elderly patients almost $50 / 50.37,39$

In the recent past, many technical improvements have been made in HD, such as the use of bicarbonate dialysate, varying the sodium content of the dialysis fluids, and better methods to assess fluid status in patients on hemodialysis. ${ }^{39-41}$ The introduction of re-combinant erythropoietin has also offered great advantages, despite the risks of hypertension and ischemic complications.

Elderly patients can do very well on HD. As early as 1979 Chester et al. reported a 2-year survival rate of $42 \%$ for $45 \mathrm{HD}$ patients older than 70 years. ${ }^{42}$ Age did not correlate with survival in this survey, nine patients older than 80 years had even a survival of $41 \%$. Although elderly dialysis patients are thought to have a lower mortality risk than younger dialysis patients, Mignon ef al. report a threefold mortality risk for 75 -year-old dialysis patients compared with an agematched cohort of non-dialysis patients. ${ }^{43}$

The EDTA-ERA Registry reports a 5 -year survival rate of $40 \%$ for patients from 65 - 69 years of age; for patients $70-74$ years of age it is nearly $30 \%$; for those over 75 years it is over $20 \%$. Ten-year survival is slightly over $20 \%$ in the age group $60-64$ and less than $10 \%$ in the group over 75 years. ${ }^{44}$ Survival rates 
differ in the different European countries. In Spain, Portugal, and lialy, the survival rate is much higher than in Austria, Norway, and Sweden. ${ }^{45}$ An important reason for this difference is probably the mortality from myocardial infaretion and cardiac ischemia. ${ }^{46,47}$ It may also partly attributed to the higher incidence of diabetes mellitus in the northern European countries. However, two recent British studies showed no significant influence on mortality of diabetes and ischemic heart disease. ${ }^{29,} 30$ Severe comorbidity influenced mortality more than the number of comorbidities. Functional status at the start of the dialysis is also important in assessment of survival.

Numerous studies show that mortality of HD patients is related to the length and frequency of dialysis treatment. Higher mortality is observed in patients treated with fewer hours of dialysis. ${ }^{48,49}$

\subsubsection{Complications}

There are a number of complications of HD in elderly patients. First of all, some authors mention hypotension as a complication more frequently seen in elderly patients than in younger dialysis patients. ${ }^{50,51}$ However, this difference is not found in all series. ${ }^{52}$ A substantial proportion of HD patients $(32 \%-62 \%)$ shows a decreased left ventricular (LV) ejection fraction due to LV hypentrophy. ${ }^{53.54}$ This may markedly affect myocardial axygen consumption, especially in patients with pre-existent cardiac disease, resulting in congestive heart failure. ${ }^{55-57}$ Another consequence of hypertrophy and a decrease in LV compliance is an increased incidence of arrhythmial's and sudden death. ${ }^{58}$ Malnutrition is frequently seen in elderly patients on maintenance HD. ${ }^{59}$ Several studies suggest that malnutrition is an important risk factor for morbidity and mortality in HD patients. ${ }^{60.61}$ Especially the presence of low serum albumin, low prealbumin, low serum cholesterol and other markers of nutritional status are correlated with increased mortality in dialysis patients. ${ }^{62-66}$ Treating malnutrifion leads to better results when a concomitant anemia is also treated. ${ }^{6}$ ?

Complications of the vascular access are responsible for a substantial percentage of the hospital admissions of the elderly ESRD patients. Ifudu et al found that diabetes mellitus and age were no independent risk factors for vascular access hospitalisation but were associated with prolonged hospital
stays.

Hemodialysis patients have a greater cardiovascular mortality than non-uremic patients. They have a higher prevalence of complicated atheromatous laesions. ${ }^{69}$ Calcification of these lesion is probably associated with secondary hyperparathyroidism resulting in an increased calcium-phosphate product. ${ }^{70}$ In favour for this hypothesis is the finding that progression of atherosclerosis is significantly lower in themodialysis patients with parathyroidectomy than in Finally prognosis of patients on HD is linked to renal vascular disease and, of course diabetes mellitus. ${ }^{61,72}$ 


\subsection{Peritoneall dialysis}

Peritoneal dialysis (PD) offers some important advantages to elderly patients, especially a better maintenance of fluid balance, preservation of residual renal function, and the fact that there is no need for vascular access. ${ }^{73.74}$

Numerous authors consider PD the treatment of choice for the elderly, particularly for those with hemodynamic instability or cardiovascular disease..$^{75.78}$ However, for patients with sensorial impairment, such as reduced vision, motor handicaps, or impaired capabilities in learning the technique, $\mathrm{PD}$ is not a suitable madality unless there is adequate family and/or social support. ${ }^{70,80}$

Complications of PD are catheter-related or infectious (peritonitis). The incidence of these complications is not higher in elderly patients than in young patients on PD. 81,82

A large survey reported that after 1 year of PD $60 \%$ of patients younger than 60 years were free of peritonitis vs. $65 \%$ of patients elder than 60 years. At 3 years these figures were 38 and $46 \%$ respectively. At 7 years 30 and $38 \%{ }^{83}$

Relapsing peritonitis is a feature in 8 to $16 \%$ of patients with peritonitis, whilst catheter removal is necessary in up to $15 \%$ of the patients, mortality due to peritonitis is 1 to $3 \%^{83,94}$ Death is the result either from sepsis or related complications, especially when the causing micro-organism is Gram-negative or fungus. ${ }^{85,86}$

The causes of peritonitis are similar in young and elderly patients on PD. ${ }^{\text {at }}$ Inguinal or abdominal hernias, fluid leakage, and vascular ischaemia of the lower extremities have a higher incidence in older PD patients than in younger patients. ${ }^{88}$

In terms of mortality, no major differences have been found between HD and PD. ${ }^{89}$ Vascular renal disease, advanced age, co-morbidity, and diabetes mellitus are major determinants of mortality.

\subsection{Renal transplantation}

In Europe, the proportion of elderly patients (60 years and older) treated by renal transplantation has increased from $2.9 \%$ in 1983 to $9.9 \%$ in $1992 .{ }^{\circ}$ In the United States of America in 1997, 36\% of all kidney transplants were performed in patients 50 years or older, and $5.7 \%$ were in patients age 65 years or older. ${ }^{91}$ Age has long been considered a risk factor for renal transplantation. Older patients have been found to have more (and more serious) complications and a higher mortality. ${ }^{92,93}$ This increased risk was associated with transplant surgery and immunosuppressive treatment. ${ }^{94,95}$ Graft survival in younger patients has been better than in older patients, primarily because of graft loss secondary to the elderly patient's death. ${ }^{96.102}$ On the other hand, graft lass due to rejection is less common in the elderly. ${ }^{98,300,103}$

The addition of cyclosporine $A$ to the inmunosupportive regimen has given a significant improvement in the survival of elderly patients receiving cadaveric renal transplants. ${ }^{104}$ Monotherapy with cyclosporine in patients over 55 years of age was reported to give a graft survival of $93 \%$ at 1 year and $90 \%$ at 3 years 
with patient survival of respectively 96 and $94 \%$ despite a high incidence of acute rejection. 105

The Spanish Monotherapy Study showed similarly good survival figures on monotherapy cyclosporine in elderly patients. ${ }^{106}$ These studies made it clear that immunosuppressive regimens without corticosteroids may be desirable in elderly patients.

Experiences of double therapy suggest that early withdrawal of corticosteroids is favourable in older recipients of kidney transplantation. ${ }^{10 \%} 109$ Triple therapy using corticosteraids, azathioprine, and cyclosporine or antithymocyte globulin (ATG), corlicosteroids, and cyclosporine hove also led to good results in elderly patients. 101,110,111 The main problern with this kind of regimens is the increased incidence of infections, especially cytomegalovirus infections, and the fact that elderly patients as less able to cope with infections than younger patients.

In general can be said that renal transplantation results in elderly recipients have improved since the intraduction of cyclosporine. Mortality, however, remains high, mainly following cardiovascular diseases and infections. In principle all immunosuppressive drugs can be used in elderly patients, but conticosteroids should be used with extreme caution. Older potients should be treated with lower doses and less immunosuppressive drugs than young patients to avoid overimmunosuppression with infectious complications. 112

Doyle ef al. reviewed the course of 206 consecutive primary renal allograft recipients, aged 60 years or older between 1980 and 1997, to identify risk factors that predicted a poor outcome. 13 Risk factors for graft loss were; current tobacca use (RR 8.1), pre-transplant non-skin malignancy (RR 3.9), Donor age $>50$ years (RR 2.3), pre-transplant vascular disease (arterial peripheral disease or venous thrombosis) (RR 2.1), time on the waiting list $<1$ year (RR 1.8), and age 65 to 70 (vs. 60-64) years (RR 1.7). Mortality was determined by pretransplant non-skin malignancy (RR 5.0), pre-transplant vascular disease (arterial peripheral disease or venous thrombosis) (RR 2.2), Age $>70$ years (vs. 60 to 64 ) (RR 2.7), Donor age $>50$ years (RR 1.9), and current tobacco use (RR 7.9).

The authors postulate that screening for these risk factor's will enable a selection of a group of low-risk elderly patients with good graft and survival outcomes.

Patients with diabetes mellitus type 11 are considered as a high-risk group. Not only are they generally over 50 years of age, but also they have considerable comorbidity. A recent survey showed that type 11 diabetics have a less overall graft survival in comparison with type $\|$ diabetics and non-diabetics over 50 years of age. ${ }^{114}$ The most common cause of graft loss is death with function. As far as immunologic graft lass is concerned no difference between the three groups could be found.

Thus, in elderly transplantation recipients, there is higher rate of graft loss due to an age-rellated increased mortality. This, however, is balanced by a significant lower number of graft losses from immunologic problems (acute and chronic rejection). Renal transplantation therefore, can offer a substantial survival advantage over dialysis in careful selected group of elderly ESRD patients. ${ }^{115,176}$ 


\section{Conclusions}

The incidence of ESRD is increasing in elderly patients. This is due to an everincreasing life expectancy, better survival after acute manifestations of cardiovascular disease, and an age-related decrease in renal function. A large percentage of the patients in chronic renal replacement programs is above the age of 65 .

The percentage of these patients who are accepted for renal transplantation is still low in comparison to patients in lower age categories, resulting in an increasingly older population using dialysis facilities.

Consequently, dialysis is not as readily available as it was in the past. Selection for RRT does occur. Yet, it is not clear which parameters can be employed to predict treatment outcome. If will become increasingly important to determine not only which patients should be treated with RRT but also for which patients this therapy is not indicated. Both measures will help prevent much unnecessary suffering and medical interventions for these patients. 


\section{Literature}

1. Evans RW, Blagg CR, Bryan ir. FA. Implications for health care policy: a social and demographic profile of hemodialysis patients in the United States. JAMA $1981 ; 245: 487-491$.

2. Eggers PW. Effect of transplantation on the Medicare end-stage renal disease program. NEngl I Med 1988,318:223-229.

3. US Renal Data System Annual Data Report. Bethesda MD: National Institutes of Health, 1991.

4. US Renal Data System: 1999 Annual Data Report: National institutes of diabeles digestiwe and Kidney diseases, Bethesdo, MD April 1999.

5. Schoubel D, Desmeules M, Mao Y. Jeffrey J Fenton S. Surviwal experience among elderly end-stage renal disease patients. Transplantation 1995;60:1389-1394.

6. Fassbinder W, Brunner FP, Brynger H, Ehrich JHH, Geer lings W, Raine AEG, Rizzoni $G$ Selwood NH, Tutreson $G$, Wing A.J. Combined repont on regular dialysis and transplantation in Europe, XX, 1989 Nephrol Dial Transplant 1991;6(S):5-35.

7. Lawrence JR. The Evolution of the End-Stage Renal Disease Progm in Australia. Renal Fialure 1994; 16(1):133-146.

8. Sheil AGR, Lawrence JR, Marris PS, Kincaid-Smith PS, Sands 1. Australian National Renal Transplantation Survey: third report by a sub-committee. Med J Aust $1974 ; 2: 656-660$.

9. International Comparisons of ESRD Therapy: US renal data system, USRDS 1991 Annual data report: The National Institute of Health, National Institute of Diabetes and Digestive and Kidney disesases, Bethesda MD. Am J Kidney Dis $1991 ; 18(5)$ (suppl 2):93-95.

10. Berlyne GM. Over 50 and uraemic = death. Nephron 1982:31:189-190.

11. Stanton J. The costs of living: kidneys, dialysis, rationing and health economics in Britain, 1995-1996. Soc Sci Med 199;49;1169-1182.

12. Roderick PJ, Ferris G, Feest TG. The provision of renal replacement therapy for adults in England and Wales: recent trends and future directions. QJM $1998,91: 581-587$

13. Segloni GP, Salmone M, Piccoli GB. CAPD in the Elderly: Halian multicenter study experience. Ady Perit Dial 1990;(S)6:82-85.

14. Pollini J, Teisser $M$. Un dilemme dificile à résovdre: Les maladies âgés récusés pour la dialyse chronique. Problèmes éthiques ou choix medical. In: Mignon F. ed. Néphrologie Prospective: Le 3ème àgle. Paris, 1990; (S):341-347.

15. Grimley Evans J. Rationing health care by age: the case against. BMJ $1997 ; 314: 822-825$.

16. Williams A. Rationing Health care by age: the case for. BMU1997;314:820-822.

17. Varekamp I, Krol LJ, Danse JAC. Age rationing for renal transplantation? The role of age in deciscions scarce life extending medical resources. Soc Sci Med $1998,47: 113-120$.

18. Mooradian AD. Biological and functional definition of the older patient: the role of biomarkers of aging. Oncology 1992;6(\$) $39-44$.

19. Friedman EA. Rationing of uremia therapy. Artificial Organs 1992;16:90-97. 
20. Kjellstrand $C M_{*}$ Moody H. Hemodialysis in Canada: a first dass medicol crisis Can Med Assoc J 199:4;150:1067-1071.

21. Kiellstrond CM. Giving life - giving death. Ethical problems of high technology medicine. Acta Medica Scandinavica 1988,(5 725):5-88.

22. Feest TG, Mistry CD, Grimes DS, Mallick NP. Incidence of advanced chironic renal failure and the need for end-stage renal replacement theropy. Br Med J $1990,301: 897-903$.

23. Parry RG, Crowe A, Stevens JM, Mason JC. Referral of elderly potients with severe renal failure: questionnaire survey of physicians. BMJ 1996;313;446.

24. Woodhouse KW, Wynne H, Baille S, James OFW, Rawlins $M$. Who are the frail elderly? $Q \|$ Med 1987;68:505-506.

25. Kilner JF. Ethical issues in the initiation and termination of treatment. Am J Kidney Dis 1990; 15:218-227.

26. American College of Physicians. American Callege of Physicians Ethics Manual. 3rd ed. Ann Intern Med 1992;117:947-960.

27. Perry $E_{r}$ Schwartz $\mathbb{R}_{r}$ Smith-Weelock $L$. Why is it difficult for staff to disuss advance directives with chronic dialysis patients? A Am Soc Nephrol 1996;7:2160-2168.

28. Farmery $E$, Milner $\mathbb{P}$. Renal replacement therapy: purchasing review and recommandations. Devizes: Wilthshire Health authority, 1997.

29. Chandra SM, Shulz J, Lawrence C, Greenwood RN, Farrington. Is there a rationale for rationing chronic dialysis? A hospital based cohort study of factors affecting survival and morbidity. BMJ 1999;318:217-223.

30. Lamping DL, Constantinovici N, Raderick P, Normand C. Henderson L, Harris $S$, Brown E. Gruen R, Victor C. Clinical outcomes, quality of life, and costs in the North Thames Dialysis Study of elderly people on dialysis: a prospective cohort study. Lancet 2000;356:1543-1550.

31. USRDS Coordinating Center. United States Renal Data System. Annual Data Report. Ann Arbor, Ml 48103, 1998.

32. US Renal Data System Annual Data report, Bethesda, MD: Natianal Instifutes af Health, aug 1992 .

33. Husebye DG. Kjellstrand CM. Old patients and uremia: rates of acceptance to and withdrawal from dialysis. Int J Artif Organs 1987,10:166-172.

34. Leggat JE jr, Bloembergen WE, Levine G. Hulbert-Shearon TE, Part FK. An analysis of risk factors for withdirawal from dialysis before death. J Am Soc Nephrol 1997:8:1755-1763.

35. United States Renal Data System 1991: Annual data report. Am J Kidney Dis $1991 ; 18: 1-127$.

36. Us Renal Data System Annual Data Report. Bethesda MD: National Institutes of Health, 1997.

37. Mignon F, Michel C, Mentre F, Viron B. Worldwide demographics and future trends of the management of renal failure in the elderly. Kidney Int 1993;43 (Suppl 4.31:518-S26.

38. Mattern WD, McGaghie WC, ef al. Selection of ESRD treatment: an international study. Arn J Kidney Dis 1989;13:457-464. 
39. Intemational Comparisons of ESRD therapy: US Renal Data System, USRDS 1991 Annual data report. The Natianal Instifute of Heath, National Institutes of Diaberes and Digestive and Kidney Diseases, Bethesda MD. Am J Kidney Dis 1991;18(5):93. 95.

40. Hakm HR, Pontzer MA, Tilton D, Lazarus JM, Gottlieb MN. Effects of acetate and bicarbonaie dialysate in Stable chronic hemadialysis patients. Kidney Int $1985.28: 535.540$.

41. Leunissen KML, Kouw P, Kooman JP, Cheriex EC. de Vries PMUM, Donker AJM, van Hooff JP. New techniques to determine fluid status in hemodialyzed patients. Kidney Int 1993;43 (S 41):S50.556.

42. Chester AC, Rakowski TA, Argy WP ir, Giacalone A, Schreiner GE. Hemodialysis in the eight and ninth decades of lite. Arch Intern Med 1979; 139:1001-1005.

43. Mignon $F$, Siohan $P$, Legallicier $R$, Khayat $R$, Viron $B$, Michel $C$. The management of uremia in the elderly: treatment choices. Nephrol Dial Transplant 1995; 10/suppl 6): $55-59$.

44. Volderrábano F, Berthoux FC, Jones EHP, Mehls O. Report on management of renal failure in Europe XXV, 1994. End stage renal disease and dialysis report. Nephrot Dial Transplant 1996; 1 ) (S 1):2-21.

45. Hakim HR, Pontzer MA, Tilton D, Lazarus JM, Gothieb MN. Effects of acetate and bicarbonate dialysate in stable chronic hemodialysis patients. Kidney Ini $1985 ; 28: 535-540$

46. Diax-Buxo JA, Adcock A, Nelms M. Experience with contnuous cyclic peritoneal dialysis in the geriatric patient. Adw Perit Dial 1990,(S)6:61-64.

47. Raine AEG, Margreiter R, Brunner FP, Ehrich JH, Geerlings W, Landais P, Loirat C, Mallick NP, Selwood NH, Tufveson $G$ et al. Repart on management of renal failure in Europe XXII, 1991. Nephrol Dial Transplant 1992;7 (S 2):7-35.

46. Held JP, Leven NW, Bobjerg RR, Pauly MV, Diamond LH. Mortality and duration of treatment. JAMA 1991;265:871-875.

49. Teraoka S, Toma H, Nihei H, Ota K, Babazono T, Ishikawa I, Shinada A, Maeda K, Koshikawa $S$, Takahashi $T$, et al. Current status of renal replacement therapy in Japan. Am J Kidney Dis 1995;25:151-164.

50. Bernard DR. Hypotension, bradycardia and syncope during hemodialysis. ASAIOJ $1979: 2: 42-48$

51. Rathous $M$, Kortets $Z$, Bernheim $J$. Results of regular hemodialysis treatment in the elderly: A retrospective study. Dial Transplant 1980;9:1015-1018.

52. Jacobs C, Diallo A, Balas EA, Nectoux M, Etienee S. Maintenance hemodialysis treatment in potients aged over 60 years. Demographic profile, profile, dinical aspects and outcome. Proc Eur Dial Trans Assoc 1985;21:477-489.

53. Lai KN, Ng J, Whitford J, Butffield J, Fasset RG, Mathew TH. Left ventricular function in uremia: Echocardographic and radionuclide assessment in patients on maintenance hemodialysis. Clin Nephrol 1985;23:125-133.

54. Hamett JD, Parfrey PS, Griffiths SM, Gault MH, Barre P, Gultmann RD. Left ventricular hypentrophy in end-stage renal disease. Nephron 1988;48:107-115

55. McDonald IL, Uldall R, Buda AJ. The effect of hemadialysis on cardiac rhythm and performance. Clin Nephrol 19816:321-327.

56. Parfrey PS, Hornett JD, Griffiths SM, Gault MH, Barre PE. Congestive heart failure in dialysis patients. Arch Intern Med 1988; 748:1519.7525. 
57. Lewy D, Garrison RJ, Savage DD, Kannel WB, Castelli WP. Left ventricular mass and incidence of coronary artery disease in an elderly cohort. The Framingham Heart Study. Arn Intern Med 1989;110:101-107.

58. London GM, Marchais SJ, Guerin AP, Metiwier F, Ponnier B. Cardiac hypertrophy and arterial alterations in end-stage renal disease: hemodynamic factors. Kidney Int $1993 ; 43(541): 542-549$.

59. Piccoli G, Bonello f, Massara $C$, et al. Death in conditions of cachexia: The price for the diallysis treatment in the elderly? Kidney Int 1993;43:S82-S86.

60. Bergstrom J. Nutrition and adequacy of dialysis in hemodialysis patients. Kidney Int 1993,43 (S 41):\$261-5267.

61. Mailloux LU, Bellucci AG, Mossey RT, Napolitano B, Moore T, Wilkes BM, Bluestone PA. Predictors of survival in patients undergaing dialysis. Am J Med 1988:84:855. 862.

62. Lowrie $\mathbb{E G}$, Lew NL. Death risk in hemodialysis patients: the predictive value of commonly measured variables and an evaluation of death rate differences between facilities. Am I Kidney Dis 1990;15:458-482.

63. Held PJ, Port FK, Agado LYC. Survival probabilities and causes of death. In: Agado LYC, Held PJ, Port FK. Eds. US renal data system annual data report. 2nd ed. Bethesda, MD: National Institutes of Health, 1991:31-40.

64. Steinman TI. Nutritional management of the chronic dialysis patient. Semin Dial 1992;5:155-158.

65. Owen WF ir, Lew NL, Liu Y, Lowrie EG, Lazarus JM. The urea reduction ratio and serum albumin concentration as predictors of mortality in patients undergoing hemodialysis. NEJM 1993;329:1001-1006.

66. Lowrie EG, Conceptual for a core pathobiology of uremia with special reference to anemia $_{s}$ malnourishment, and mortality among dialysis patients. Semin Dial $1997 ; 10: 115-119$

67. Paskalev E. Influence of anemia on treatment of malnutrition in patients on hemodialysis. Nephron 2000;86:215-216.

68. Ifudu O, Mayers JD, Cohen LS, Paul H, Brezsnyak WF, Avram MM, Herman Al, Friedman EA. Correlates of vascular access and non-vascular access-related hospitalizations in hemodialysis patients. Am J Nephrol 1996;16:118-123.

69. Ritz E, Deppisch R, Stier E, Hansch G. Atherogenesis and cardiac death: Are they relatedcto dialysis procedure and biocompability? Nephrol Dial Transplant 1994 ; $($ suppl 2):165-172.

70. Kabaya T. Nitta K, Kimura H, Kawashima A, Mimuro T, Narusawa K, Nihei H. An increased serum level of parathyroid hormane is a risk factor for atherosclerosis in hemodialysis patients. Nephron 2000;86:213-21.4.

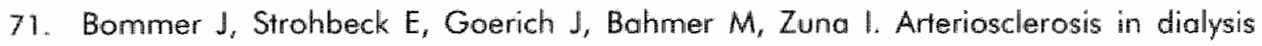
patients. IArtif Organs 1996;19:638-644.

72. Collins AJ, Hanson $G$, Umen A, Kjellstrand $C$, Keshaviah P. Changing risk factor demographics in end-stage renal disease patients entering hemodialysis and the impact on long-term mortality. Am J Kidney Dis 1990;15:422-432.

73. Gentile DE (and the Geriatric Advisory Commiftee): Peritoneal dialysis in geriatric patients: A survey of clinical practice. Adv Perit Dial 1991;6 (S):29-32.

74. Maiorca R, Cancarini GC, Camerini C, Manili L, Brunori G. Modality selection in the elderly: Medical factors. Adv Perit Dial 1990,6 (S):18-26. 
75. Nicholls A, Waldek S, Platts MM, Moorhead PJ, Brown CB. Impact of continuous ambulatary peritoneal dialysis on treatment of renal failure in patients aged over 60. BM 1984;288:18-19.

76. Vlochojonnis J, Kurz P. Hoppe D. CAPD in elderly potients with cardiovascular risk factors. Clin Nephrol 1988,30(S 1),513-517.

77. Nissenson AR, Diaz-Buxo JA, Adcack A, Nelms M. Peritoneal dialysis in the elderly patient. Am J Kidney Dis 1990;16:335-338.

78. Nolph KD, Lindblad AS, Wovak JW, Steinberg SM. Experiences with the elderly in the notional CAPD Registry. Adv Peritoned Dial 1990;6(S):33-37.

79. Michel $C$, Bindi P, Viron B. CAPD with private home nurses: an alternative treatment for elderly and disabled patients. In: Nissenson $A R$, ed. Peritoneal dialysis in the geriatric patient. Adv Peritoneal Diall 1990;(suppl): $331-335$.

80. Nissenson AR. Opinion: how can the care of elderly dialysis patients be improved? Semin Dial 1992;5:25-26.

81. Segoloni GP, Salomone M, Piccoli GB. CAPD in th elderly: Halian multicenter study experience in the elderly. Adv Perit Dial 1990;6 (suppl):41-46.

82. Nissenson AR, Gentile DE, Soderblom R. CAPD in the elderty: Southern California/Southern Nevada experience. Adv Perit Dial 1990;6 (S):51-55.

83. Tzamaloukas A.H. Pritonitis in peritoneal dialysis patients: an overview. Adv Renal Replace Ther $1996,3: 232-236$.

84. Gokal R. Peritoneal dialysis. Prevention and control of infection. Drugs \& Aging $2000 ; 4: 269-282$.

85. Woadrow $G$, Turney JH, Brownjohn AM. Technique failure in peritoneal dialysis and its impact on patient survival. Perit Dial Int 1997;17:360-364.

86. Fried LF, Bernardini J, Johnston JR, Piraino B. Peritonitis influences montality in peritoneal dialysis patients. J Am Soc Nephrol 1996;7:2176-2182.

87. Soreide R, Svarstad E, Versen BM. CAPD in patients above 70 years of age. Adv Perit Dial 1991;7:73-76.

88. Macias-Nuñez JF, Camerom JS. Treatment of end stage renal disease in the elderly. In: Cameron JS, Davison AM, Grunfeld J, et al, eds. The Oxford Textbook of Clinical Nephrology. London; Oxford 1992:1621-635.

89. Benevent, Benzakour M, Peyronmet P, Legarde C, Leroux-Robert $C$, Charmes J.P. Comparison of continuous ambulatory peritoneal dialysis and hemodialysis in the elderly. Adv Perit Dial 1990;6 (S):68-71.

90. Valderrabano F, Jones EHP, Mallik NP. Report on management of renal failure in Europe XXIV, 1993. Nephral Dial Transplant 1995; 10(suppl 5): 1-25.

91. U.S.Scientific Registry for Transplant Recipients and the Organ Pracurement and Transplantation Newwork: United Network for Organ Sharing 1997 Annual Report. Division of Transplantation, Office of Special Programs. Health Resources and Services Administration, U.S.Dept of Health and Human Services, Richmond VA, 1997 (thttp://WWw. UNOS.org/DATA/anrpt97/).

92. Wedel $N$, Brynger $H$, Blohme 1. Kidney transplantation in patients 60 years and older. Scand J Urol Nephrol 1980;(suppl) 54:106-108.

93. Ost L, Groth $\mathrm{CG}_{*}$ Lindholm B, Lundgren G, Magnussen G, Tillegard A. Cadaweric renal transplantation in Patients over 60 years and above. Transplantation 
94. Brunner FP, Fassbinder W, Broyer M, Oules R, Bynger H, Rizzoni G Challah 5 , Selwood NH, Dykes SR, Wing Al. Survival on renal replacement therapy: data from the EDTA Registry. Nephrol Dial Transplant 1988;3:109-122.

95. Tapson IS, Rodger RSC, Mansy H, Elliot RW, Ward MK, Wilkinson R. Renal replacement therapy in patients over 60 years. Postgrad Med $₫ 1987 ; 63 ; 1071$. 1077.

96. Schulack JA, Mayes JT, Johnston KH. Hricik. DE. Kidney transplantation in patient aged sixty years and older. Surgery 1990;108:726\%733.

97. Morris GE, Jomeson NV, Small J, Evans DB, Calne R. Cadaveric renal trasnplantation in elderly recipients: is it worthwile? Nephrol Dial Transplant 1991:6:887-892.

98. Vivas CA, Hickey DP, Jordan ML, O'Donovan RM, Lutins J, Shapiro R, Slarzi TE, Hakala TR. Renal transplantation in patients 65 years old or older. I Urol $1992 ; 147: 990-993$.

99. Benedetti E, Matas AJ, Hakim N, Fasolla C, Gillingham K, McHugh L, Najarian IS. Renal transplantation for patients 60 years of age or older. A single-institution experience. Ann Surg 1994;220:445-460.

100. Tesi RJ, Eikhammas EA, Davies EA, Henry ML, Ferguson RM. Renal transplantation in older people. Lancet 1994;343:461-464.

101. Albrechtsen D, Leivestad T, Sodal G, Bentdal O, Berg KJ, Brekke I, Fauchald P, Flatmark A, Jakobsen A, Lien B, Nordal K, Pfeffer P, Thorsby E, Soreide O. Kidney transplantation in patients older than 70 years of age. Transplant Proc 1995;27:986-988.

102. Ismail N, Hakim RM, Helderman $J H$. Renal replacement therapies in the elderly. II Renal transplantation. Am J Kidney Dis 1994;23:1 - 15 .

103. Berthoux FC, Jones. EHP, Mehls O, Valderrábano F. Transplantation report 1: renal transplantation in reciepients aged 60 years or older at time of grafting. Nephrol Dial Transplant 1996;11 (S 1):37-40.

104. Pirsch JD, Stratta RJ, Armburst MJ, D'Alessandro AM, Solinger HW, Kayaloglu M, Belzer FO. Cadaveric renal fransplantation with cyclosporine in patients more than 60 years of age. Transplantation 1989:47:259-261.

105. Andreu $ل_{s}$ de la Tarre M, Oppenheimer F, Campistol JM, Rickart ML, Vilardell J, Talbot $R$, Carretero P. Renal transplantation in elderly recipients. Transplant Proc $1992 ; 24[1] ; 120-121$.

106. Spanish Monotherapy Study Group. Cyclosporin monotherapy versus OKT3 and cyclosporine versus prednisone and cyclosporin as induction therapy in alder renal transplant patients: a multicenter randomized study. Transplant Proc 1994:26:2522-2524.

107. Ferham 1, Brattstrom C, Durai F, Grath CG. Kidney transplantation in patients between 65 and and 75 years of age. Transplant Proc 1989;21(2):2018-2020.

108. Lundgren $G$, Persson $H$, Albrechtsen D, Brynger H, Flatmark A, Fradin L, Groth CG, Lindholm $A$, Weibull $H$. Recipient age: an important factor for the outcome of cadaver renal transplantation in patients treated with cyclosporine. Transplant Proc $1989 ; 21: 1653-1654$. 
109. Morales M. Muñaz MA, Campo C, Andres A, Araque A, Alamo C. Praga M,

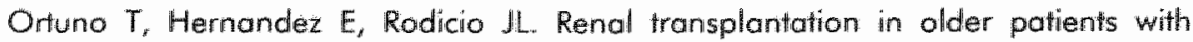
double therapy with optional change to cyclosporine monotherapy: long-term results. Transplant Proc 1994;26:5211-5212.

110. Hestiri D, Frimat L. Hubert J, Renoult E, Huu TC, Kessler M. Renal transplantation in patients over sixty years of age. Clin Nephrol 1994;42:232-236.

111. Barry JM, Lemmers MJ, Meyer MM, de Mattos A, Bennett WM, Norman DJ. Cadaver kidney transplantation in patients more than 65 years ald. World I Urol $1996 ; 14: 243-248$.

112. Morales JM, Campistol JM, Andrés A, Herrero JC. Immunosuppression in Older renal transplant patients. Drugs \& Aging 2000; $16(4) ; 279-287$.

113. Doyle SE, Matas AJ, Gillingham K, Rosenberg ME. Predicting clinical outcome in the elderly renal transplant recipient. Kidney Int 2000;57:2144-2150.

114. Kronson W. Gillingham Ki, Sutherland DER, Matas AJ. Renal transplantation for type II diabetic patients compared with type I diabetic patients and aptients ower 50 years oll: a single-center experience. Clin Transplantalion 2000:1 4:226:234.

115. Lufft $V$, Kliem $V$, Tusch $G$, Dannenberg $B$, Brunkhorsit R. Renal transplantation in older adults. Transplantation 2000,69:790-794.

116. Johnson DW, Herzig K, Purdie D, Brown AM, Rigby RU Nicol DL, Hawley CM. A comparison of the effects of dialysis and renal transplantation on the survival of older uremic patients. Tronsplantation 2000;69:794-799. 


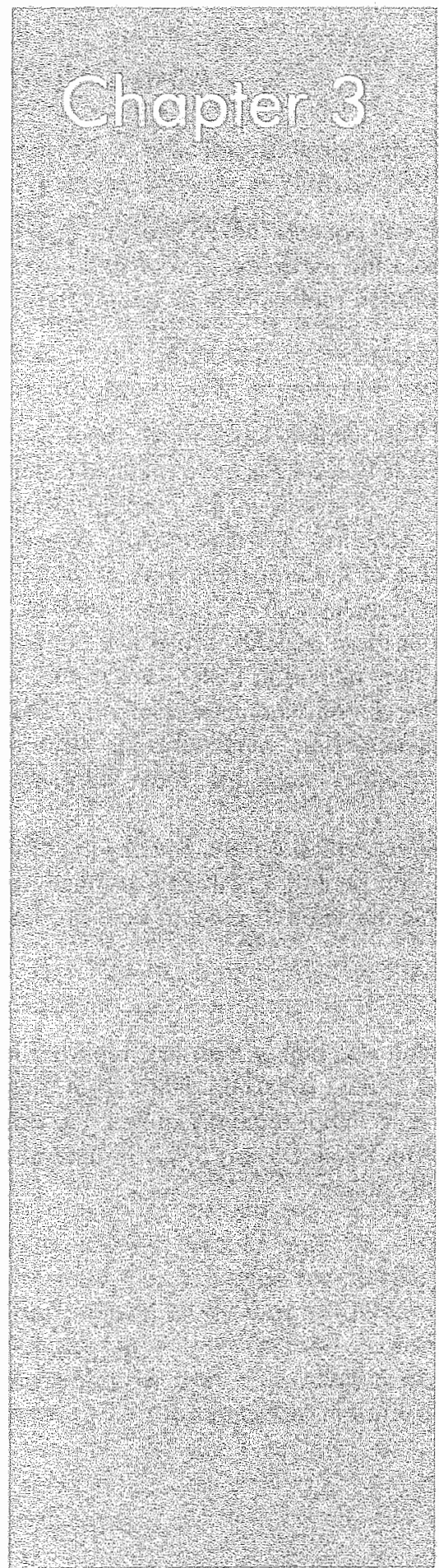

Clinical characteristics of elderly patients with end-stage renal disease: a retrospective study in the Dutch population

WJ Mulder, JFBM Fiolet, KML Leunissen, HFP Hillen 


\section{Abstract}

\section{Objective}

A retrospective study was carried out among 331 elderly patients (65.95 years of age) in four hospitals with dialysis facilities in order to assess the incidence of end-stage renal disease (ESRD) as well as the accessibility of renal function replacement programs for the elderly.

\section{Results}

The incidence of ESRD was estimated to be 2.2 per 1000 elderly inhabitants. There were more men than women $(59 / 41 \%)$ in this group. Patients had an extensive medical history and comorbidity. The mean number and the diversity of events in the medical history were high (4.5 in male and 5.3 in female patients). Cardiavascular disease, hypertension, gastro-intestinal disorders, and diseases of the urogenifal tract accounted for $63 \%$ of these events. We also found extensive comorbidity with a Charlson index of 1 in $29.9 \%$ of the patients and of 2 or more in $16 \%$ of these patients. While few patients had renal biopsies taken, a large number of diagnoses related to ESRD were made. In 118 patients the onset of renal failure was acute. The clinical diagnoses related to ESRD were multiple $(580$ diagnoses in 331 patients). Hypertension, renal wascular disease, postrenal causes, cardiac failure, and diabetes mellitus were the most frequently occurring diagnoses related to ESRD.

There were 35 patients $(41 \%)$ in a renal function replacement program. Seventy $(52 \%)$ of the patients treated did not survive the 2-year inclusion period: 112 (57\%) of those not treated by renal replacement therapy (RRT) died within the same 2 years. In both groups, comorbidity and age played an important role.

\section{Conclusions}

The incidence of renal failure in our elderly population was higher than that reponted in the literature. This is due to the fact that our method of data collecting differs from most surveys. Accessibility of RRT programs for elderly patients in our region is limited and age is a major criterion. However, the survival rate $-51 \%$ for treated versus $57 \%$ for untreated patients - indicates that patient selection for RRT is not optimal. 


\section{Introduction}

Prior to 1980, few elderly patients with end-stage renal disease (ESRD) were able to participate in dialysis programs. Since then, however, the situation has gradually changed.

Patients 65 years of age and older now represent the most rapidly growing segment of the ESRD- population in North America, Europe, and Australia. ${ }^{1.5} \mathrm{~A}$ number of factors are responsible for this increase.

First of all, technical improvements in the field of vascular access, in dialysis procedures, and in membrane materials and dialysate fluid composition, as well as the increased availability of dialysis facilities, have made it possible to treat a growing number of elderly patients. Renal transplantation, while fairly successful in carefully selected elderly patients, is still largely confined to younger patients due to the scarcity of transplant organs..$^{6.8}$ Therefore, once elderly patients are admitted to chronic renal replacement programs, they usually remain in dialysis, leading to an increase in the mean age of patients undergoing renal replacement therapy (RRT). There has also been a substantial increase in the number of patients with diabetes mellitus in the ESRD and dialysis populations during the past two decades. This is due both to an increased prevalence of diabetes in the general population and to an increased acceptance of diabetics into renal replacement programs. ${ }^{9.10}$ in the 1960 s and early 1970 s the survival of diabetics in renal function replacement programs was reported to be 3-6 months; this was because of high morbidity and mortality rates attributed to blindness and coronary artery, cerebrovascular, and peripheral vascular diseases. ${ }^{11-14}$ Thus, during that period, in North America and Europe, diabetes was considered to be an exclusion criterion for dialysis. Since the late 1970s and early 1980s, better results have been reported, and today diabetics are frequently seen undergoing dialysis. ${ }^{15,16}$

Most reports an ESRD in the elderly focus on potients enrolled in renal function replacement programs. Despite the fact that many elderly patients, when carefully managed, can adjust well to ESRD, a substantial number of them are not seen in the dialysis department.

In a survey of physicians in the United Kingdom, a previously healthy octogenarian would not be referred for dialysis by $68 \%$ of primary care physicians or accepted for dialysis by $28 \%$ of nephrologists. ${ }^{7}$

The present study was undertaken to assess the incidence of ESRD in elderly patients in a well-defined region, as well as to gain insight into the clinical presentation and characteristics of these patients. We were also interested in determining the accessibility of RRT programs for these patients. 


\section{Subjects and methods}

We retrospectively studied the incidence of ESRD, the clinical data of patients with ESRD, the number of patients admitted to RRT programs, and the survival of ESRD potients with and without RRT. To this end, a search was performed of the laboratory records in the four hospitals with dialysis facilities in our region Laurentius Hospital Roermond, Maasland Hospital Sittard, Atrium Hospital Heerlen, and the University Hospital in Maastricht - of patients 65 years and over with a serum creatinine of at least $400 \mu \mathrm{mol} / 1(4.5 \mathrm{mg} / \mathrm{dl})$ measured between January 1, 1992 and December 31, 1993 the inclusion period.

These four participating hospitals are situated in the region of South Limburg, the Netherlands. This region has a total population of 1.25 million inhabitants and shares borders with Belgium to the south and the west and with Germany to the east. Insurance policies do not allow medical treatment of patients across the border. Therefore, in every respect, this region is well defined.

The four hospitals have a target population of about 1 million people. All laboratory data were retrieved from computerized files of the hospital information systems. The laboratories of these hospitals perform tests on inhospital patients and on those attending outpatient clinics, as well as for all primary care physicians in this region.

The medical files of these patients were studied and data were extracted concerning age, gender, socioeconomic status, functional status, medical history, primary renal diagnosis, comorbidity, medical interventions, and clinical course. Comorbidity was defined as diseases present at the moment the diagnosis ESRD was made. Medical history and comorbidity were entered following the International Classification of Diseases, 9th revision, Clinical modification (ICD-9-CM). ${ }^{18}$ We estimated the severity of comorbidity using the Charlson index. ${ }^{19}$ This index contains a list of nineteen conditions, some of them representing two degrees of severity of the same condition. One of these conditions, moderate or severe renal disease, was not scored in our population since it was the primary disease.

The interval between the first indication of impaired renal function and the moment serum creatinine reached a value of $400 \mu \mathrm{mol} / /$ or more was referred to as the renal thistory. A short renall history ( $<4$ weeks) was defined as acute renal failure, a longer renal history as chronic renal failure.

In cases of RRT, we discriminated between acute therapy (started within 4 weeks after reaching a serum creatinine of $400 \mu \mathrm{mol} / \mathrm{l}$ or higher) and non-acute therapy (started after 4 weeks of the onset of ESRD).

All statistical analyses were done using SPSS for Windows 7.5 (SPPS Inc., Chicago). Data are presented as the mean value \pm SD or number (percent). Student's $t$ test was used to compare continuaus variables. For categorical variables, the chi-square test or, when appropriate, the Fischer exact test was used. Survival was calculated from the moment the patient entered the study, Patients still alive at the end of the study (31-12-1999) were censored. The 
survival curves were made using the Kaplan-Meier procedure, a method of estimating time-to-event models in the presence of censored cases.

The study was approved by the medical ethics board of the university hospital of the University of Maastricht.

\section{Results}

\section{Patients}

During the 2-year study period, 567 patients aged 65 years or older were found to have a serum creatinine of at least $400 \mu \mathrm{mol} / 1$.

Data could be obtained for 331 of these patients - 194 men $(59 \%)$ and 137 women $(41 \%)$ - due in part to incomplete records and in part to the fact that the hospital's laboratory facilities are also open to general practitioners. Several patients of the primary care physicians were not referred to the hospital, and thus not registered in hospital records.

Our findings suggest a yearly presence of 280 elderly patients with ESRD in the region of our hospitals (target population 1 million). At present, $13 \%$ of the totall population is 65 years of age or older, so we estimate the yearly prevalence of ESRD in the elderly population to be 2.2 per 1000 elderly inhabitants. The ellinical characteristics of our 331 patients are summarized in Table 3.1.

Table 31 Basic dinical charactertstics

\begin{tabular}{|c|c|c|}
\hline & Male & Penalle \\
\hline Number of patients & 194 & 137 \\
\hline Median age & $74(65-92)$ & $73(65-95)$ \\
\hline Mean age & $74,18(\mathrm{sD} 651)$ & $74.5(\mathrm{SD} 7 \mathrm{1})$ \\
\hline Age groups & & \\
\hline 64.70 & $62(32 \%)$ & $48(35 \%)$ \\
\hline 7175 & $54(28 \%)$ & $34(25 \%)$ \\
\hline $75-80$ & $49(25 \%)$ & $25(18 \%$ \\
\hline $3>80$ & $29(15 \%)$ & $30(22 \%)$ \\
\hline Serum creatimine & $654 \mu \mathrm{mol} / \mathrm{H}$ & $618 \mathrm{\mu mol} /$ \\
\hline & $(S D 27164)$ & $(5 D 254,09)$ \\
\hline Body weigh/ (mean) & $72.5 \mathrm{~kg}(\mathrm{SD}) 1 \mathrm{~s})$ & $62.5 \mathrm{~kg}(\mathrm{SD} 128)$ \\
\hline Height (mean) & $172,1 \mathrm{~cm} \cdot(\mathrm{SD} \quad 5.8)$ & $163.7 \mathrm{~cm}(\mathrm{SD} 6.2)$ \\
\hline $\mathrm{BM}$ & $245 \mathrm{~kg} / \mathrm{m}^{2}$ & $24.4 \mathrm{~kg} / \mathrm{m}^{2}$ \\
\hline RR systolic & $1473 \mathrm{mmHg}(\mathrm{SD} 35.2)$ & $150.2 \mathrm{mmHg}(5 \mathrm{D} 367)$ \\
\hline $\mathrm{RR}$ díastolic & $80.8 \mathrm{mmHg}(\mathrm{SD} 17.6)$ & $81,5 \mathrm{mmHg}(\mathrm{SD} 19.5)$ \\
\hline Heart frequency & $86.9 \mathrm{~b} / \mathrm{min} / \mathrm{SO} / 9.4)$ & $88.3 \mathrm{~b} / \mathrm{min}(5 \mathrm{D} / 8.6)$ \\
\hline Irregular pulse & 17 & 9 \\
\hline Pulmonary edema & 49 & 28 \\
\hline
\end{tabular}


There was no significant difference in age between the male and female patients. In almost every age group, there were more male than female patients. One-third of all patients were in the youngest age group (64-70 years) and 18\% were in the oldest age group (>80 years).

The mean serum creatinine was $639 \mu \mathrm{mol} / /$ (range: $400-1845 \mu \mathrm{mol} / \mathrm{L}$; SD: 264.74); no statistical difference could be found between male and female patients (Table 3.1).

The mean bady mass index (BMI) of the total group of patients was $24.4 \mathrm{~kg} / \mathrm{m}^{2}$. These data are comparable with those in the normal Dutch population. ${ }^{20}$ However, the percentoge of obese persons was lower in our group than in the general population $(7.4 \%$ vs. $11.5 \%)$.

We estimated the renal function of these patients using the Cockcroft and Gault formula for age-adjusted creatinine clearance. ${ }^{21}$ We found a mean creatinine clearance $(\mathrm{Ccr})$ of $11,1 \mathrm{ml} / \mathrm{min}$.

In male patients, the mean Cor was $10 \mathrm{ml} / \mathrm{min}$ (range: $3-25 \mathrm{ml} / \mathrm{min}$; SD: 3.59 ), and in females $8 \mathrm{ml} / \mathrm{min}$ (range: $2.21-16 ; \mathrm{SD}: 2.98$ )

The mean systolic blood pressure was $148.5 \mathrm{mmHg}$ at the moment of first admission. Female patients had a higher systolic blood pressure than male patients (150.2 vs. $147.3 \mathrm{mmHg}$ ), leading to an overall statistically significant difference between the groups $(p<0.05)$. A total of 18 patients $(9$ male and 9 femalej had a systolic blood pressure below $99 \mathrm{mmHg}$. A systolic pressure above $180 \mathrm{mmHg}$ was found in 70 patients ( 36 male and 34 female).

The mean diastolic pressure was $80.8 \mathrm{mmHg}$ in the male patients and 81.5 $\mathrm{mmHg}$ in the female patient group. The percentage of patients with a diastolic blood pressure of $95 \mathrm{mmHg}$ or more was $14.4 \%$ in the male group and $15.8 \%$ in the female group.

The mean pulse frequency was almost the same in the two patient groups 187 $\mathrm{b} / \mathrm{min}$ vs. $88 \mathrm{~b} / \mathrm{min}$ for males and females, respectively). Clinical signs of supraventricular rhythm disorders were present in 17 male and 9 female patients.

\section{Socio-economic status}

185 patients were living with a partner at the moment they developed ESRD, significantly more male patients than female patients (Table 3.2). On the other hand more female patients were widowed. No statistical significant differences were found between having children or the number of children between male and female patients. The mean number of children was 2.3 for male patients and 2.5 for female patients. In $35 \%$ of the male patients and $39 \%$ of the female patients the children provided at least some care.

For almost 100 patients it was possible to retrieve information over the former profession from the medical file. This was the case in 84 male and 10 female patients. The former occupations were classified using the International Standard Classification of Occupations (ISCO-88). Table 3.2 shows the distribution over the ten major groups. Group 7 craft and related trade workers is most often found. In this group are 26 male patients who used to work in the coalmines that were in operation in this part of the Netherlands upon to 1969. 
Table 3.2 Former profiession

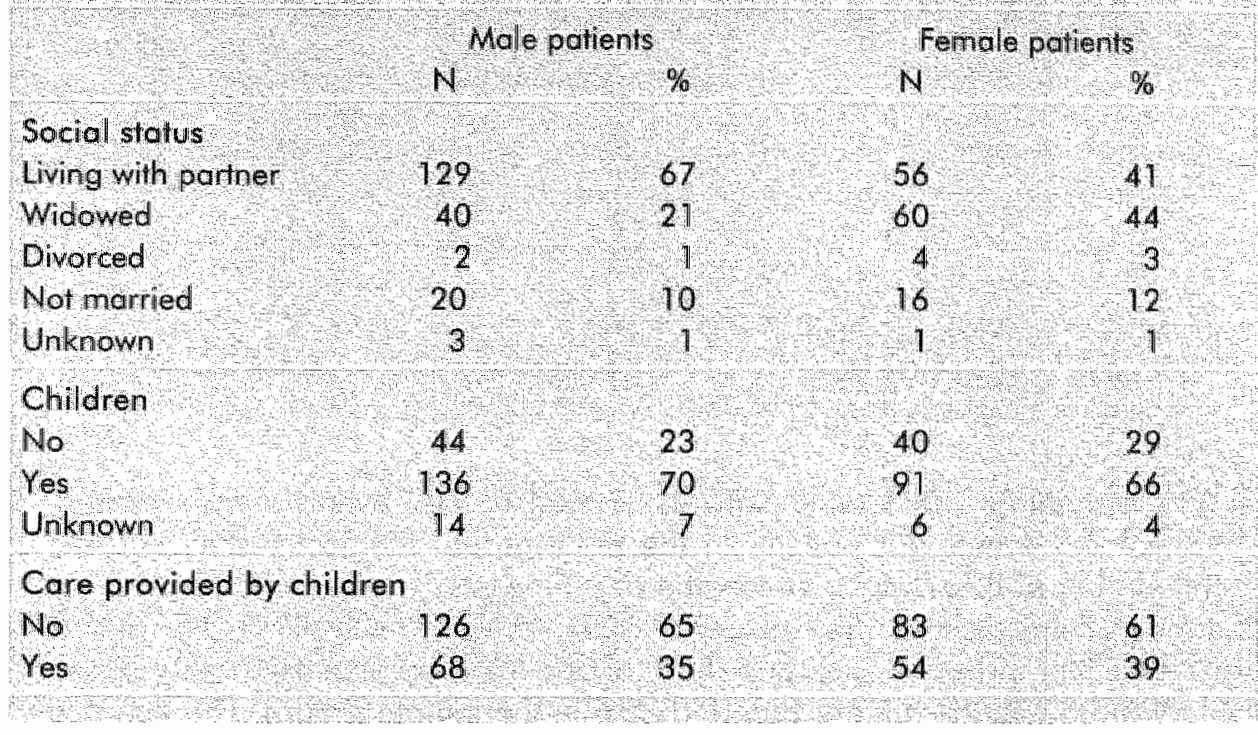

Table 3.3 Former occupation of 100 patients with ESRD elassified according to the international standard classification of occupations

Former profession

1 Legislators, senior officials and managers

2 Professionals

3 Tedhnicians and associate professionds

4 Clerks

5 Service workers and thop and morket sales workers

6 Skilled agriculture and fishery workers

7 Craft and related trades workers

8 Plant and machine operators and assemblers

9 Elementairy occupotions

0 Armed forces

Total
Male patients Femole patients

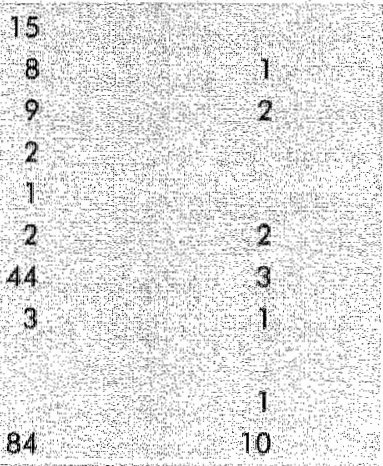

\section{Medical history}

The medical history of the relatively aged study group was extensive, including a totat of 1593 events. Only seven patients (one female and six male) did nat have a single event in their medical history (Table 3.4). 
Table 3.4 Number of events in medical history of 331 patients with ESRD

\begin{tabular}{|c|c|c|}
\hline Events & Number of patients & Percentoge \\
\hline 0 & 7 & 21 \\
\hline 12 & 61 & 18.4 \\
\hline $3-4$ & 92 & 277 \\
\hline $5-6$ & 85 & 25.6 \\
\hline$>6$ & 86 & 259 \\
\hline Total & 331 & 100 \\
\hline
\end{tabular}

In the remaining 136 female patients, a total of 723 events were reported, a mean of 5.3 events per patient. In the male group, medical history showed a total number of 870 events, or a mean of 4.5 events.

Cardiovascular disease, and especially ICD 401.403, ICD 410-414, and ICD 440-448, comprised about one-third of the medical events in the patients" history (36.3\% in the male group and $30 \%$ in the female group). The number of patients who only had an event from this group is, however, limited. There were five patients with only coronary artery disease, four with only hypertension, and six with only arterial vascular disease in their medical history.

A combination of two cardiovascular diseases without another disease occurred in six patients; three manifestations of cardiovascular disease without an event from onother group of diagnoses were seen in only five patients.

Besides cardiovascular diseases (ICD 390-459), Gasiro-Intestinal diseases (ICD 520-579) and diseases of the urogenital tract (ICD 580-629) form the majarity of diseases found in the medical history. These three groups accounted for $63 \%$ of the events among the male patients and for $55 \%$ of the events among the female patients.

When events from each diagnostic group were studied as dichotomous variables, some significant differences could be found between male and female patients. A higher incidence of endocrinological diseases and gastrointestinal diseases was found in the female patients. Chronic pulmonary diseases were more often seen in the group of male patients. The latter is probably due to the fact that many of our male patients used to work in coalmines that were once located in this region.

\section{Comorbidity}

Comorbidity was also extensive in our patients. Forty patients had no comorbidity at the moment of onset of renal failure (Table 3.5). In male as well as female patients, cardiac disease (mainly cardiac failure) was the most frequently occurring comorbidity. Other diseases frequently seen in both male and female patients were Gl-tract diseases, uragenital tract diseases, and malignancies (Table 3.6). Type 2 diabetes mellitus was frequently seen in female 
patients. Again, pulmonary diseases were frequently encountered as comorbidity in the male patient group. There were no significant differences in the total number of diseases between male and female patients.

A Charlson score of zero was found in 179 patients, 99 male and 80 female (Table 3.7 ).

Table 3.5 Number of comarbidities

No. Comorbidities Number of Patients (\%)

$\begin{array}{ccc}\text { Mer of Patients }(\%) & \text { Male } & \text { Female } \\ 40(12.1) & 19 & 21 \\ 124(37.5) & 72 & 52 \\ 117(35.3) & 71 & 46 \\ 50(15.1) & 32 & 18 \\ 331(100) & 194 & 137\end{array}$

Table 3.6 Total counts of comorbidity

Cardiac diseases

Total

Gl-tract diseases

127

61

UG-tract diseases

52

Malignancies

Arteriall vascular disease

34

32

Pulmonary diseases.

25

Hematological diseases

23

Endocrinological diseases

20

Other

44

$\begin{array}{cc}\text { Male pts } & \text { Female pts } \\ 79 & 48 \\ 39 & 22 \\ 31 & 21 \\ 22 & 12 \\ 18 & 14 \\ 21 & 4 \\ 13 & 10 \\ 9 & 11 \\ 26 & 18\end{array}$

Table 3.7 Charlson index

$\begin{array}{lccc}\text { Charlson index Score } & \text { Total Patients }(\%) & \text { Male }(\%) & \text { Female }(\%) \\ 0 & 179(54.1) & 99(51.0) & 80(58.3) \\ 1 & 99(29.9) & 62(32.0) & 37(27.0) \\ \geq 2 & 53(16.0) & 33(17.0) & 20(14.5)\end{array}$

Renal history

There was a wide range in renal history (Table 3.8). The median renal history in our group was 13 months (SD $=83$ manths). In 118 patients it was short: ESRD developed within 1 month, in 112 patients even within 2 weeks.

Thus, in about one-third of our population of elderly patients, we found an acute onset of renal failure. The percentage of patients with acute renal failure 
increases with age. In patients aged 80 years and over, $46 \%$ had a short renal history.

Table 3.8 Renal history

Renal history

$\leq 2$ weeks

$\leq 1$ year

$\leq 5$ years

$>5$ years

Total
Male patients

181
Female patients

47

17

35

35

134
Total

112

39

78

86

315

In contrast, a number of patients developed renal failure slowly, over a long period of time. In 86 patients, renal history was 5 years or more; in 44 of these patients, renal history even exceeded 10 years. The largest percentage of patients with a long renal history $(32 \%)$ was found in the youngest age group (65-70 years). In 16 patients, renal history could not be computed due to missing data.

\section{Renal diagnosis}

In the records we studied, there was a total of 580 diagnoses related to ESRD, a mean number of 1.7 diagnoses in the male and 1.8 in the female patient group (Table 3.9).

This abundance of diagnoses is probably due to the fact that a renal biopsy was performed in only two patients in order to establish a pathological diagnosis of ESRD. Hypertension, vascular renal disease, postrenal couses, and cardiac failure were most frequently mentioned among the male patients. Taken together, these diseases comprised $50 \%$ of the causative diagnoses made in the group of male patients. In the female patient group, hypertension, type 2 diabetes mellitus, renal vascular disease, and cardiac failure were the mast frequently reported causes of renal failure. These four diseases made up $50 \%$ of the diagnoses in the female patients. Hypertension, Aype 2 diabetes mellitus, and glomerulonephritis were reported significantly more often in female patients, whereas postrenal obstruction and unknown cause were significantly more often present in the male patient group. Dehydration was more often present in female patients, but the difference was not statistically significant.

In only 13 patients was a positive family history of renal disease mentioned. This is probably due to the fact that an inherited renal disease becomes manifest much earlier in life. 
Table 3.9 Renal diagnosis

Diagnosis

Hypertension

Vascular renal disease

Dicbetes mellitus

Postrenal cause

Cardiac failure

Pastoperative renal failure

Dehydration

Malignancy

Nephrosclerosis

Sepsis

Glomerulonephritis

Nephrocalcinosis

Other:

Unknown

Total
Male palients Femole patients

$\begin{array}{lll}43 & 46 & P=0.021 \\ 50 & 25 & \\ 26 & 36 & P=0.003 \\ 44 & 2 & P=0.001 \\ 29 & 21 & \\ 24 & 10 & \\ 16 & 8 & \\ 20 & 3 & 17 \\ 20 & 13 & \\ 10 & 17 & \\ 12 & 12 & P=0.049 \\ 9 & 5 & \\ 5 & 6 & \\ 21 & 251 & \\ 329 & & \end{array}$

Renal replacement therapy $(\mathbb{R R T})$

A thotal of 135 patients (41\%) from our group of 331 elderly patients with ESRD were admitted to a renal function replacement program. In most cases, passive center hemodialysis was the choice of treatment; only 19 patients received peritoneal dialysils (CAPD).

Most patients treated were from the youngest age group. This group contained $39 \%$ of all male patients treated and $43 \%$ of all female patients treated. The percentage of patients treated declined with age: in the highest age group, only one out of every five patients was treated with RRT.

A different picture arises when we take into account the way RRT was started. Acute RRT was undertaken in $33 \%$ of the patients treated in the youngest age group. In the three older age categories, this percentage was $46 \%, 63 \%$, and $75 \%$, respectively.

A relation was found between the use of RRT and the primary renal diagnosis. In patients diagnased as having nephrosclerasis, glomerulonephritis, or polycystic renal disease, RRT was more frequently applied. Postrenal causes of renal disease, and cardiac diseases provided less reason for starting RRT. Of course dehydration never was a reason for RRT.

Of the 135 patients treated, 62 (33 male and 29 female) died. Twenty-one patients did not survive 1 month on RRT. Another 11 patients died within 1 year after starting therapy. In the second year after starting RRT, 8 more patients died. All deaths within 2 years after starting therapy occurred in the group of patients treated with passive hemodialysis. The diagnoses cardiac disease, type 
2 diabetes mellitus, and postrenal causes of renal disease negatively influenced survival. In the case of postrenal causes this is probably due to the primary diagnosis (cancer of the lower urinary tradt). The diagnosis glomerulonephritis was, in our population, strongly assaciated with a longer survival.

Patients not treated with RRT also had a high mortality rate. Of the 196 patients in this group, 112 (65 male and 47 female) died within the observation period. Again, cardiac diseases, but also malignancies, were associated with a poor prognosis. A better survival was found in the group of patients with postrenal causes of renal disease. Probably due to selection.

Overall survival was substantially influenced by comorbidity, as is illustrated by the Kaplan-Meier survival plot based on the Charlson index for the total group of patients (Figure 3.1).

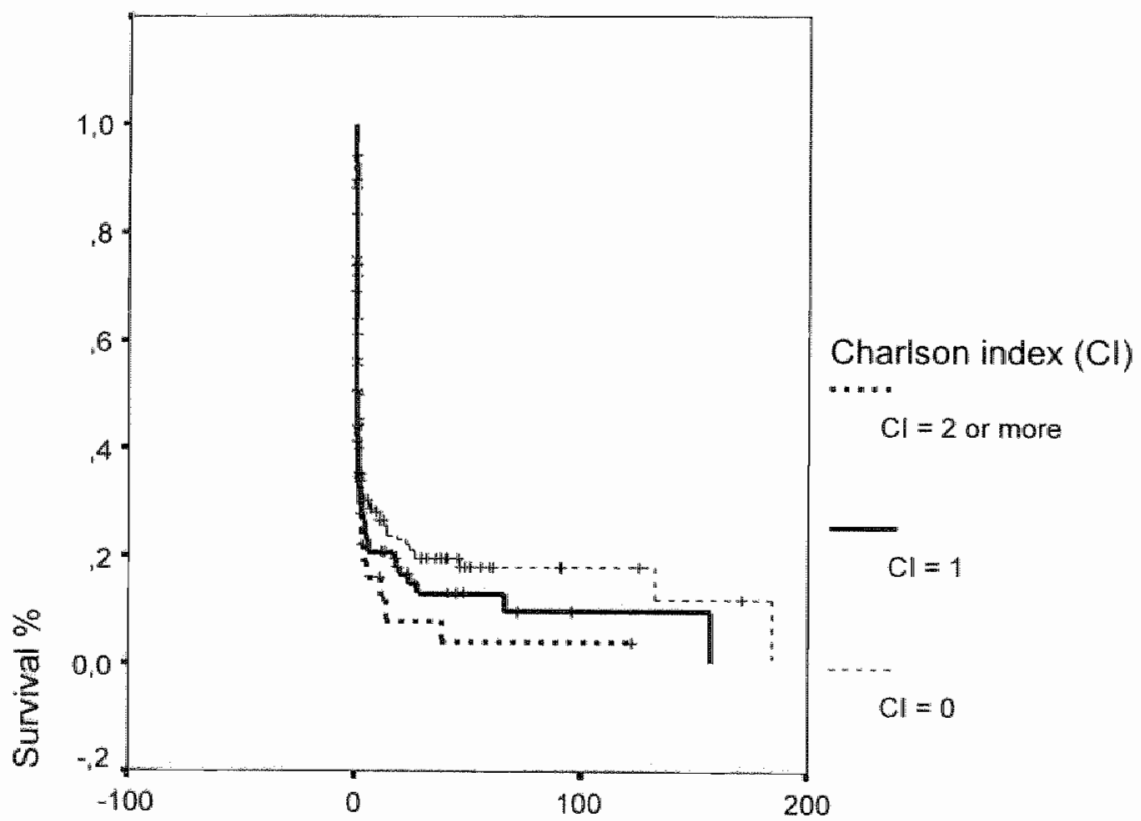

Survival in months

Figure 3.1 Overall survival by Charlson index

\section{Discussion}

Our group of elderly ESRD patients is characterized by a striking male preponderance. This is in sharp contrast with the distribution of the sexes in the general elderly population.

This altered distribution is most likely due to the importance of atherosclerotic diseases in the efiology of ESRD. 
The incidence of ESRD found in our elderly population $(2.2$ per 1000 individuals) is higher than that reported in the literature. ${ }^{10}$ This is mainly due to the fact that the incidence of renal failure in the elderly is normally estimated in patients accepted for, or already in, renal replacement programs. Our higher incidence may still be an underestimation, due to the fact that we based our investigation on laboratory data obtained from hospitals with dialysis facilities. In our region, a general physician can obtain laboratory investigations from laboratories not situated in a hospital. Patients who, for one reason or another, were not referred to the hospitals participating in our study were not included in our search.

The number of patients from whom a renal biapsy was taken to establish the diagnosis was very low in our population. However, this reluctance of nephrologists to perform renal biopsies in elderly patients seems to be common practice. $4,22,23$

The most common reported causes of ESRD in the elderly are vascular renal disease, presumably secondary to hypertension, and diabetes. The central role of thypertension is widely accepted. $4,24,25$

Although vascular disease is reported to be one of the main causes of ESRD in elderly patients, the number of patients we found with exclusively cardiovascular events in their medical history was remarkably small. The number of patients who had events from other diagnostic groups, especially Gl-tract and urogenital tract diseases, was extensive. This finding suggests that ESRD is a disease that afflicts patients towards the end of their life, when they already suffer from a number of diseases that impair their health and general condition, superimposed on the anatomical and physiological changes brought on by aging. ${ }^{26}$

The incidence of acute renal failure in our study increased with age. The highest incidence of acute renal failure was found in the group of patients above 80 years of age. This introduces the possibility of selection bias. The rapid deterioration of a patient could have been the reason for a hospital admission. whereas more slowly progressing renal failure in an elderly patient could merely have been considered a sign that he/she was approaching the end of life, thus not leading to a referral.

In support of this hypothesis is the finding that 106 of the 112 pattients with acute renal insufficiency met the criterion for ESRD while in the hospital. Most were admitted at the time this occurred or just before. In all, only 70 patients were admitted to the hospital after the diagnosis of ESRD had been made.

Our data suggest that age is a factor for withholding treatment. Fifty percent of the patients in the youngest age group began RRT, whereas only $20 \%$ of the patients in the group 80 years of age and above did. Ageism in ESRD treatment has been reported in a number of European countries. ${ }^{27.29}$ Several surveys among different groups of physicians suggest that this "inequality" is partly due to physician bias. 17,25

While age is often considered to be the main factor in deciding whether or nat to start RRT, comorbidity may play an even more important role. ${ }^{30}$

The majority of our patients were treated with passive center dialysis. Only $14 \%$ of those treated underwent peritoneal dialysis. Throughout the warld there is a wide variation in the type of RRT offered to elderly patients. In Australia, New 
Zealand, and France there seems to be a clear preference for home peritoneal dialysis for patients older than 60 years. ${ }^{31,32}$

The percentage of elderly patients undergoing hemodialysis versus chronic peritoneal dialysis (CAPD) in our survey is comparable to that in the United States. ${ }^{10}$ In spite of any global differences, peritoneal dialysis is considered the treatment of choice for dialysis of the elderly, particularly those with cardiovascular disease or hemodynamic instability. ${ }^{33-35}$ Our data illustrate this statement by showing a better initial survival of patients treated with CAPD. These patients undoubtly were selected for CAPD based on better initial performance. Overall survival after slightly more then 2 years was $50 \%$. A highly significant statistical difference was found in mean survival between patients who underwent acute RRT and those who chose to enter a RRT program (106 vs. 1091 days, respectively, $p=0.000)$. Our data, therefore, confirm reports that early death in dialysis is often the result of late referral. ${ }^{36,37}$ The majority of our patients was also only referred to the hospital just before or at the time they met the criteria for ESRD. Thus, early recognition of impaired renal function and early referral seem to be very important in the elderly patient.

After our first analysis, a number of questions remain unanswered. First of all, it is unclear which patient characteristics were used to base a treatment decision on in our patient population. Secondly, it has yet to be determined which prognostic factors for patient survival can be found in both the RRT and the nonRRT groups. Third, based on our collected data, methods need to be developed that will allow us to estimate the chance of successful decision making (i.e., whether or not to start RRT).

Evidence-based decision-making is not only in the interest of the patient and the patient's family, but it is also important for physicians and dialysis staff. For these reasons, our group is currently conducting additional and extensive analyses of our present and new data. 


\section{Literature}

1. Eggers PW. Mortality rates among dialysis patients in Medicare"s End-stage Renal Disease program. Am J Kidney Dis 1990; 15(5): 414-421

2. Posen GA, Jeffrey JR, Fenton SS, Arbus GS. Results from the Canadian Renal Failure registry. Am I Kidney Dis 1990;15(5): 397-401.

3. Brunner FP, Selwaod NH. Results of renal replacement therapy in Europe, 1980 to 1987. Registration Committee of the EDTA-ERA. Am J Kidney Dis 1990;15(5): 384. 396

4. Porusch JG, Faubert RF. Chronic renal failure. In Porusch IG, Faubert RF, eds. Renal Diseose in the Aged. Boston:Little Brown, 1991;285-313.

5. Disney AP' Demography and survival of patients receiving treatment for chronic renal failure in Australia and New Zealand: report on dialysis and renal transplantation treatment from the Australia and New Zealand Dialysis and Transplantl Registry. Am J Kidney Dis 1995;25(1): 165-175.

6. Schulak JAA, Hricik. DE. Kidney transplantation in the elderly. Geriatric Nephrol Urolo $1990 ; 1: 105-112$.

7. Cantanovich $D$, Baatard R, Baranger T, Tirouvanziam A, Le Sant JN, Hourmont M, Dantal J, Soukikkou JP. Cadaveric renal transplantation after 60 years of age. A single center experience. Transpl Int 1994;7(1):33-38.

8. Becker BN, Ismail $N$, Becker $Y T_{\text {r }}$ et al. Renal transplantation in the older and stage renal disease patient. Semin Nephrol 1996;16:353-362.

9. U.S.Renal Data System. USRD 1991 Annual Data Repoit. Bethesda, MD: National Institutes of Health, National Institute of Diabetes and Digestive and Kidney Diseases, August 1991.

10. U.S.Renal Data System. USRD 1997 Annual Data Report. Bethesda, MD. National Instifutes of Health, National Institute of Diabetes and Digestive Kidney Diseases, April 1997 .

11. Chazan Bl, Rees SB, Balodimus MS, Younger D, Ferguson BD. Dialysis in diabetics. A review of 44 patients. JAMA 1969;209:2026-2030.

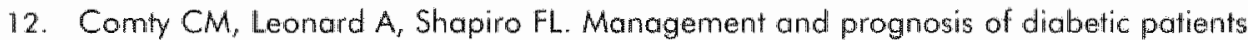
treated by chronic hemadialysis. Am Soc Nephrol 1971:1:5-15.

13. Comty CM, Kjellsen D, Shapiro FL. A reassessment of the prognosis of diabetic patients treated by chronic hemodialysis. Trans Am Soc Artif Intern Organs $1976 ; 22: 404$.

14. Ghavamian M, Gutch CF, Kopp KF, Kolff WJ. The sad truth about hemodialysis in diabetic nephropathy. JAMA 1972;222:1386-1389.

15. Kiellstrand CM. Whitley $K$, Comty CM. Dialysis in patients with diabetes mellitus nephropathy. Diabel Nephropathy 1983;2:15-17

16. Whitley $K Y$, Shapira $F L$. Hemadialysis for end-stage renal diabetic nephrapathy. In Friedman EA, L'Esperance FA, eds. Diabetic Renal Retinal Syndrome. New York: Grune and Stratton, 1986,349-362.

17. Parry RG, Crowe A, Stevens JM, Mason JC. Referral of elderly patients with severe renal failure: questionnaire survey of physicians. BMJ 1996;313:466. 
18. Classificatie van Ziekten. Geboseerd op de Classification of Diseases, 9th revision, Clinical Madification (ICD-9.CM). SIG/lnformatiecentrum voor de Gezondheidszorg, Utrecht, 1986.

19. Charlson ME, Pompei P, Ales $\mathrm{KL}$, Mackenzie CR. A new method of classifying proginostic comarbidity in longitudinal studies. Development and walidation. J Chron Dis 1987,40(5):373-383.

20. Bergmans FEH, Saris WHM. Energiebehoefte van de oudere mens. In: Visser Aph. (ed) Over Oud. Veroudering in gezondheidswetenschappelitk perspectief. Thesis publishers Amsterdam, 1990.

21. Cackroft DW, Gault MH. Prediction of creatinine dearance from serum creatinine. Nephron 1976:16:31-41.

22. Lewison SP. Renal disease in the elderly: the role of renal biopsy. Am J Kidney Dis 1990; 6:300-306.

23. Mignon $F$, Michel $C$, Mentre F, Viron B. Worldwicle demagraphic and future trends of the management of renal failure in the elderly. Kidney Int 1989;42/suppl 41):518-526.

24. Glickman JF, Kaiser DL, Bolton WK. Aetiology and diagnasis of chronic renal unsufficiency in the aged. In Macias-Nunez JF, Cameron JS eds. Renal function and Disease in the elderly. London: Buttherworths 1987,485-508.

25. Brown WW, Davis BB, Spry LA ef all. Aging and the kidney. Arch Intern Med 1986;1 146:1790.1796.

26. Radecki $S$, Nisseson AR. Dialysis far chronic renal failure: comorbidity and treatment differences by disease etiology. Nephrol 1989;9:115-123:

27. Rotellar E, Lubelzar RA, Rottelar $C$, et al. Must patients over 65 be hemodialyzed? Nephron 1985;41:152-156.

28. Berlyne GM. Over 50 and uremic. Nephrom 1982;45:257-263.

29. Kjellstrand $C M$. Tyden $G$. Inequalities in chronic dialysis and transplantation in Sweden. Acto Med Scand 1988;224:149-156.

30. Chanda $S M$, Schulz J, Lawrence $C$, Greenwoad RN, Farrington $K$. Is there a rationale for rationing chronic dialysis? A hospital based cohort study of factors affecting survival and morbidity. BM.1 1999,318:217-223.

31. Disiney APS. Dialysis treatment in Australia, 1982 to 1988. Am J Kidney Dis 1989:15:402-409.

32. Mignon F, Siahan P, Legallicier $R$, Khayat $R$, Viron $B$, Michel $C$. The management of uraemia in the elderly: treatment choices. Nephrol Dial Transplant 1995;10/suppl 6): $55-59$.

33. Mattern WD. Mcgagie WC, et al. Selection of ESRD treatment: an international study. Am J Kidney Dis 1989;13:457-464.

34. Nissenson AR, Diaz-Buxo JA, Adock A. Nelms M. Peritoneall dialysis in the elderly poitient. Am J Kidney Dis 1990; 16:335-338.

35. Nissenson AR. Opinion: how can the care of elderly dialysis patients be improved? Semin Dial 1992;5:25-26

36. Innes A, Rowe PA, Burden RP, Margan AG. Early deaths on renal replacement therapy: the need for early nephrological referral. Nephrol Dial Transplant $1992,7: 467.471$.

37. Ratdiffe PJ, Philips RE, Oliver DO. Late refernal for maintenance dialysis. BMJ $1984 ; 288: 441-443$. 


\section{Treatment selection criteria and prognostic factors in elderly patients with end-stage renal disease}

WJ Mulder, HFP Hillen, KML Leunissen, JFBM Fiolet

Submitted for publication 


\section{Abstract}

\section{Background}

The demand for renal replacement therapy (RRT) for elderly patients with end-stage renal disease (ESRD) is increasing worldwide. The rising incidence of ESRD in the elderly is generating a great deal of controversy and debate about the appropriateness of spending scarce resources for expensive medical techniques on a group of patients with a limited life expectancy. Though not always explicitly, age is indeed, one of the tactors used to ration dialysis treatment. Anather criterion for selection is comorbidity. We conducted a retrospective survey to assess the percentage of elderly ESRD patients enrolled in RRT programs. We also attempted to determine what factors are involved in selecting elderly patients for RRT and what prognostic factors for survival are found in elderly patients on RRT.

\section{Methods}

A retrospective study was carried out on 27.4 patients, aged 65 years and older who developed ESRD in 1992 and 1993. The patients were recruited from four hospital-based renal units. Case finding was done using the computerized laboratory files of the participating hospitals. During this inclusion period 96 patients were enrolled in RRT programs and 178 were no treated with RRT.

Survival was assessed until 31-12-1999 (end of the study).

\section{Results}

In the group of patients who entered RRT and died in the study period, mean survival was 570 days in the agle group $65-70,641$ days in the age group $71-75,351$ days in the age group 76-80, and 102 days in the group patients over 80 .

In patients that not were treated by RRT mean survival of those who died during follow-up was for the different age groups 418, 370,322, and 221 days respectively. Survival was dependent on age and comorbidity. In the group treated with RRT, the causative diagnosis of nephrasclerosis and age influenced the prognasis. Lagistic regression analysis showed that selection for treatment was significantly associated with serum creatinine, with the causative diagnosis of glomerulonephritis, and with functional problems in urine production.

\section{Conclusion}

Selection for RRT does accur in medical practice. Selection criteria can be divided into medical criteria (serum creatininel, nephrological diagnoses (glomerulonephritis and nephrosclerosis\}, and existing comorbidity. The ability to perform activities of daily living, mobility, and the presence of a partner also influence treatment decisions. Finally, age and the length of renal history both influence survival, whereas the application of RRT does not. 


\section{Introduction}

Chronic renal replacement therapy (RRT) programs have gradually become accessible to elderly patients over the last ten years. Improvements in diagnostic and therapeutic procedures for patients with cardiovascular diseases have led to better survival. However, this has also contributed to an increase in the number of patients with late renal complications of vascular diseases. Patients with type 2 diabetes mellifus with vascular complications are now admitted to chronic RRT programs. Renal transplantation is still mainly confined to younger patients, due to a shortage of donor organs. All of these factors have led to a situation in which elderly patients comprise a steadily increasing segment of the patient population in RRT programs in North America, Europe, Australia, and New Zealland. ${ }^{1.5}$

Elderly patients with end-stage renal disease (ESRD) can be divided into two separate groups. ${ }^{6}$ The first group consists of patients who adjust very well to dialysis with a high quality of life or who appear to be satisfied with a reasonable quality of life that may, however, be unacceptable to a younger patient. 7.8 The second group is characterized by comorbidity and impaired functional capacity. Some of these patients improve markedly with dialysis. Others, however, deteriorate rapidly.

Renal replacement therapy is expensive, and treatment capacity is not unlimited. Patient selection is, therefore, widely practiced. ${ }^{10.13}$ Physicians often mention the estimated medical benefit from dialysis for the individual patient as the most important criterion in the decision to begin dialysis. Age, in itself, is not an appropriate independent criterion in this decision. ${ }^{14}$ Non-referral to nephrologists by the general practitioner and non-acceptance by nephrologists both seem to occur. ${ }^{13,15-19}$ Thus, not all patients are referred or accepted for RRT. However, no clear abjective criteria have yet been defined for patient selection. Dialysis is considered inappropriate for patients with a poor prognosis, especially those with multiple organ failure, non-uremic dementia, malignancies and metastatic disease, or debilitating neurological diseases. ${ }^{20}$ Mast elderly ESRD patients die of a cardiovascular disease. ${ }^{2,21.24}$ The second most common cause of death in the U.S., however, is withdrawal from dialysis, indicating the burden that renal failure and RRT inflict on the elderly patient. ${ }^{25,26}$

In this retrospective study, we address three questions: (1) What percentage of elderly ESRD patients is enrolled in RRT programs? (2) What are the main factors involved in selecting elderly patients for RRT? (3) What are the prognostic factors for survival in elderly patients on RRT, as well as in those not on RRT? 


\section{Subjects and methods}

We retrospectively studied the incidence of ESRD, the clinical data of elderly patients with ESRD, the percentage of elderly patients enrolled in RRT programs, and the survival of ESRD patients with and without RRT. To facilitate this, a search was first conducted of the laboratory records of the four hospitals with dialysis facilities in our region (Laurentius Hospital Roermond, Maasland Hospital Sittard, Atrium Hospital Heerlen, and the University Hospital of Maastricht) for patients 65 years of age and older with a serum creatinine of at least $400 \mu \mathrm{mol} / \mathrm{l}(4.5 \mathrm{mg} / \mathrm{dl})$, measured between January 1,1992 and December 31, 1993. Because we were interested in the process of selection for ESRD treatment, we excluded all patients who developed ESRD before January 1, 1992, the beginning of the observation period. To assess the survival of our patient group, we made great efforts to determine the clinical outcome of these patients up until January 31,1999 , the end of the study.

The four participating hospitals are situated in the South Limburg region of the Netherlands. This region has a total population of 1.25 million inhabitants and has borders to the south, west, and east with Belgium and Germany. Insurance policies do not allow medical treatment of patients across the border. Therefore, this region is, in every respect, well-defined. The population served by these four hospitals is about one million persons. All laboratory data could be retrieved fram computerized files of the hospital information systems. The hospital laboratories perform tests for inpatients, for outpatient clinics, and for all primary care physicians in the region.

The medical files of the patients were studied and data were extracted regarding age, gender, socioeconomic status, functional status, medical history, primary renal diagnosis, comorbidity, medical interventions, and clinical course. Medical history and comorbidity were entered following the International Classification of Diseases, 9th revision, Clinical modification (ICD9.CM). ${ }^{27}$

The period between the first indication of impairment of renal function and the moment the serum creatinine reached a value of at least $400 \mu \mathrm{mol} / \mathrm{l}$ was referred to as the renal history.

A short renal history ( $<4$ weeks) was defined as acute renal failure; a longer renal history was considered to be chronic renal failure. In every patient creatinine clearance was calculated using the Cockroft and Gault formula. ${ }^{28}$ In the case of RRT, we discriminated between acute therapy, when therapy was started within 4 weeks after reaching a serum creatinine of $400 \mu \mathrm{mol} / 1$ or thigher, and non-acule therapy, when it started after 4 weeks of the onselt of ESRD.

To assess the severity of comorbidity, we calculated for each patient the Charlson index for comorbidity. ${ }^{29}$ This is a good, validated scoring system for comorbidity and prognosis based on 1-yearr mortality rates of 19 frequently occurring internal diseases. Moderate or severe renal impairment was not scored for our patients since it was the primary disease (Table 4.1). The height 
of the score is determined by the relative montality risk within one year affer a clinical admission for these diseases.

Table 41 Charlson weighted index of comorbidily

Index

1 . Myocardial infarction

Congestive heant fallure

Peripheral vascular disease

Cerebrovascular diseases

Dementia

Chronic pulmonary disease

Connective tissue disease

Ulcer disease

Mild liver disease

Diabetes
Index

2 Hemiplegio

Moderate or severe renal disease

Diabetes with end argan damage

Any tunnor

Leukemía

Lymphoma

3 Moderate or severe liver disease

6. Metastatic solld umor

AIDS

The functional status of the patients was investigated by making an assessment of each patient's ability to perform activities of daily living, of his/her mobility, and of urinary continence. For this we used Katz' scale of basic activities of daily living ( $A D L$; bathing, dressing, toileting, transferring, and feeding). ${ }^{30}$ In each of these five categories, three ratings were possible: good, able to perform with help, and complete dependency. Possible ratings for mobillity were: good mobility including walking stairs, good mobility, mability with aid or with a walking device, bed/chair only, and bedridden. The socio-economic status of the patients was investigated, by collecting data on living conditions, presence of a (supporting) partner and need for informal and/or professional help.

Finally, data were collected on urinary continence in our patient population. This was done because, in previous investigations, we had found that urinary continence is a prognostic factor for dinical outcome in elderly patients. "In this category, ratings were: complete incontinence, some incontinence, little incontinence, the use of some kind of catheter, the presence of a urostoma and, given the special group of patients we studied, anuria.

\section{Statistical analysis}

All statistical analyses were made using SPSS for Windows 7.5 (SPSS Inc, Chicago, IL, USA). Some of the analyses were performed by the Department of Methodology and Statistics of the University of Maastricht.

Data are presented as the mean walue \pm SD or number (percentage). Student"s t-test was used to compare continuous variables; for categorical variables, the chi-square test or, when appropriate, the Fischer exact test was used. 
For ordered categorical variables, such as scores or number of comorbid diseases, the chi-square for linear trend was used. Two-sided p-values not greater than 0.05 were considered significant.

For the clinical endpoint RRT, adds ratios (OR) are reported. All significant characteristics were entered into a logistic regression, with RRT as the dependent variable, using a stepwise, backward selection of variables. Only significant variables $(p<0.05)$ were kept in the model. Results are given as odds ratios for treatment with RRT. To determine mean and median survival we excluded the patients still alive at the end of the study, because it is not good possible to determine mean survival in the presence of censored cases. The survival plots are drawn for the patients who died during the study.

The study was approved by the medical ethics board of the University Hospital of the University of Maastricht.

\section{Results}

\section{Patients}

With our retrospective search of the laboratory records we found a total of 567 patients who met the criteria of a serum creatinine of at least $400 \mu \mathrm{mol} / \mathrm{l}$ and age 65 years or older. We were able to retrieve hospital records from 331 patients with sufficient data for this study. The clinical characteristics of these patients have been described earlier. ${ }^{32}$ Only patients who developed ESRD during the observation period were included. Our survey thus comprises data from 274 patients, 164 male and 110 female. The characteristics of this patient group are summarized in Table 4.2.

The mean age of the patients on RRT was significantly lower than that of patients not treated. Serum creatinine was higher in the treatment group and, consequently, the creatinine clearance computed with the Cockroft and Gault formula is lower. Body mass index was significantly higher in the group of patients not treated with RRT. Pulmonary edema was seen more often in the group of patients not treated with RRT, although the difference is not significant.

\section{Medical history}

A total of 828 medical events were mentioned in the medical histories of our 274 patients. In the untreated group, six patients had no medical event, as compared to four patients in the RRT group. The mean number of medical events in the total patient population was 3 events with a standard deviation of 1.6.

Substantially more events were recorded in the group of patients not treated with RRT, although no statistically significant difference was found in either the total number of events or the number of events in the subgroups. 
Table 42 Basic dinical charaderistics of the patient groups studied.

\begin{tabular}{|c|c|c|c|}
\hline & RRT & No RRT & $\begin{array}{l}\text { Chisquate } \\
\text { linear frend }\end{array}$ \\
\hline Number of potients & 96 & 178 & \\
\hline male & 56 & 108 & \\
\hline - female & 40 & 70 & 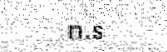 \\
\hline Median age & $72(65-92)$ & $75(65-92)$ & $n s$ \\
\hline Mean age & $72.86(\mathrm{SO} 5.59)$ & $75.80(\mathrm{SD} 6.89)$ & $p<006$ \\
\hline Age groups (years) & & & $\mathrm{p}=003$ \\
\hline $64-70$ & $39(41 \%)$ & $48(27 \%)$ & \\
\hline $77-75$ & $26(27 \%)$ & $44(25 \%)$ & \\
\hline $76-80$ & $20(210)$ & $43(24 \%)$ & \\
\hline 880 & $11111 \%$ & $43(24 \%)$ & \\
\hline Serum creotinine & $725 \mathrm{\mu mol} / \mathrm{s}$ & $549 \mathrm{mmol} / \mathrm{H}$ & $p<005$ \\
\hline & {$[\mathrm{SD} 376,76)$} & $(50203.85)$ & \\
\hline Body weight Imean) & $681 \mathrm{~kg}(\mathrm{SD}) / 3)$ & $699 \mathrm{~kg}(\mathrm{SD} / 2,68)$ & n,s \\
\hline Body moss index (BMAl) & $239 \mathrm{~kg} / \mathrm{m}^{2}$ & $24.5 \mathrm{~kg} / \mathrm{m}^{2}$ & $p=006$ \\
\hline Systolic blood pressure & $1537 \mathrm{mmHg}(\mathrm{SD} 32)$ ) & $142.3 \mathrm{~mm} H \mathrm{~g}(\mathrm{SO} 38,0)$ & n.s \\
\hline Diastolic blood pressure & $83 \mathrm{mmHg}(5017.7)$ & 707 munfo $(\mathrm{SD} 195)$ & n.s. \\
\hline Heart rate & $88.3 \mathrm{~b} / \mathrm{min}[\mathrm{SD} / 7 \mathrm{8})$ & $894 \mathrm{~b} / \mathrm{min} / \mathrm{SO} 20 \mathrm{a} 7 \mathrm{]}$ & ns. \\
\hline Iregular pulse (no pls) & 8 & 13 & ns \\
\hline Pulmonory edemal (too pls) & 24 & 44 & ns \\
\hline Partner & 61 & 86 & $p=0,16$ \\
\hline No Partner & 35 & 92 & $0 \mathrm{n}=1,664$ \\
\hline & & & $0,1213,10$ \\
\hline
\end{tabular}

As expected, we found a rellatively high number of cardiovascular diseases. Seventy-seven patients had one cardiovascular event in their medical history 133 in the RRT group and 44 in the untreated group). Two cardiovascular events were found in 54 patients (13 in the RRT group and 41 in the untreated group). Three or more cardiovascular events were found in the medical history of 24 patients ( 8 in the RRT group and 16 in the untreated group). Eighty patients, however, had not had a single cardiovascular event in their medical history (26 in the RRT group and 54 in the untreated group).

Urogenital tract diseases, gastrointestinal tract diseases, malignancies, and endocrinological diseases were also extensively represented, all of them more frequently in the group of patients not treated with RRT.

\section{Comorbidity}

In 33 patients (9 untreated and 24 treated), no comorbidity was present at the moment ESRD was diagnosed. One comorbid disease was present in 98 patients, two were present in 99 patients, and three in 44 patients. The difference in the number of comorbidities between treated and untreated 
patients was statistically significant (test for linear trend $p<0.005$ ). Cardiac, gastrointestinal tract, and urogenital tract diseases were seen as frequently in the treated group as in the untreated group. There were more patients with peripheral vascular disarders and pulmanary diseases in the untreated group. This difference, however, was not statistically sigmificant.

We calculated the Charlson index for comorbidity for the members of our patient population. In the total group of patients, $52 \%$ had a score of $0,30 \%$ a score of 1 , and $78 \%$ a score of 2 or higher (Figure 4.1 ). The difference in frequency of the Charlson scores in treated and untreated patients reached a pvalue of 0.004 (chi-square for linear trend).

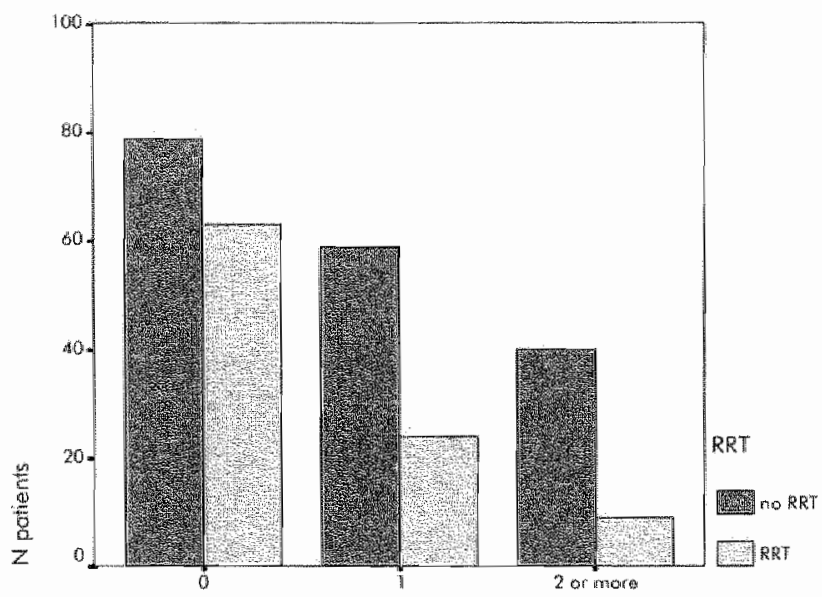

Charlson score

Figure 4.1 Charlson score patient groups

\section{Renall history}

A wide range in renal history was found. In 111 patients $(41 \%)$, renal history was short: ESRD developed within one month, in 102 patients even within just 2 weeks. Thus, in a substantial part of our population of elderly patients, we found a more or less ccute onset of renal failure. The percentage of patients with acute renal fallure tended to increase with age. In the youngest age group (65-70 years) 29 patients $(39 \%)$ had a renal history of 1 month or less. (Table 4.3 ) In patients 80 years of age and older, $51 \%$ had a short renal history.

In contrast, in many patients there was a slow development of the renal disease. In 121 patients, renal history renal history was 1 year or more; in 64 patients the renal history even exceeded 5 years. The largest percentage of patients with a long history (-1 year) - 52\% - was found in the youngest agle group. In the group of patients over 80 years of age, this percentage was $40 \%$. In 15 patients renal history could not be computed due to missing data.

Of the patients who died during the inclusion period mean survival was determined. (Table 4.3, figure 4.2) The best survival was seen in the group with 
the longest renal history, in the youngest age group. Furthermore, survival is strongly influenced by age; a higher percentage of patients from the higher age groups die and the mean survival has a tendency to be shorter.

Table 4.3 Renal history and survival by age group in 259 elderly patients with ESRD

\begin{tabular}{|c|c|c|c|c|}
\hline Renal history & Age groups: & $N$ & Pts died $(\%)$ & Mean survival (SD \\
\hline \multirow{4}{*}{ Q.14 days } & $65-70$ & 26 & $9(35)$ & $105.67(205.18)$ \\
\hline & $71-75$ & 26 & $14(54)$ & $64.43(157.73)$ \\
\hline & $76-80$ & 26 & $15(58)$ & $15.07(20.77)$ \\
\hline & $>80$ & 28 & $22(79)$ & $21.41 \quad(28.48)$ \\
\hline \multirow[t]{4}{*}{$15-30$ days } & $65-70$ & 3 & $1(33)$ & 32100 \\
\hline & $71-75$ & 1 & $1(100)$ & 7.00 \\
\hline & $76-80$ & 0 & 0 & \\
\hline & $>80$ & 1 & $1(100)$ & 4.00 \\
\hline \multirow[t]{4}{*}{$31-182$ days } & 65.70 & 7 & $4(57)$ & $4425(55.01)$ \\
\hline & $71-75$ & 6 & $4(67)$ & $2675(38,08)$ \\
\hline & $76-80$ & 7 & $5(71)$ & $17.20(8.96)$ \\
\hline & $>80$ & 4 & $2(50)$ & $8.00(11.31)$ \\
\hline \multirow[t]{4}{*}{$183-365$ days } & $65-70$ & 0 & 0 & \\
\hline & 71.75 & 1 & $1(100)$ & 13.00 \\
\hline & $76-80$ & 1 & 0 & \\
\hline & $>80$ & 1 & $1(100)$ & 7.00 \\
\hline \multirow[t]{4}{*}{$1-2$ years } & $65-70$ & 7 & $5(71)$ & $71.80(112.60)$ \\
\hline & 71,75 & 6 & $1(17)$ & 108.00 \\
\hline & $76-80$ & 2 & $1(50)$ & 200 \\
\hline & $>80$ & 2 & 0 & \\
\hline \multirow[t]{4}{*}{$2-5$ years } & $65-70$ & 13 & $5(38)$ & $25,20(29.65)$ \\
\hline & $71-75$ & 12 & $6150)$ & $42.33(67.14)$ \\
\hline & $76-80$ & 11 & $9(82)$ & $1022(3.03)$ \\
\hline & $>80$ & 4 & $2(50)$ & $3.50(3.54)$ \\
\hline \multirow{4}{*}{$>5$ years } & $65-70$ & 19 & $5(26)$ & $260,60(34), 88)$ \\
\hline & $71-75$ & 16 & $8(50)$ & $22.50(27.14)$ \\
\hline & $76-80$ & 12 & $8(67)$ & $29,13(2720)$ \\
\hline & $>80$ & 17 & $12(71)$ & $975(13.31)$ \\
\hline Total & & 259 & 142 & \\
\hline
\end{tabular}

Renal history of 15 patients could not be computed due to missing data.

\section{Renal diagnosis}

In the records we studied we found a total of 409 diagnoses related to ESRD. In 164 patients $(60 \%)$, one renal diagnosis was made. Two diagnoses were reported in 88 patients $(32 \%)$. In 22 patients $(8 \%)$, three or more diagnoses were reported. This abundance of diagnoses was probably due to the fact that in only 
11 patients a renal biopsy was performed to establish a dinical diagnosis of the ESRD.

The total number of diagnoses made in the group of patients treated with RRT was 148 versus 261 in the untreated group. The difference in the number of diagnoses between the two groups was statistically significant $(p=0.001)$.

Cardiac diseases, postrenal causes, and dehydration were all less often present in the group af treated patients (Table 4.4). Glomerulonephritis and nephrosclerosis, not surprisingly, were significantly more often seen in the group of patients treated with RRT.

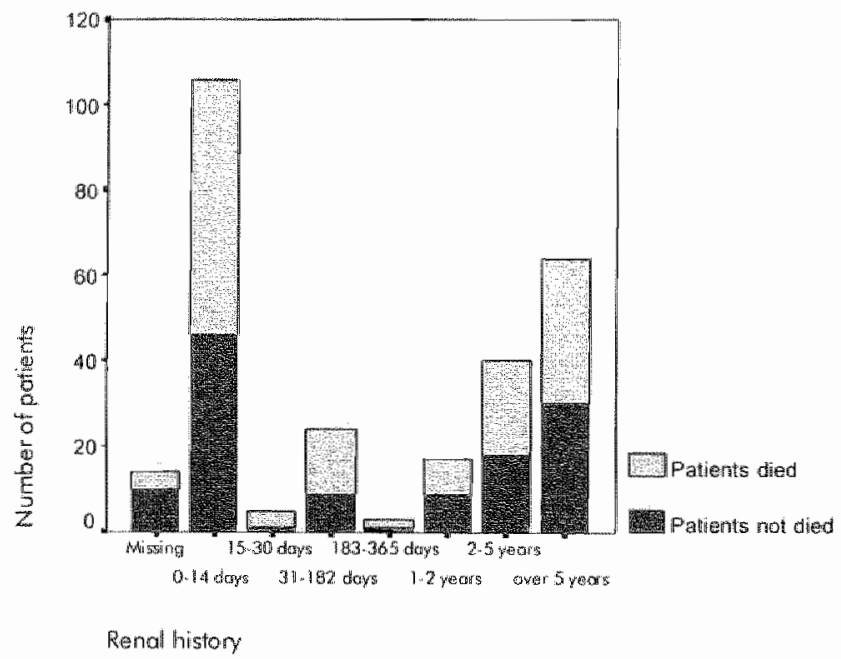

Figure 4.2 Renal history and survival in 259 elderly patients with ESRD

\section{Functional status}

It was possible to assess the activities of daily living of 268 patients from the data in the medical records.

In the categories bathing, dressing, and transfers, we found a significant difference between the patients treated with RRT and those not treated in favour of the treated group.

For 267 patients an assessment of mobility could be made. Again, we saw a trend in favour of the patients treated with RRT. When we divided mobility into two categories - good or impaired - the difference between the two patient groups reached statistical significance.

The same picture emerged in the evaluation of urinary continence. Patients not treated with RRT were more often incontinent, had a catheter, or were more often anuric than the treated group. We recoded this variable into four dichotomous variables: (1) urinary problems (no problems versus problems), (2) urinary contimence (continence versus incontinence), (3) urinary catheter (catheter versus no catheter), and (4) urine production (production versus no production.). For urinary problems and continence, we found significant 
differences, both with a p-value below .005 . The odds ratios were $.335(95 \% \mathrm{Cl}$ $.191-.587)$ and $.092(95 \% \mathrm{Cl}: .028-309)$, respectively.

Table 4,4 Renal diagnosis.

\begin{tabular}{|c|c|c|c|c|}
\hline Renal diognosis & RRT & No RRT & chi-square & Odds ratio \\
\hline Cardiar disease & 10 & 38 & $\mathrm{p}=0.023$ & $O R=0.428(0,203-0,904)$ \\
\hline Yascular disease & 25 & 33 & & \\
\hline Hypentension & 30 & 31 & $\mathrm{p}=0.009$ & $O R=2155(1,207-3.849)$ \\
\hline Postrenal couse & 8 & 45 & $\mathrm{p}=0.001$ & $\mathrm{OR}=0.269(0,1210.597)$ \\
\hline Glomerulo-nephitis & 16 & 4 & $p=0,000$ & $\mathrm{OK}=8 \mathrm{~s}(2,8) 826,857)$ \\
\hline Sepsis & 5 & 17 & & \\
\hline Posiloperative & 11 & 20 & & \\
\hline Delaydration & 2 & 30 & $p=0000$ & $O R=0,105(0,0250,449)$ \\
\hline Nephrocaleinosis & 7 & 11 & & \\
\hline Nephrosclerosis & 14 & 12 & $p=0.035$ & $\mathrm{OR}=2.362(1.045,537)$ \\
\hline Polycystic disease & 4 & 1 & & \\
\hline Nephredomy & 1 & 0 & & \\
\hline Unknown & 15 & 19 & & \\
\hline & 148 & 261 & & \\
\hline
\end{tabular}

$\mathrm{OR}=$ odds ratio in brackets $95 \%$ confidence interval

OR before entered in logistic regression

Finally, we investigated the social context of our patient group, i.e., whether they lived independently, alone or with a partner, or in some kind of care-giving situation, indwelling with their children, in a home for the elderly/nursing home or in a cloister. Though the untreated patients tended to be more in need of care than the treated patients, the difference was not statistically significant. In the group of treated patients, there were significantly more living together with a partner than living alone $(p=0.016)$. We found an odds ratio of $1.864(95 \%$ $\mathrm{Cl}: 1.121-3.102)$, indicating that patients with a partner have a greater chance of being accepted for RRT than patients who live alone (Table 4.2).

Logistic regression analysis

In a univariate analysis of our patients comparing RRT and no RRT, we found 13 variables with a significant difference, age, serum creatinine, BMI, presence of a partner, number of comorbidities, causing diagnoses cardiac, hypertension, postrenal causes, glomerulonephritis, dehydration and nephrosclerosis, urine problems and continence. Since the dependent variable is treatment (yes or no), a dichotomous variable, we performed a logistic regression analysis to see which of the characteristics were the most important. Backward selection of the variables was used. 
The reported odds ratios are per unit of the independent variable, except for serum creatinine, where we reported the OR per 1000 units in order not to lose this coefficient in our model.

In this way, we obtained an OR of 26.6 for serum creatinine, an OR of 6.5 for glomerulonephritis, and an OR of 1.7 for patients with a urinary catheter. ORs larger than 1 mean that mare of these patients are selected for RRT. For all other variables, an OR below 1.0 was found. Urinary incontinence, for instance, had an OR of .098, indicating an almost ten times smaller chance of being admitted to a RRT pragram. All ORs are given in Table 4.5.

Table 4.5 Results of logistic regression andysis

\begin{tabular}{|c|c|c|c|}
\hline Voriable & Significance & OR & \\
\hline Creatinine & 0.000 & 26.600 & $(6.233113515)$ \\
\hline Cardicic couse of ESRD & 0,007 & 0.311 & $(0.133-0.725)$ \\
\hline Postrenel couse of ESRD & 0,000 & 0.095 & $(0.031-0.290)$ \\
\hline Glomerulonephifis & 0.009 & 6.479 & $(1.58026 .560)$ \\
\hline Dehydration & 0.002 & 0.094 & $(0.020-0.434)$ \\
\hline Incontinence & 0.000 & 0098 & $(0.027-0.349)$ \\
\hline
\end{tabular}

$O R=$ odds ratio, in brackets $95 \%$ confidence interval

Survival

Eight patients in the treated group were still alive at the end of the study. Eight patients in the treated group were still alive at the end of the study, five in the youngest age group, the other three in the higher age groups. A comparison of the characteristics of these 8 patients with the 88 patients who died during this follow-up period is difficult due to the skewness of the distribution. Moreover, the moment we ended the follow-up was necessarily arbitrary. For the dichotomous variables, we only found a significant difference for nephrosclerosis $(p=0.015$, OR: $128, \mathrm{Cl}: 0.028-0.595)$. For the continuous variables, only age reached significance (T-test: $T=-1.995, p=0.049)$.

Overall survival was influenced by age. Survival of the patients who died during the study are shown in Table 4.6 .

In all but the highest age group mean and median survival is better in the patients who underwent RRT in comparison to the patients who did not receive renal replacement therapy. In patients over the age of 80 years, mean survival is better in the group not treated patients. Treotment gives in this age group only a slightly better median survival. In figure 4.3 the survival curves of the age groups are shown for all patients who died during the study.

Acute onset of ESRD in the elderly was accompanied by an increased mortality. A longer and more gradual onset of renal failure, with the possibility of a timely onset of treatment, was characterised by a better patient survival (Figure 4.4). 
However, when renal history was more than 5 years, there was an increase in the number of patients dying during the follow-up period (Figure 4.4).

Table 4.6 Mean and median survival of the patients who died in the study period

$$
\text { RRT NoRRT }
$$

$$
A g e=65-70
$$

mean survival

median survival

$$
\begin{gathered}
\text { Age }=71-75 \\
\text { mean survival } \\
\text { median survival }
\end{gathered}
$$

$$
640.6
$$$$
541
$$

$$
\mathrm{Age}=76-80
$$

mean survival

median survival

$$
\text { Age }>80
$$

mean sunvival

median sunvival

\section{0,8}

70

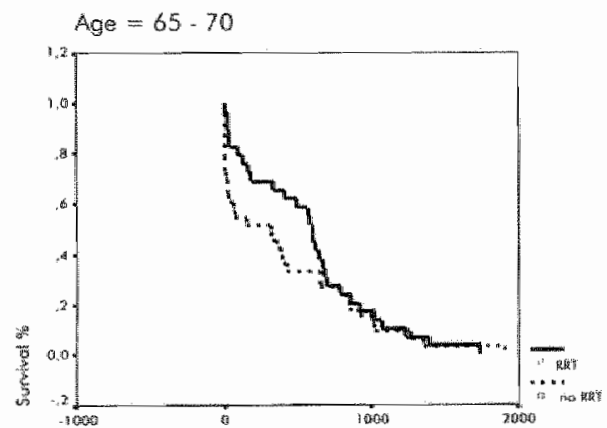

Siturived ind doty

Age $=76-80$

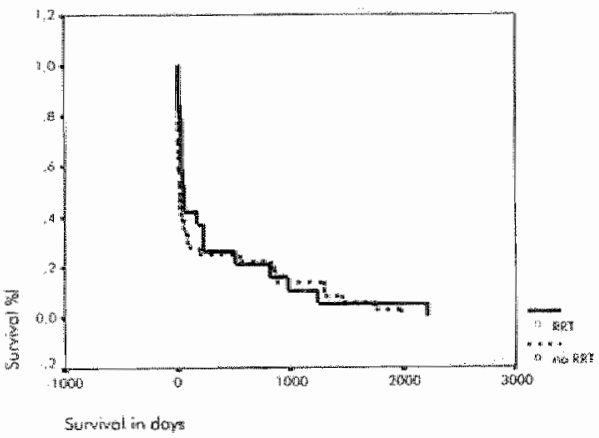

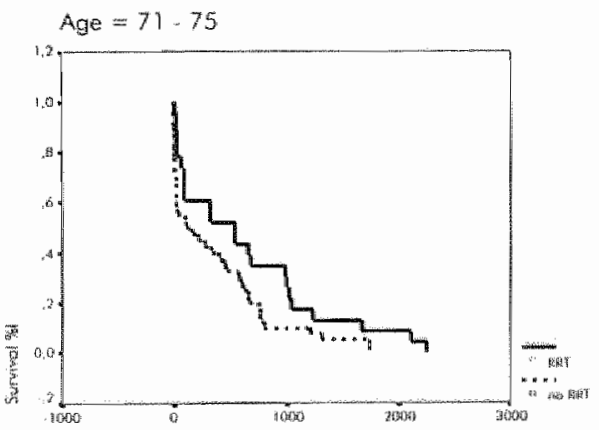

survival if degys Age $=80$

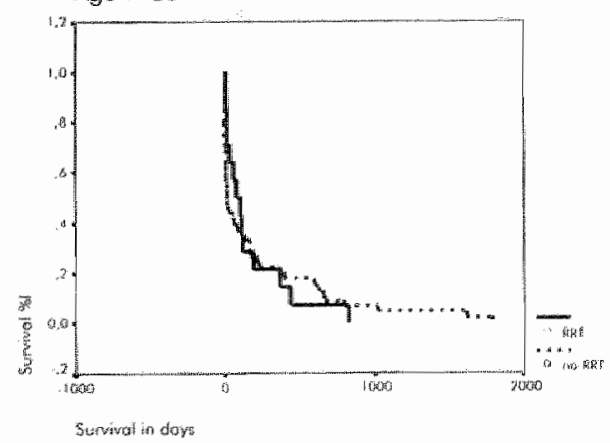

Figure 4.3 Surviwal and age 
In each age group, the influence of comorbidity was clearly visible. Survival was shorter within each age class when a higher Charlson score was present (Figure 4.5).

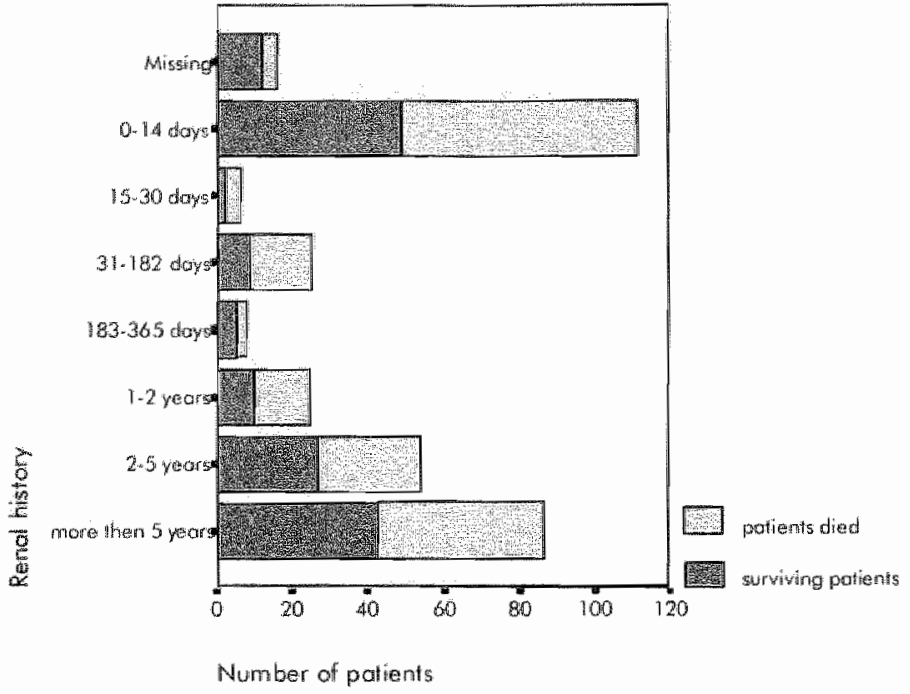

Figure 4.4 Death in relation to renal history

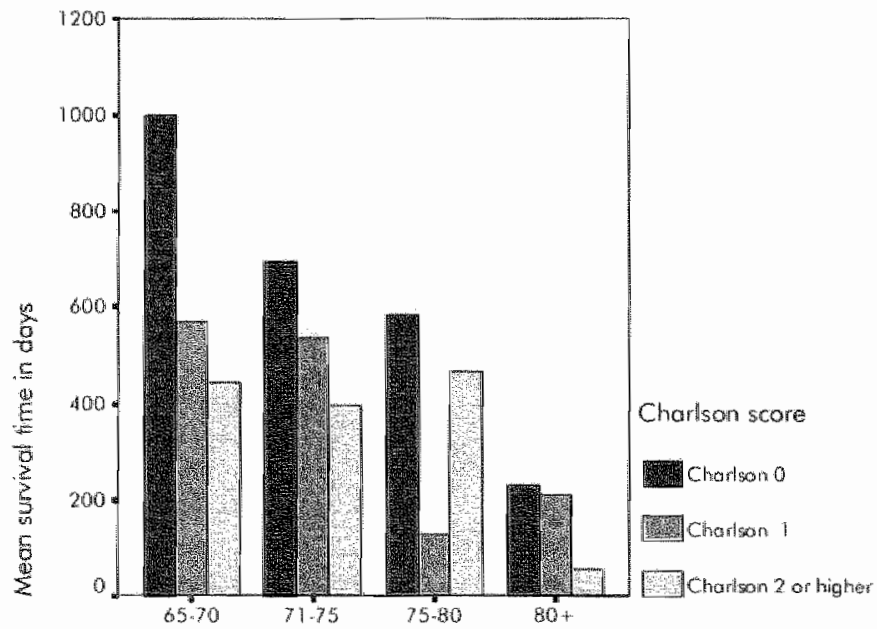

Age groups

Figure 4.5 Survival in relation to Charlson index 


\section{Conclusions}

We compared elderly patients with ESRD who underwent RRT with those who did not and found a number of differences. It seems reasonable to suggest that these differences were at least partly due to selection by the nephrologists in charge of the RRT departments of the participating hospitals.

From our findings, it appears that factors that favour treatment include a high serum creatinine, the causative diagnosis of glomerulonephritis and/or nephrosclerasis, younger age, lower body mass, a low Charlson index (indicating less comorbidity), and the presence of a partner. In contrast, dehydration, postrenal causes of renal impairment, cardiac causes of renal failure, and problems with the urinary tract appear to be factors that favour a no treaiment decision. In a logistic regression model using a stepwise backward strategy, serum creatinine, the diagnosis of glomerulonephritis, and the need for a urinary catheter were the independent factors that favoured treatment. Nephrologists are probably not aware of all these factors when they are confronted with an elderly patient with ESRD. Nevertheless, it is conceivable that, especially in an elderly patient, the presence of a partner who clearly wishes to keep the patient alive can also influence the treatment decision. The importance of comorbidity is not surprising; in other disciplines as well (e.g., oncology), decisions are based in part on existing comorbidity. ${ }^{33}$ Interestingly, problems with urine production and continence are considered to be an expression of the poor condition of a patient. These findings are in line with the finding that urinary incontinence is associated with a poor prognosis in elderly in-hospital patients. ${ }^{32}$

Although age is generally not considered to be a selection criterion, it did seem to influence our study population, not only in the treatment decision but also in the survival of treated patients. Treatment is more often offered to younger patients than to older patients, resulting in a significant difference in the mean age between treated and untreated groups. Survival is influenced by age. Overall survival was best in the youngest group we studied, which is in accordance with the literature. ${ }^{34-36}$ Treatment resulted in better survival in all but the oldest age group in our study, compared to the no treatment group. Given these results, it would seem appropriate to offer RRT to patients up until the age of 80 years. In patients over 80 years, comorbidity has to be considered as a major factor influencing survival since only patients with a low Charlson index were found to survive in our data.

Thus, for the eldest patients, RRT should only be ottempted in those with no, or only minor, comorbidity.

One must bear in mind that ours was a selected population. If is widely known that elderly patients with ESRD are often not referred to the haspital by the general physician. This phenamenon probably influenced the finding that an acute deterioration of renal function in out population was most often seen in the eldest age group. A slow and gradual loss of renal function in this group is probablly accepted as a hallmark of the end of life and does not usually lead to 
referral. However, survival appears to be influenced by renal history. Patients with a long renal history and, consequently, a more gradual and less aggressive progression of their renal disease, are probably more suited candidates for RRT. It may be concluded that the "wrong" category of elderly patients is usually referred to the hospital, especially in the eldest age group.

Thus, selection of elderly patients for RRT does occur in daily medical practice, primarily on the bosis of a high serum creatinine and the nephrological diagnoses of glomerulonephritis and nephrosclerosis, but also on coexisting comorbidity. Age also seerns to play a role in the treatment decision, although nephrologists may not be fully aware of this selection criterion. The ability to perform activities of daily living, mobility, and the presence of a partner (operating as a "defender" of the patient"s interests) are additional factors that are taken into account in treatment decisions. One must remain alert to any slow and gradual deterioration in renal function in elderly patients so that a timely intervention can be of benefit to this group of patients. 


\section{Literature}

1. Macias-Nuñez JF, Cameron JS. Treatment of end stage renal disease in the elderly. In: Cameron JS, Davidson AM, Grunfeld J, et al, eds. The Oxford Textbook of Clinical Nephralogy. London: Oxford, 1992:1621-1635.

2. Porusch JG, Faubert RF. Chronic renal failure. In: Poirusch JG, Foubent RF, eds. Renal Disease in the Aged. Bosion: Little Brown, 1991:285-313.

3. Barbanel C. Renal Disease and dialysis in elderly patients. Contrib Nephral $1989 ; 71: 95-99$.

4. Disney APS. Dialysis treatment in Australia, 1982 to 1988. Am I Kidney Dis. $1990 ; 15: 402-409$.

5. US Renal Data System Annual Data Report. Bethesda MD: National Institutes of Health, 1997

6. Brown WW. The Geriatric Dialysis Patient. In: Henrich WL ed. Principles and Practice of Dialysis. Baltimore Williams \& Wilkins se edition 1999, 460-476.

7. Westlie L, Umen A, Nestrund S, Kjellstrand CM. Mortality, morbidity and life satisfaction in the wery old dialysis patient. Am Soc Artif Intern Organs $1984 ; 30: 21-30$.

8. Chester AC, Rakowski TA, Argy WP ir, Giacalone A, Schreiner GE. Hemodialysis in the eight and ninth decades of life. Arch Intern Med 1979:139:1001-1005.

9. Horina $J H$, Holzer H, Reisinger EC, Kresj GJ, Neugebauer GS. Elderly patients and chronic hemodialysis. Lancet $1992 ; 339: 183$.

10. Singer PA. End-Stage Renal Disease Network of New England. Nephrologists" experience with and attitudes towards decisions to forego dialysis. J Am Sac Nephrol $1992 ; 2: 1235-1240$.

11. Kjellstrand CM, Moody H. Hemodialysis in Canada: a firsi-class medical crisis Can Med Assoe J 1994;150:1067-1071.

12. Friedman EA. Rationing of uremia therapy. Artificial Organs 1992; 6:90-97.

13. Chandna SM, Schulz J, Lawrence C, Greenwood RN, Farringtion K. Is there a rationale for rationing chronic dialysis? A hospital based cohort study of factors affecting surwival and morbidity. BM 1999:318:217-223.

14. Kilner JF. Ethical issues in the initiation and termination of treatment. Am I Kidney Dis $1990 ; 15: 218-227$.

15. Mendelsohn DC, Kua BT, Singer PA. Referral for dialysis in Ontario Arch Intern Med 1995; 155:2473-2478.

16. Feest TG, Mistry CD, Grimes DS, Mallick NP. Incidence of advanced chronic renal failure and the need for end stage renal replacement therapy. BMJ $1990 ; 301: 897-900$.

17. Porry RG, Crowe A, Stevens JM, Mason JC Rodlerick P. Referral of elderly patients with severe renal failure: questionnaire survey of physicians. BMJ 1996;313:466.

18. Holley JL, Foulks CJ, Moss AH. Nephrologist' reported attitudes about factors influencing recommendations to initiate or withdraw dialysis. I Am Soc Nephrol $1991: 2: 1235-1240$. 
19. Kiner JF. Seltecting patients when resources are limited: a study of US medical directors of kidney dialysis and transplantation facilities. Am I Public Health 1988.78:144-147.

20. Hirsch DJ, West ML, Cohen AD, Jondal KK. Experience with not offering dialysis to patients with poor prognosis. Am J Kidney Dis 1994;23:463-466.

21. Moiorica R, Cancarini, GC, Camerini C, et al. Madality selection for the elderly: medical factors. Adv Peritoneal Dial 1990;6(S): 18-25.

22. Taube DH, Winder EA, Ogg CS, et al. Succesfull treatment of middle aged and eiderly potients with end stage renal disease. BMJ 1983;286:2018-2020.

23. Henrich WL. Dialysis considerations in the elderly patient. Am J Kidney Dis $1990 ; 16: 339-341$

24. Port FK. Mortality and causes of death in patients with end-stage renal failure. Am I Kidney Dis 1990;15:215-217.

25. US Renal Data System Annual Data Report. Bethesda, MD: National Institutes of Health, Aug 1992.

26. Husebye DG, Kjellstrand CM. Old patients and uremia: rates of acceptance to and withdrawal from dialysis. Int J Artif Organs 1987;10:166-172.

27. Classificatie van Ziekten. Gebaseerd op de Classification of Diseases, 9th revision, Clinical Modification (ICD-9-CM). SIG/Informatiecentrum voor de Gezondheidszorg. Utrecht, 1986

28. Cocroft DW, Gault MH. Prediction of creatinine clearance from serum creatinine. Nephron 1976;16:31-34.

29. Charlson ME, Pompei $P$, Ales $K L$, Mackenzie $C R$. A new method of classifying prognostic comorbidity in longitudinal studies: development and validation. J Chron Dis 1987,5:373-383.

30. Katz S, Ford AB, Moskowitz RW, et al. Studies of illness in the aged. The index of ADL: A standardized measure of biolagical and psychosocial function. JAMA $1963 ; 185: 914-919$.

31. Fiolet JFBM. Flankerend geriatrisch beleid Academical thesis Maastrich 1995.

32. Mulder WJ, Fiolet JFBM, Leunissen KML, Hillen HFP. End-stage renall failure in elderly patients. Clinical characteristics. A retrospective study in the Dutch population. Submitted for publication.

33. Sataviano WA, Ragland DR. The effect of comorbidity on 3-year survival of women with primary breast carcinoma. Ann Int Med 1994;120:104-110.

34. Davies S., Russel L, Bryan J, Phillips L, Russel Gl. Comorbidity, urea kinetics, and appetite in comlinuous ambulatory peritoneal dialysis patients: their interrelationship and prediction of survival. Am J Kidney Dis 1995;26:353-361.

35. Mailloux LU, Napolitano B, Belluci AG, Mossey RT, Vernace MA, Wilkes BM. The impact af comorbid risk factors at the stant of dialysis upon survival of ESRD patients. ASAIO J 1996;42:164-169.

36. Merkus MP, Jager KJ, Dekker FW, de Haas RJ, Boesschoten EW, Krediet RT. Predictors of poor outcome in chronic dialysis patients: The Netherlands Cooperative Study on the adequacy of Dialysis. The NECOSAD Study Group. Am I Kidney Dis 2000;35(1):69-79. 


\section{The illness burden of end-stage renal disease in elderly patients}

WJ Mulder, JFBM Fiolet, KML Leunissen, HFP Hillen

Submitted for publication 


\section{Abstract}

\section{Background}

The incidence of end-stage renal disease (ESRD) in elderly patients is increasing. Elderly patients are often nof suitable candidates for renal transplantation and are mastly treated by passive center hemodialysis. The resources for this type of renal function replacement therapy, howewer, are not unlimited, and there has been much debate about the appropriateness of using expensive medical techniques on a patient group with a limited life expectancy. Thus, it is inevitable that selection decisions for dialysis treatment are made in this patient category. In order to determine which medical factors should be taken into account when making these decisions, we performed a multicenter study to assess the impact of ESRD on elderly patients. We also investigated which beneficial effects can be expected from dialysis treament for elderly patients.

\section{Methods}

A multicenter, langitudinal, comparative trial was performed from June 1, 1996 until June 1, 1997 on 16 ESRD patients selected for, but not yet on, RRT, 107 patients in stable condition on RRT, and 59 consecutive patients referred to the autpatient facility of the geriatric department. A follow-up survey of these patients was carried out in 2000. Baseline characteristics, medical history, and comorbidity were assessed in each patient and an extensive functional assessment was made regarding the impact of the disease on well. being.

\section{Results}

Patients on dialysis scared lower on mobility and on their functional performance of activities of daily living than did pre-dialysis patients and older control patients. The mainor impact of renal disease on elderly pre-dialysis patients was a deterioration of functional capability over a period of 3 months. Nevertheless, the sickness impact profile showed the patients on RRT as having the highest score. Although physical condition may improve as result of the treatment, the feeling of well-being does not. Because no signs of depression could be found in these patients, we speculated that their feeling of no longer being "in contral" was the cause of this high score on the sickness impact profile.

The follow-up survey in September 2000 showed that over $52 \%$ of the RRT population had died since intake, compared to $38 \%$ of the pre-dialysis patients and $16 \%$ of the contral group. These findings indicate not only the serious consequences of renal failure in elderly patients but also the limited effects of RRT on the survival of these patients. 


\section{Introduction}

Hemodialysis was first used in the 1940 s to sustain life in patients with acute renal failure. it soon became clear that while treatment was rather complicated, life could be prolonged, where otherwise death was swift and certain. Early dialysis regimens were often more focused on maintaining the fluid balance than on remowing metabolic waste products. When tolerance of dialysis improved as a result of better permeability of the membrane, the substitution of bicarbonate for acetate in the dialysate, and the achievement of better fluid maintenance, the concept of dialysis shifted from merely sustaining life to striving for optimal patient survival. This is very important because, for many patients, dialysis therapy is not just a time bridge to renal fransplantation, which is often considered the preferred form of renal replacement therapy (RRT). Many elderly patients are not suitable candidates for renal transplantation; others are unable to comply with the complicated medical regimens involved in transplantation. Still other patients have high antibody titers to many HLA class one antigens, or will never find the right donor kidney. Elderly patients are often not candidates for renal transplantation because of the physiological impairment of advanced age.

In the Netherlands, the number of patients receiving dialysis care doubled between 1985 and 1995.' Moreover, during this period, there was a considerable increase in the number of alder and sicker patients accepted for dialysis.

Studies on quality of life are not conclusive. Some have found the quality of life of dialysis patients to be inferior to that of the general population. ${ }^{2,3}$ Others have found no difference. ${ }^{4}$

The aim of the present study was to assess the impact of end-stage renal disease (ESRD) on elderly patients and to compare their quality of life with that of elderly patients without apparent renal impairment. We also sought to determine whether RRT reduces sickness impact in this population.

\section{Study Design}

A multicenter study on the impact of ESRD in elderly patients was conducted at four hospitals: the University Hospital in Maastricht, the Atrium Hospital in Heerlen, Maasland Hospital in Sittard, and Laurentius Hospital in Roermond. These four hospitals are the only centers with RRT facilities in the south-eastern part of the Netherlands.

In the period from June 1, 1996 until June 1, 1997, patients selected for, but not yet started on, RRT were asked to participate in this study. Due to the study design, which calls for a number of tests and the need to abserve the patient over a long period of time, those patients who underwent acute RRT were not included in the study. To determine whether elderly renal patients improve in 
physical and mental well being when treated with RRT, a number of elderly patients in stable condition on RRT in these four hospitals were also investigated. Elderly patients before initiation of maintenance dialysis often suffer from anorexia and weight loss, generalised weakness, encephalopathy, nausea and vomiting. ${ }^{5}$ RRT may improve the physical condition of elderly patients. To determine whether physical recovery also leads to improvement of functional ability and the feeling of well being, and to assess the extent of this functional improvement, we compared the pre-dialysis and dialysis patients in this aspect with a number of elderly patients as a control group. We selected a group of consecutive elderly patients referred to the outpatient clinic of the Department of Medicine and Geriatrics of the University Hospital Maastricht. These control patients were included when no apparent impairment of the renal function las measured by serum creatinine) was found. Data were collected on medical history, use of medication, and present (co-) morbidity. Baseline characteristics at the physical examination were recorded, and every patient was extensively interviewed with regard to mobility, their ability to perform activities of daily living (ADL), and their need for informal or professional care. In September 2000 , we performed a follow-up survey to assess the clinical course of the patients originally included in the study.

\section{Functional assessment}

The functional status of the patients was determined by assessing each patient's ability to perform $A D L$, as well as his/her mability and urinary continence. The Katz' scale of basic activities of daily living (bathing, dressing, using the toilet, getting in and out of bed, and eating) was used. In each of these five categories, three ratings were possible: good, able to perform with help, and complete dependency. Possible ratings for mobility were: good mobility including walking stairs, good mobility, mobility with support or walking device, bed/chair only, and bedridden. Ratings for urinary continence were: complete incontinence, some incontinence, little incontinence, the presence of a catheter and the ability to handle this, the presence of a urostoma and, given the special group of patients we studied, no urine production at all.

In addition to ratings in these fields, the functional status of every patient was estimated using the Barthel index of activities of daily living?. Each patient was given an individual score in each category, and a total score was computed as well. Someone with a score of 16 or more was considered to be functionally independent. Those with scores of 15 or below were considered dependent.

\section{Cognitive Function}

Every patient was screened for cognitive disorders using the Mini Mental State Examination. ${ }^{8}$ The MMSE is a widely used, brief screening tool for use at the bedside by physicians, nurses, social workers, or technicians. It tests time and space orientation, registration, attention, calculation, recall, and language. The sensitivity and specificity of the MMSE are adequate for detection of cognitive deterioration or dementia in a cammunity as well as in a hospital population. 


\section{Functional health status}

The most widely used functional status health questionnaire is the Sickness Impact Profile (SIP), developed in the late 1970s in the Unifed States. The SIP has been translated into many languages, including British English, Swedish, German, French, Danisth, and Nonwegian. ${ }^{10}$ In 1985, a Dutch version of the SIP appeared."

We decided to use a short version of the SIP, the SIP68. This instrument was developed in Maastricht and widely tested. It has proven to be a valid and reliable instrument for measuring health related functional status and is in every respect a goad alternative to the original Sickness Impact Profile (Appendix 11]. ${ }^{12}$ Most patients were able to fill out the questionnaire independently; howewer, when necessary, assistance was offered by a specialized trial nurse.

\section{Functional observations}

The specialized trial nurse observed the RRT and pre-dialysis patients and made an assessment of their feelings of helplessness, aggression, depression, physical or mental invalidity, and their degree of inactivity.

The BOP, an observation scale especially designed for elderly patients and commonly used in many Dutch geriatric departments, was used. The dialysis patients were observed during their stay in the dialysis department. The predialysis patients were observed during their visit to the nephrology departiment and were also visited at their homes. During the observation period, we repeated this functional observation in 13 dialysis patients and 4 pre-dialysis patients after a period of 3 months.

\section{Statistics}

All statistical analyses were made using SPSS for Windows 7.5 (SPSS Inc, Chicago, IL, USA). Data are presented as mean values \pm SD or number (percentage).

Student's t-lest was used to compare continuous variables; for categorical variables, the chi-square test or, when appropriate, the Fischer exact test was used. For ordered categorical variables, such as scores, the chi-square test for linear trend was used. Two-sided p-values not greater than 0.05 were considered significant.

Survival plot was made by using the Kaplan-Meier method based on estimating conditional probabilities at each time point. Patients still alive at the end of the study were censored.

\section{Results}

During the observation period of 6 manths, we collected data on 182 patients: 16 pre-dialysis patients, 107 dialysis patients, and 59 control patients. In the dialysis group, 95 patients were on chronic, passive center dialysis and 12 were on CAPD. Baseline characteristics of these patients are summarized in Table 5.1. 
The number of pre-dialysis patients was very small. The main reason for this low number of patients was that we only could interview patients who were expected to start RRT within a short periad of time. Patients who underwent acute RRT were not included. Acute onsel of RRT is most often seen in the elderly population, as demonstrated in earlier investigations.

All three subgroups showed a male prepanderance. Mean age was comparable in the pre-dialysis and dialysis groups. The outclinic patient population was notably older.

Table 5.1 Potient characteristics

\section{$N(0,9)$}

Mean age (years)

$$
\begin{aligned}
& 65-70 \\
& 71-80
\end{aligned}
$$

$\geq 81$

Meon serum creatinine ( $/ \mathrm{mol} / \mathrm{l})$

Meansystalic blood pressure

Mean diastolic blood pressure

Mean body weight ( $\mathrm{kg}$ )

Socidal status

Living with partner

Widowed

Divorced

Not married

Living conditions

Independently with partner

Indiependently alone

lindwelling with oblldren/

home for the elderly/

monostery/ nursing home

* Difference statistically significant

$\begin{array}{ccc}\text { Pre-dialysis pts } & \text { Dialysis pts } & \text { Control pts } \\ 16(10,6) & 107(60,47) & 59(38,21) \\ 72.63 & 72.59 & 77.92^{*} \\ 8 & 41 & 9 \\ 5 & 56 & 27 \\ 3 & 10 & 23 \\ 475 & 809^{*} & 94 \\ 152 & 141 & 151 \\ 75 & 85 & 81 \\ 74 & 78 & 68^{*} \\ N(\%) & N(\%) & N(\%) \\ 8(50) & 66(62) & 26(44) \\ 7(44) & 29(27) & 27(46) \\ 1(6) & 3(3) & 5(9) \\ & 9(8) & \\ 8(50) & 59(55) & 24(41) \\ 6(38) & 19(18) & 26(44) \\ 2(12) & 30(28) & 9(15)\end{array}$

Mean serum creatinine was much higher in patients on RRT than in those with ESRD but not yet on RRT. The mean serum creatinine in the control group showed only slightly impaired renal function, probably due to a functional loss caused by aging.

There were no large differences in mean systolic and diastolic blood pressure among the three groups, although mean diastolic pressure was slightly elevated in the patients on RRT.

Mean body weight was notably lower in pre-dialysis patients than in those on RRT. This is probably due to the poor physical condition of this group of patients. 
A lower body weight was also found in the contral group, most likely as a result of their higher age.

Most patients in both groups were living independently with their partner or alone.

Thirty patients in the dialysis group (28\%), however, were living with their children or in a home for the elderly, indicating that they were in need of a certain amount of care.

\section{Mobility and ADL-ability}

In the pre-dialysis group, all patients had a reasonable degree of mability. Twelve patients $(75 \%)$ could walk independently and were able to climb stairs. In the group of dialysis patients, this was true of $60 \%$ of the patients. Fourteen patients were in need of support and five were bedridden. In the group of elderly controls, 54 patients $(93 \%)$ were able to walk independently (Table 5.2 ).

Table 5.2 Mobility

\begin{tabular}{|c|c|c|c|c|c|c|}
\hline & Pre-dia & potients & Dialysis & gaflents. & Control & oitients: \\
\hline & $8(\%)$ & $\rho(\%)$ & $8(\%)$ & $9(\%)$ & $6(\%)$ & $9(\%)$ \\
\hline lg abllity & & & & & & \\
\hline pendent incl stairs & $7(70)$ & $4(67)$ & $40(67)$ & $25(53)$ & $26(68)$ & 15171 \\
\hline Independent & $2(20)$ & 1171 & $17(28)$ & $4(9)$ & $11(29)$ & $3(14)$ \\
\hline with aid & 1,10 & 11171 & $3(5)$ & $10(21)$ & & 3114 \\
\hline with support & & & $4(7)$ & $3(6)$ & $1(3)$ & \\
\hline air: & & & & 5011 & & \\
\hline Valking distance & & & & & & \\
\hline$>50 \mathrm{~m}$ & $6(60)$ & $4(67)$ & $39(65)$ & $18(38)$ & $31(82)$ & \\
\hline$>10<50 \mathrm{~m}$ & $4(40)$ & & $18(30)$ & $16(34)$ & $7(18)$ & $6(76)$ \\
\hline$<10 \mathrm{~m}$ & & $2(33)$ & $315)$ & $13(28)$ & & $5(24)$ \\
\hline Devices & & & & & & \\
\hline No devices & $7(70)$ & $4(66)$ & 43172 & 271571 & $25(66)$ & $12(5)$ \\
\hline Walking stick & $3(30)$ & 1171 & $12(20$ & 10121 & $13(34)$ & $6(29)$ \\
\hline Other walking device & & 1171 & $3(5)$ & 4191 & & 3114 \\
\hline Wheel chair & & & $2(3)$ & 6113 & & \\
\hline
\end{tabular}

The walking distance they were able to walk differed between the groups, and this difference was statistically significant $(p=0.001)$ in the female patient group. In the five categories of ADL-ability - bathing, dressing, using the toillet, eating, and getting in and out bed - 79\% of the control patients were independent, compared to $90 \%$ of the pre-dialysis patients and $70 \%$ of the dialysis patients (Table 5.3). Three patients from the control group and four from the dialysis group were completely dependent in these activities. These four patients were all an passive center hemodialysis. Yet, there were no significant differences in ADL-ability between CAPD and hemodialysis patients. It is interesting to note 
that patients in the pre-dialysis group were never completely dependent in these activities and that only two patients from this group were in need of help.

The mean score on the Barthel index did not differ significantly among the three groups of patients. The mean scare was 17.47 (SD:2.10) in control patients, 18.75 (SD:1.91) in pre-dialysis patients, and 17.30 (SD:3.33) in dialysis patients. Only two patients (12.5\%) in the pre-dialysis group had a score below 15. The highest percentage $(26 \%)$ of patients with a score below 15 was found in the dialysis group (Figure 5.1). Thirteen of the 59 control patients $(22 \%)$ had a total Barthel score below 15. Thus, the pre-dialysis group appeared to be quite a homogenous group with a good ADL and mobility status. After 3 months, there was no deterioration in status in this group.

Table 5.3 Scores on ADL-activities of pre-dialysis, dialysis and control patients

\begin{tabular}{|c|c|c|c|c|c|c|}
\hline & Premd & atients & Dialys & atients & Cont & atients \\
\hline & 18 & 9 & 8 & 9 & 8 & 9 \\
\hline Weishing & & & & & & \\
\hline Independent & B & 5 & 43 & 32 & 30 & 16 \\
\hline whit aid & 1 & 1 & 15 & 13 & 6 & 3 \\
\hline dependent & & & 2 & 2 & 2 & 1 \\
\hline Dressing & & & & & & \\
\hline independent & 8 & 5 & 48 & 36 & 34 & 18 \\
\hline wilh aid & 1 & 1 & 412 & 10 & 3 & 1 \\
\hline dependent & & & 1 & 1 & 1 & 1 \\
\hline Using the toile & & & & & & \\
\hline Independent & 9 & 6 & 58 & 42 & 38 & 19 \\
\hline with aid & & & 2 & 4 & & 1 \\
\hline dependent & & & & 1 & & \\
\hline Getting in and & & & & & & \\
\hline independent & 9 & 6 & 56 & 41 & 36 & 19 \\
\hline with aid & & & 4 & 4 & 2 & 1 \\
\hline dependent & & & & 2 & & \\
\hline Eoting & & 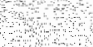 & & & & \\
\hline independent & 9 & 6 & 59 & 46 & 38 & 20 \\
\hline with aid & & & 1 & 1 & & \\
\hline nden & & & & & & \\
\hline
\end{tabular}

Care was predominantly provided by the partner. In $43 \%$ of the patients lall groups), the partner was mentioned as the main caregiver. For male patients, this was true of $54 \%$ of the patients versus $21 \%$ in the female group (Table 5.4 ). In the group of contral patients, $24 \%$ of the men were being cared for by their partner; this was true of $67 \%$ of the male patients in the pre-dialysis group and of $72 \%$ in the dialysis group. When a distinction was made between informal help, i.e., that given by children, neighbours, friends, etc., and formal care, i.e., 
provided by nurses or specialized caregivers, we found that $76 \%$ of all male patients and $81 \%$ of all female patients were in need of informal assistance. Formal assistance was provided to $61 \%$ of the male patients versus $75 \%$ of the female patients. Among the three groups of patients, the difference reached statistical significance in male patients when formal help was concerned $(p=0.005)$ and in female patients in the case of informal assistance $(p<0.000)$.

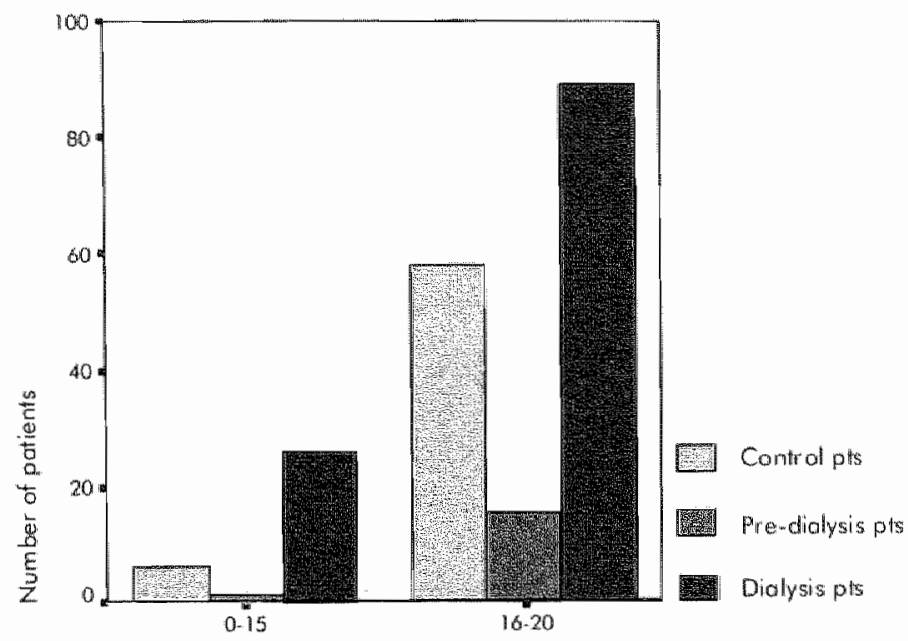

Total Barthel score

Figure 5.1 Totol Barthel score

\section{Cognition}

The mean score on the MMSE in all patients was 25.47 (range 11-30). We found no difference among the three patient groups: mean MMSE in the control group was 25.59 , in the pre-dialysis group 25.73 , and in the dialysis patients 25.37. Some 155 patients had a score above 22 on the MMSE, indicating no cognitive problems. Only five patients scored 17 points or below, strongly suggesting cognitive impairment. All but one of these five patients were in the dialysis group.

The MMSE score showed a strong association with ADL-ability; in general, a better MMSE score was found in patients with a good ADL-ability (Table 5.5). 
Table 5.4 Help providers. Use of formal ond informal help of pre-dialysis, dialysis and control patients

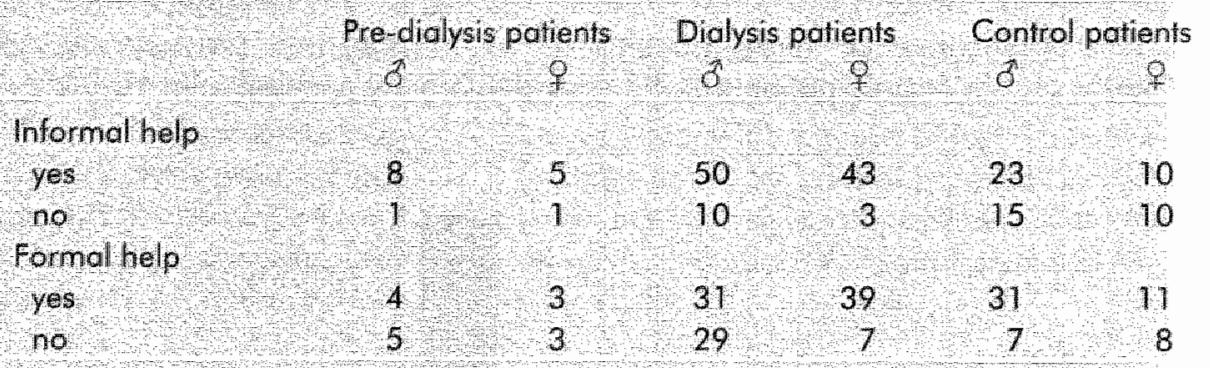

Data from one male pre-dialysis patient and one female control patient nat obtained.

Table 5.5 ADL-ability and MMSE-score, association between scores on ADL-obility and MMSE

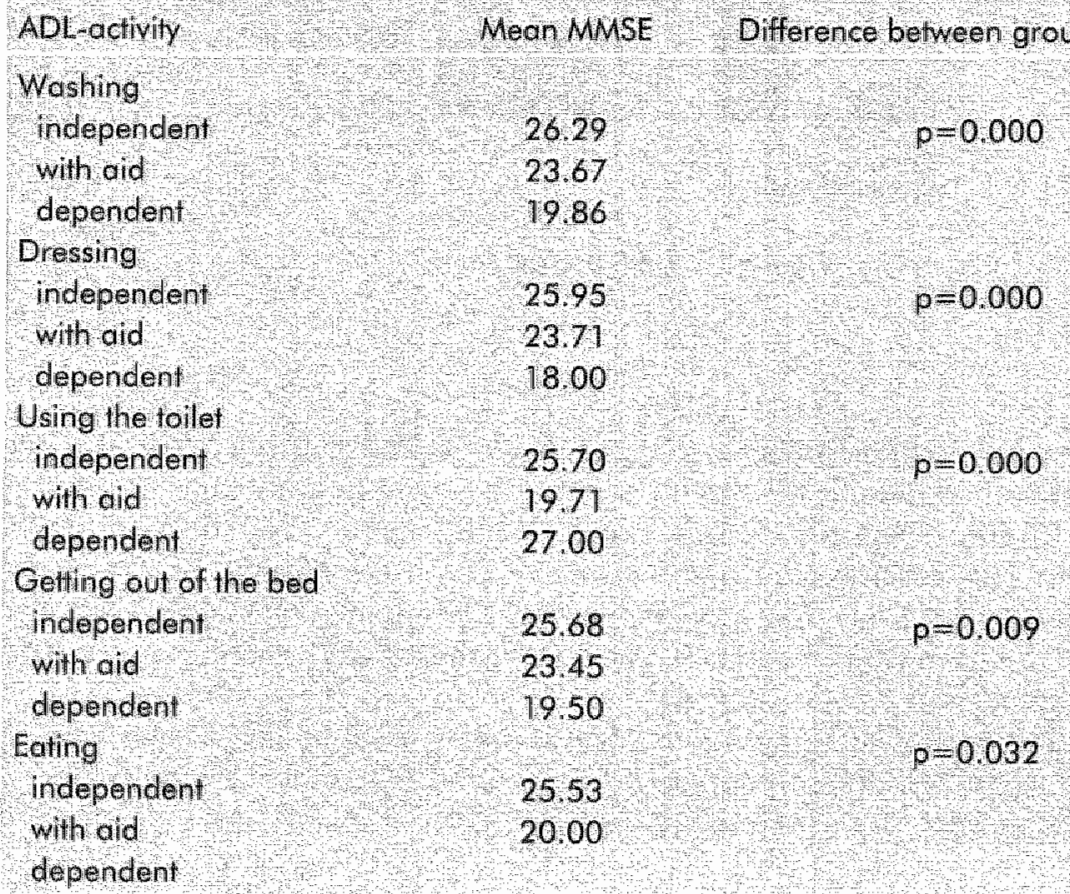

Data from one male pre-diallysis patient and one female contral patient not obtained.

The same association was found between mobility and mean MMSE, althaugh no statistical significance was reached. The best mean MMSE score was found in the group of patients with good mobility (mean MMSE: 25.73) in comparison 
with patients with severely impaired mobility, which had a mean MMSE score of 23.60. A significant positive correlation was found between the MMSE score and the Barthell Index score (Spearman's rha:.268, significant at the .01 level, twosided). No correlation was found between age and mean MMSE score. Nor did gender have any correlation with the score on the MMSE.

During the observation period, a second MMSE score was obtained from 39 patients: 23 dialysis patients, 11 pre-dialysis patients, and 5 control partients. There was no noticeable decrease in the MMSE score.

\section{Sickness Impact}

The mean scare on the SIP6 8 was 20.09 in the cantrol group. In the pre-dialysis group, we found a comparable score of 19.13 , but in the dialysis group, the score was substantially higher, $26.44(p=0.001)$ The mean SIP68 score in patients on RRT differed from that in patients on hemodialysis and CAPD: 27.10 versus 20.25; however, this difference was not statistically significant. The patients on CAPD had a substantially lower score on the item regarding somatic autonamy.

The frequency of scores on the SIP68 and on individual subscales is shown in Table 5.6.

Significantly higher tatal SIP68 scores were found in patients with impaired mobility $(p=0.000)$, resulting in a positive correlation (Pearson correlation: 0.438 significant at the 0.01 level, 2 -tailed). Dependency in ADL-activities also resulted in a higher total SIP68, again resulting in a positive correlation (Pearson correlation: 0.592 , significant at the 0.01 level, two-tailed).

These correlations are reflected in the finding that patients in need of much assistance (informal and formal) had significantly higher SIP68 scores (mean SIP of 21.39 versus $29.80, p=0.000$ ). In this respect, it was not surprising to find a positive correlation between the MMSE results and the total SIP68 scores, with a Pearson correlation of 0.487 , significant at the 0.01 levell, 2 -tailed.

Higher SIP68 scores were found in female patients than in male patients (mean SIP: 25.48 vs. 22.15) and in elderly patients (>75 years of age) compared to younger patients ( $<75$ years). These differences, however, were not statistically significant.

In patients with urinary incontinence, higher SIP68 scores were found, in accordance with the frequency of involuntary loss of urine. In patients with complete urinary continence, we found a mean total SIP68 score of 21.61; in those with frequent urinary loss, the mean score was 29.44 . In patients with complete incontinence, the mean SIP68 was 23.45. The difference between these three groups is statistically significant $(p=0.002)$.

\section{Functiond abservation}

A functional observation was made in 14 pre-dialysis patients and 106 dialysis patients. The results are shown in Table 5.7. No significant differences could be found between the two patient groups. However, on each item, dialysis patients had higher mean scores than pre-dialysis patients. 
As mentioned earlier, we repeated this functional abservation in 13 dialysis patients and 4 pre-dialysis patients after a period of 3 months. No statistical significant difference was found between the wo observations. Yet, a certain trend is discernable. In dialysis patients, the scores were generally lower at the fime of the second observation, especially with regard to feelings of helplessness, physical and psychic invalidity, and inactivity. In addition, during the second observation, a higher score was found with regard to feelings of aggression.

Table 5.6 Frequency of score on the SIP 68 and individual subscales

Mean
score.

Somatic autonomy (number of trems 17 )

$\begin{array}{lllll}\text { control pts. } & 1.6 & 2.38 & 4.8 & 0 \\ \text { pre-dialysis pis. } & 1.47 & 2.26 & 53.3 & 0 \\ \text { dialysis pts. } & 2.62 & 3.17 & 32.7 & 0\end{array}$

Mobilty control (number of items 12 )

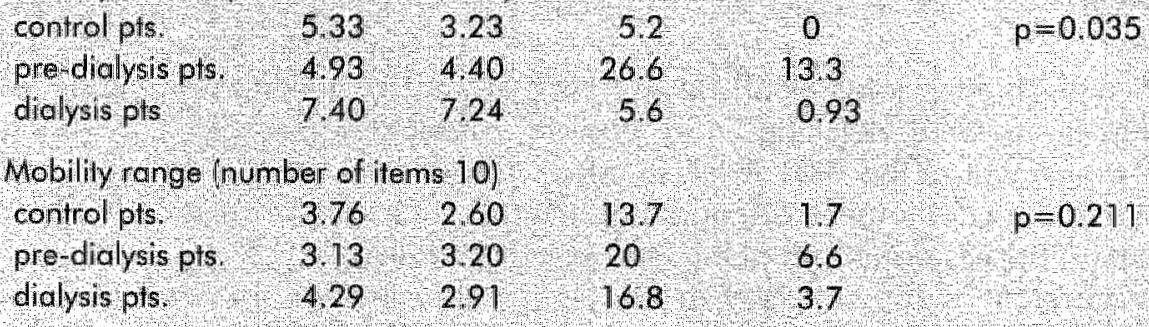

Social behavior (number of tiems 12 )

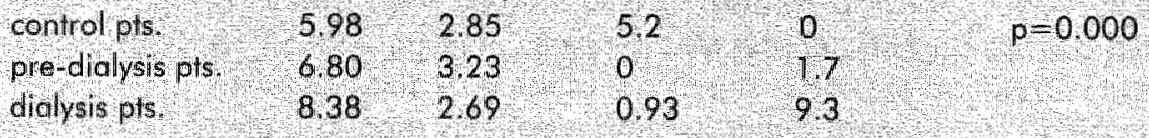

Emotional stability (number of items 6 )

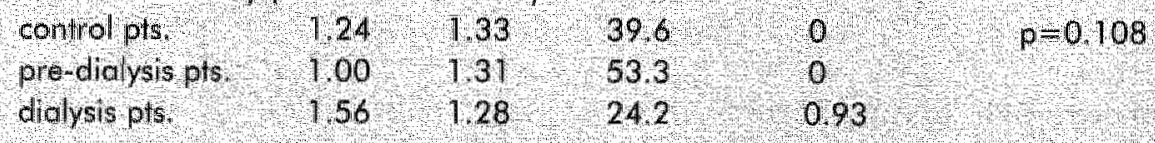

Psych, autonony and communicaticn (number of tems 1 )

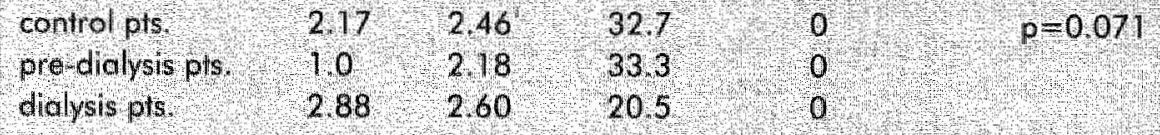

Tolal SIP68

$\begin{array}{llllll}\text { conirol pts. } & 20.09 & 10.84 & 3.4 & 0 & 0 \\ \text { pre-dialysis pts. } & 19.13 & 13.87 & 0 & 0 \\ \text { dialysis pls } & 28.31 & 23.18 & 0 & 0\end{array}$


Table 57 Fundional absenation of pre-dialysis, dialysis and control patients

tem

$$
\begin{aligned}
& \text { Pre-dialysis pts, } \\
& \text { mean score }
\end{aligned}
$$

Dialysis pts.

mean score

Difference

Helplessness (scale 0.46)

Aggression (scale 0-10)

Physical invalidity $(0.6)$

Depressive behaviour (scale 0-6)

Psychic invalidity (scole 0.8 )

Inactivity (scale $0-14$ )

$\begin{array}{ll}4.57 & 7.50 \\ 0.07 & 0.58 \\ 0.64 & 1.42 \\ 1.64 & 2.96 \\ 0.29 & 0.50 \\ 3.0 & 4.96\end{array}$

750

0.58

296

4.96 benveen:

groups Anova

$$
\begin{aligned}
& p=0.294 \\
& p=0.300 \\
& p=0.256 \\
& p=0.384 \\
& p=0.418 \\
& p=0.037
\end{aligned}
$$

In the pre-dialysis group, the second observation was characterized by higher scores on helplessness, physical invalidity, and inactivity, probably due to deteriaration in the patient's condition. No increase in feelings of aggression was encountered in this group.

\section{Clinical course}

In due course, all but one pre-dialysis patient entered a RRT program. That one patient refused to. All other patients underwent passive center hemodialysis.

By September 2000, 6 patients $(37.5 \%)$ from the pre-dialysis population had died. Fiffy-six patients (52.3\%) from the dialysis population died between the intake date and September 1, 2000. Control patients had a much better prognosis over time: 50 patients were still alive at the end of the study and only $9(16.3 \%)$ died during follow-up. The difference between the groups was highly significant $(p=0.000)$.

The mean survival of the pre-dialysis patients who died was 410.3 days; for the dialysis patients this was 565.5 days. The six control patients who died had a mean survival of 431.6 days. Survival of all patients until the end of the study is depicted as a Kaplan-Meier survival plot in Figure 5.2.

Neither survival rate nor mean survival was different in CAPD patients versus hemodialysis patients; however, the small number of patients on CAPD makes it impossible to draw conclusions from this result.

\section{Discussion}

Renal failure in elderly patients is a serious condition with a high marbidity and a bad prognosis quo ad vitam. Dialysis patients are worse off in terms of mobility and ADL-ability than control patients, even those who are older than they are. Consequently, they are in need of more help, informal and professional, than contral patients and even pre-dialysis patients. In male patients especially, the disease places a heavy burden on the partner. 
In spite of the fact that our group of control patients was significantly older than the patients with ESRD, mortality was much higher in the latter group. Survival in the pre-dialysis patients was probably somewhat better in this survey due to the fact that patients who entered acute RRT were not included. Acute onset of RRT in elderly patients is associated with a poor prognosis, as we reported before. ${ }^{13}$

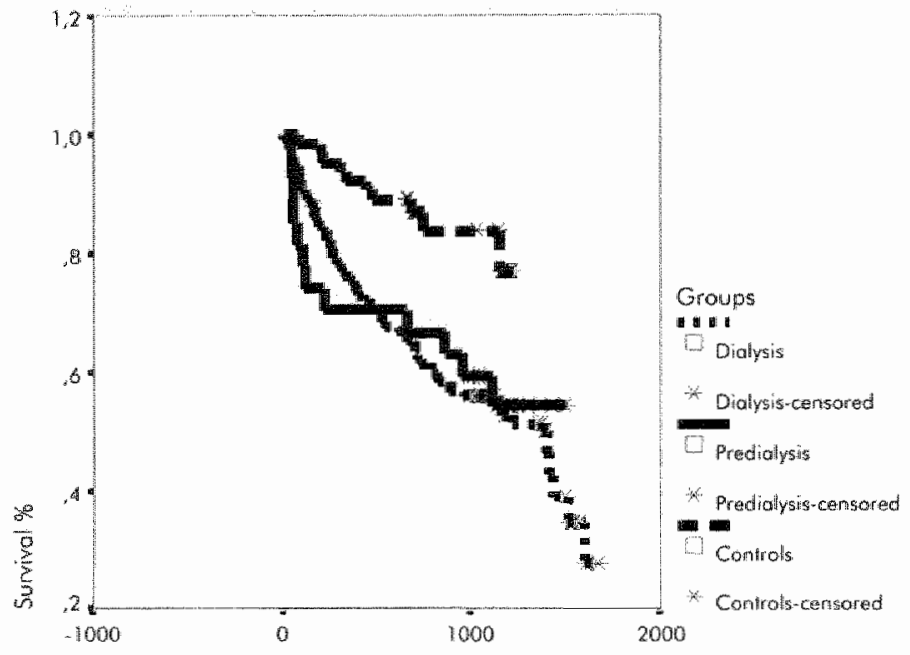

Surviwal in days

Figure 5.2 Survival of a predialysis patients, dialysis patients, and controls.

Nevertheless, patient characteristics of the group of pre-dialysis patients indicate the major impact of renal failure in the elderly. These patients have a lower body mass and show rapid deterioration, as shown in the functional observation scale. At the same time, in comparison with dialysis patients, they score well on mobility, ADL-ability, and cognition. This is mast likely the result of selection. Only patients who perform well are selected to enter RRT within a short period of time. Patients in worse physical condition are likely to be included in a RRT program. Patients with limited mobility, ADL-ability, and most certainly cognition are more likely to be excluded from RRT.

Very interesting is the score on the sickness impact profile. Scores of pre-dialysis patients resemble those of elderly patients without renal disease. We did not expect this finding. Our hypothesis was that, due to the great impact of renal failure, pre-dialysis patients would suffer more from their disease. By improving their physical condition and restoring a feeling of well being, RRT was expected to lead to better performance on the SIP68. We can only speculate about the cause of these results. Functional observations gave no indication of more depressive feellings in RRT patients. One possible reasan may be that these patients no longer felt in control when on RRT. The relatively high score of dialysis patients on the item "social behaviour" in the SIP68 lends some support to this explanation. Higher scores on mobility control and somatic autonomy also point in this direction. In any case, this finding is in sharp contrast to the 
general notion that RRT not only prolongs life but also improves the quality of life.

It is possible that patients on CAPD have a better appreciation of the quality of their lives. Their mean total SIP68 score suggests as much. We were not able to find other differences between the two RRT modalities, but the percentage of CAPD patients was relatively low in our study population. Perhaps a greater effort should be made to include more elderly patients in CAPD programs.

The better appearance of the pre-dialysis patients is without doubithe result of selection. Only in the case of a good performing patient the decision can be made to postpone the start of RRT. Their better performance on mobility and ADL-tests, as well on the SIP68, makes it indeed tempting to do so. However their shorter survival, when started on dialysis confronts us with difficult to solve dilemma.

The group of pre-dialysis patients was very small in this study and we did not perform a formal follow-up procedure, making it hard to draw solid conclusions. However, it is clear that a proper timing of the onset of RRT is essential. The scarcity of dialysis facilities forces us to make choices. This seems to be a disadvantage of the well performing patient, who would probably do better on RRT when started earlier. 


\section{APPENDIX I Barthel Index}

\section{BOWELS}

\section{2 continent (for preceding week)}

1 accasional accident (once a week or less)

0 any worse grade of incontinence for needs enemas for continence)

\section{BLADDER}

2 continent (for preceding week) or able fo manage any device (e.g. cotheter and bag) without help.

1 accasional accident (once a day or less) or catheterised and needs help with device.

0 any worse grade of incontinence.

FEEDING, food pleced within reach

2 able to cut up food, spread butter, etc, without thelp

1 needs some help cutting or spreading

0 needs to be fed.

\section{GROOMING}

1 independent washing face, combing hair, shaving, and brushing teeth (when implements are provided)

0 needs help.

\section{DRESSING}

2 independent putting on all clothes, ind. fastening buttons, zippers, etc. (Clothes may be adapted).

1 needs some help but can do at least half

O needis more help than this

TRANSFER, bed to chair and back:

3 needs no help

2 needs minor help, verbal or physical: Can transfer with one person easily, or needs supervision.

1 needs major help: two people or one strong/trained person, but con sit unaided.

0 cannol sit; needs skilled lift by two people (or hoist)

\section{TOHLET USE}

2 able to get on and off toilet or commade, to undress and dress sufficiently, and to wipe self without physical or verbal help.

1 needs some help, can wipe self and do some of the rest with minimal help only.

0 needs more help than this.

MOBILITY around house ar ward, indoors:

3 may use aid (stick or frame etc. bul not wheelchairl.

2 needs thelp of one person, verbal or physical, including help standing up.

1 independent in wheelchair, incl. able to negotiate doors and comers unaided.

0 needs more help than this.

\section{STAIRS}

2 independent up and down, and can carry ary necessary walking aid

Ineeds help, verbal or physical, or help carrying aid

0 unable

\section{BATHING}

1 able to get in and out of bath or shower, washes self without help (may use any aids)

0 unable. 


\section{APPENDIX II SIP 68 Questionnaire}

\section{Somatic autonomy}

1. Iget around in a wheelchair.

2. I gel dressed only with someone's help.

3. I do not move into or out of bed by myself, but am moved by a person or mechanical aid.

4. I stand up only with someone's help.

5. I do not fasten my clothing, e.g., require assistance with buttons, zippers, shoelaces.

6. I do not walk at all.

7. I do not use stairs at all.

8. I make difficult moves with help, e.g., getting into or out of cars, bathtubs.

9. I do not bathe myself completely, e.g., require assistance with bathing.

10. I do not bathe myself at all, but am bathed by someone else.

11. I do not have control of my bladder.

12. I om very clumsy in body movements.

13. I do not have control of my bowels.

14. Ifeed myself with help from someone else.

15. I do not maintain balance.

16. I use a bedpan with assistance.

17. I am in a restricted position all the lime.

\section{Mobility control}

1. I go up and down stairs more slowly, e.g., one step at a time, stopping often.

2. I walk shorter distances or stop to rest often.

3. I walk more slowly.

4. I use stairs only with mechanical support, e.g., handrail, cane crutches.

5. I walk by myself but with some difficulty, e.g., I limp, wobble, stumble, have a stiff leg.

6. I kneel, stoop, or bend down only by holding onto something.

7. I do not walk up or down hills.

8. I get in and out of bed or chairs by grasping something for support or using a cane or walker.

9. I stand only for a short period of time.

10. I dress myself, but do so very sllowly.

11. I have difficulty using with my hands, e.g., turning foucets, using kitchen gadgets, sewing, doing carpentry.

12. I move my hands or fingers with some limitation or difficulty. 


\section{Psychic autonomy and communication}

1. I have difficulty reasoning and solving problems, for example, making plans, moking decisions, learning new things.

2. I howe difficuly doing activities inwolwing concentration and thinking.

3. I read slowly to things that are said or done.

4. I make more mistikes than usual.

5. I do not keep my attention on any activity for long

6. I forget alot, e.g., things that hoppened recently, where I put things, appointments.

7. I am confused and start several actions at a time.

8. I do not speak dearly when I am under stress.

9. I hove difficully speaking, e.g., I get stuck, stutter, stammer, slur my words.

10. I do not finish thingis / start.

11. Uhave trouble writing or typing.

\section{Social behaviour}

1. My sexual activity has decreased.

2. I am cutting down the length of visits with friends.

3. I om drinking fewer fluids.

4. Il am daing fewer community activities.

5. I am doing fewer social activities with groups of people.

6. I am gaing out for entertainment less often.

7. I stay away from hiome only for brief periods of time.

8. I am eating much less than usual.

9. I am nol doing heawy work around the house.

10. I do my hobbies and recreation for shorter periods of time.

11. I aim doing less of the regular daily work around the house than I would usually do.

12. I am cutting down on some of my usival inactive recreation and pastimes, e.g. watching $T V$, playing cards, reading.

\section{Emotional stability}

1. I fften act irritable toward thase around me, e.g. I snap at people, give sharp answers, criticize easily.

2. I act disagreeable to family members, e.g., I act spiteful, I am stubborn.

3. I have frequent outbursts of anger at family members, e.g., I strike at them, scream, throw things at them.

4. I act irritable and impatient with myself, e.g., I speak badly about myself, I swear at myself, I blame myself for things that happen.

5. I do not joke with family members as I usually do.

6. It telk less with those around 


\section{Mobility range}

1. I am not doing any of the shopping that I would usually do.

2. Ham not going into town.

3. I am not doing any of the house cleaning that I would usually do.

4. I am not doing any of the regular work around the house that I would usually do.

5. I stay home most of the time.

6. I am not doing any of the clothes washing that 1 would usually do.

7. I am not going out to visit people at all.

8. I am getting around only within one building.

9. I have given up taking care of personal or household business affairs, for example paying bills, banking, warking on budget.

10. I do not get around in the dark or in unlit places without someone's help 


\section{Literature}

1. Registratie Nierfunctievervanging Nederland: Statistisch jaarverslag 1998. [Dutch renal replacement registry. Annual Statistical report 1998] Rotterdam: Stichting Renine, 1998.

2. Khan IH, Garrat AM, Kumar A, Cody DJ, Catto GRD, Edward N, Macleod AM. Patients perception of health on renal replacement therapy: evaluation using a new instrument. Nephrol Dial Transplant 1995; 10:684-689.

3. Meyer KB, Espindle DM, DeGiacomo JM, Jenuleson CS, Kurtin PS, Ross Davies A: Monitoring dialysis patients' health status. Am J Kidney Dis 1994;24:267-279.

4. Auer J, Gokal R, Stout JP, Hillier VF, Kinsey J, Simon G, Oliver D. The Oxford/Manchester Study of dialysis patients. Scand I Urol Nephrol suppl $1990 ; 131: 31-37$.

5. Porush JG, Faubert RF. Chronic renal failure. In: Porush JG, Faubert RF, eds. Rend disease in the Aged. Boston: Little Brown 1991:285-313

6. Katz S, Ford AB, Moskowitz RW, et al. Studies of illness in the aged. The index of ADL: a standardized measure of biological and psychsocial function. JAMA $1963 ; 185: 914-919$.

7. Mahoney FI, Barthel D. Functional evaluation: the Barthel Index. Maryland State Med J 1965;14:56:61.

8. Folstein MF, Folstein SE, McHugh P. Mini-Mental state: A practical method for grading the cognitive sitate of patients for the clinician. I Psych Research 1975;12:189-198.

9. Berger $M$, Bobitt RA, Carter WB, Gilson BS. The Sickness Impact Profile: development and final revision of a health status measure. Med Care 1981;21:787. 805.

10. De Bruin AF, de Witte LP, Stevens FCJ, Diederiks JPM. Sickness Impact Profile: the stare of the an of a generic Rncrional status measure. Soc Soi Mled i992;35:10031014.

11. Luttik $A$, Jacabs $H$, de Witte LP. Een Nederlandse versie wan de Sickness Impact Profile. Vakgroep Huisartsengeneeskunde, Riksuniversiteit Utrecht, 1985.

12. de Brvin AF.The measurement of sickness impact: The construction of the SIP.68 Academical thesis Rijksuniversiteit Limburg, Maastricht, 1996.

13. Mulder WJ, Fiolet JFBM, Leunissen KML, Hillen HFP. Treatment selection criteria and prognostic factors in elderly patients with end-stage renal disease. Submitted for publication. 


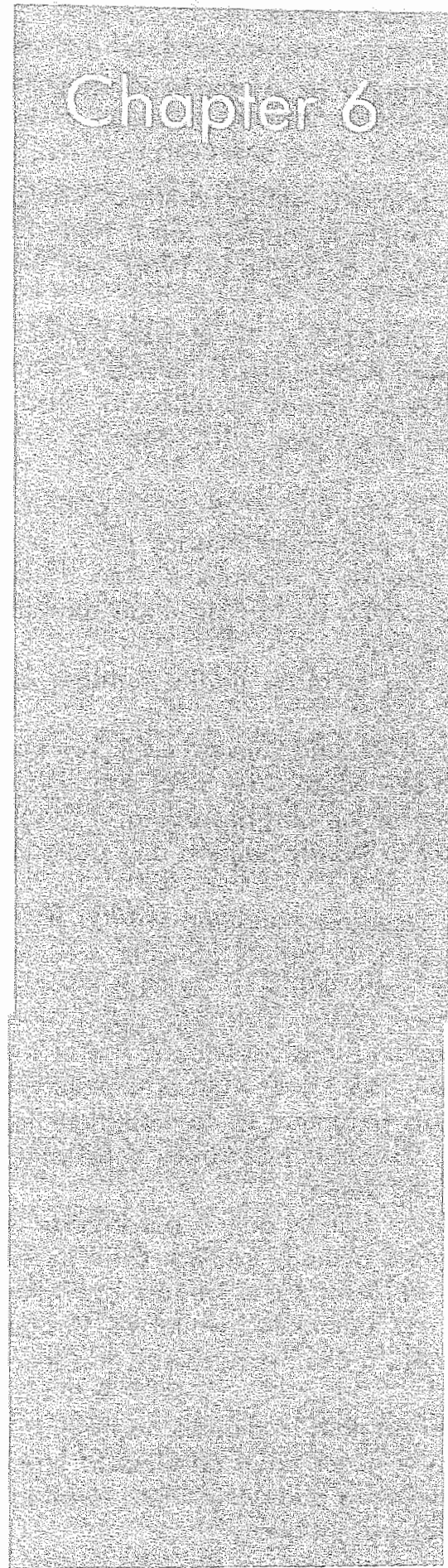

\section{General discussion: Rationing of renal replacement therapy in elderly patients with end-stage renal disease}

WJ Mulder, HFP Hillen, KML Leunissen

Submitted for publication 


\section{Rationing of renal replacement therapy in elderly patients with end-stage disease}

In the early years of the last century the first experiments with an artificial kidney were performed in animals. Although in the nineteen fourties some humans received dialysis, maintenance dialysis became only available in 1960 with the development of the vascular dialysis canula.'

In the Netherlands nowadays, dialysis care is provided in 48 dialysis centers. Most of these centers offer peritoneal dialysis and hemodialysis. Between 1985 and 1995 the number of patients receiving dialysis almost doubled to nearly 4000 , and it has been growing since. Each year more than 1300 patients start dialysis treatment. ${ }^{2}$

Recent Dutch data (RENINE) indicate that on 1 January 19986437 patients were treated with some form of renal function replacement therapy (40.7 per $10^{5}$ inhabitants). Distribution of the different treatment modalities was: 2322 (36\%) passive centre hemodialysis, 847 (13\%) CAPD, 93 (1.5\%) home dialysis and 3175 (49.5\%) had a functioning renal transplant.

Despite 450 renal transplantations there was an increase in the number of patients for a dialysis treatment.

Dialysis technology has been improved the last decade, nevertheless annual mortality of dialysis patients has increased from 13 to $21 \%$ over the same period. This increasing mortality rate is seen worldwide and according to many investigators this is due to an increasing number of elderly patients and patients with more comorbidity.

Especially in elderly patients renal failure is a serious condition with a high morbidity and still a bad prognosis quo ad vitam. In elderly patients, treated with RRT, survival is limited in comparison with younger patients. Renal transplantation is still limited mosily to the young patient with end-stage renal disease due to a scarcity of donor kidney's, resulting in a continuous rise of the mean age in the dialysis facilities. On 1 January 1992 over $40 \%$ of the dialysis patients were 65 years of age or over. Dialysis treatment is no treatment for renal failure, but is a life sustaining technique. Treatment decisions concerning dialysis therefore are decisions concerning life and death.

From the moment of introduction of maintenance dialysis only a percentage of patients who could have potentially survived were actually treated. Even in the United States of America with its, from our point of view, almost unlimited resources, dialysis treatment is widely but not unlimited available. Budget limitations, but also scarcity in machines and staff, make the necessity of patient selection still unavoidable.

Despite the fact that selection has always been an item in dialysis treatment, a general concept how to perform this selection is never been developed. Locall institutions each designed its own method of deciding and when these methods were revealed they received much, and often adverse, publicity. ${ }^{3.4}$

National governments have often undertaken measures to facilitate general accessibility of dialysis. However there are also examples of national restrictions 
for this kind of life saving treatments. The most striking example is of course the United Kingdom where resources were and still are restricted by financial constraints.

Sociological or medical criteria are offen used in selection decisions. The age criterion is prabably most widely used, with the intention to screen out the very young and the oldest patients. In dialysis the age criterion has been employed during the seventies and eighties of the last century. ${ }^{5}$ In the Netherlands, agedbased decisions on dialysis remained in operation until the mid eighties. In heart transplantation still many centers accept only candidates who are less then 55 years of age. Often is stated that an age criterion is legitimate because it screens out elderly patients, who are in no physical condition to benefit from treatment. ${ }^{\circ}$ In this way age-criteria are used as some kind of medical-benefit criterion. From a more sociological point of view, the benefit that society will receive of the treatment of an elderly patient is probably less than of a young patient. Also an economic argument can be used to justify selection on basis of age. Modern medicine has accomplished compression of morbidity, meaning that many diseases become overt at the end of life. A large percentage of the medical costs are made for elderly patients. So when age is used to screen out patients a considerable amount of money can be saved.

In many ways an age criterion seems to be an objective criterion. However objectivity does not necessarily makes a criterion appropriate. Elderly patients may well be the weakest group of patients and thereby a.vulnerable group, who might be easily excluded. However this should be a reason for special care instead of less care. In this respect the term intergenerational solidarity is often used indicating that a caring society should provide the same kind of attention to the elderly (and the very young) as is given to economically active part of the population.

Nevertheless for dialysis some kind of selection or better perhaps rationing will be necessary. A definition of rationing could be a clear and direct limitation on individual access to a scarce good or service according to some categorical criteria other than the market. "These criteria should be preferably not political but medical, evidence based, criteria.

Our data show that in the Netherlands rationing is not altogether clear and overt. Although most nephralogists do not consider age as a selection criterion, we found in our study less patients from the eldest age group in the treatment population. Treatment is more often offered to younger patients than to older patients, resulting in a significant difference in the mean age between treated and untreated groups. ${ }^{8}$ Whether the general physician also plays a role in this phenomena remains unclear. Besides this ageism there is also a trend of sexism. In our studies we find an overrepresentation of male patients. In the literature however, we also do find this male preponderance." End-stage renal disease has to be considered as - a late - manifestation of atherosclerolic disease. This explains probably why men are more often seen at the nephrology department. Women, with a later onset of atherosclerotic disease, often do not reach this late stage of vascular impairment because they die from other causes. 
From our findings, it appears that other factors that favour treatment include a high serum creatinine (indicating a severe renal impairment), the causative diagnosis of glomerulonephritis and/or nephrosclerosis, lower body mass, a low Charlson index (indicating less comorbidity), and the presence of a partner.

We did found in our retrospective survey a mean survival time of 463.2 days for elderly patients treated with RRT vs. 323.4 days for patients who did not receive RRT. In the age group 65-70 mean survival was 484.7 days (median survival 397 days). Patients aged $71-75$ had a mean survival of 468.5 days (median 273 days). In the age group $75-80$ mean survival was 328.2 days with a median survival of 28.5 days. In the age group over 80 , mean survivall was 192.9 days with a median survival of 32 days.

in all but the highest age group mean and median survival was better in the patients who underwent RRT in comparison to the patients who did not receive renal replacement therapy. In patients over the age of 80 years, mean survival was better in the group not treated patients. Treatment did give in this age group only a slightly better median survival. ${ }^{10}$ Given these results there are few arguments to offer RRT to patients over 80 years of age. In this age group only strong individual arguments can be a reason to offer RRT.

The diagnoses cardiac disease, diabetes mellitus type II, and postrenal causes of renal disease negatively influenced survival. The latter prabably because the high incidence of a malignancy of the prostate as a cause for postrenal obstruction. The diagnosis glomerulonephritis was, in our population, strongly associated with a longer survival.

In each age group, the influence of comorbidity was apparent. Survival was shorter within each age class when a higher Charlson score was present. This is in accordance with literature. A Charlson index of 0 is correlated with a oneyear survival of $88 \%$, an index of $1-2$ with a one-year survival of $74 \%$; an index of $4-5$ and -5 are respectively correlated with a one-year survival of 48 and 15\%." (Figure 6.1) Cardiovascular disease, diabetes mellitus malignancies and diabetic organ damage are all represented in the Charlson index. In our data these conditions are associated with a shorter survival. Therefore it seems reasonable to reconsider RRT in patients with a Charlson index of $>2$.

Problems with urine production and continence are considered to be an expression of the poor condition of the patient These findings are in line with the finding that urinary incontinence is associated with a poor prognosis of elderly in-hospital patients. ${ }^{12}$

Acute onset of ESRD in the elderly was accompanied by an increased mortality in our study population. Especially the elderly patients who reach the criteria for end-stage renal disease within two weeks, acute renal failure, have a bad prognosis. ${ }^{10}$ In these patients there is a rapidly progressive disease with a very serious impact on the patient. A longer and more gradual onset of renal failure, with the possibility of a timely anset of treatment, was characterized by a better patient survival. However, a long renal history of more than 5 years, before treatment was started shows an increase in the number of patients dying during 
the follow-up period. This phenomenon is seen in male as well female patients. This emphasizes once more that the moment RRT is started is very crucial in elderly patients.

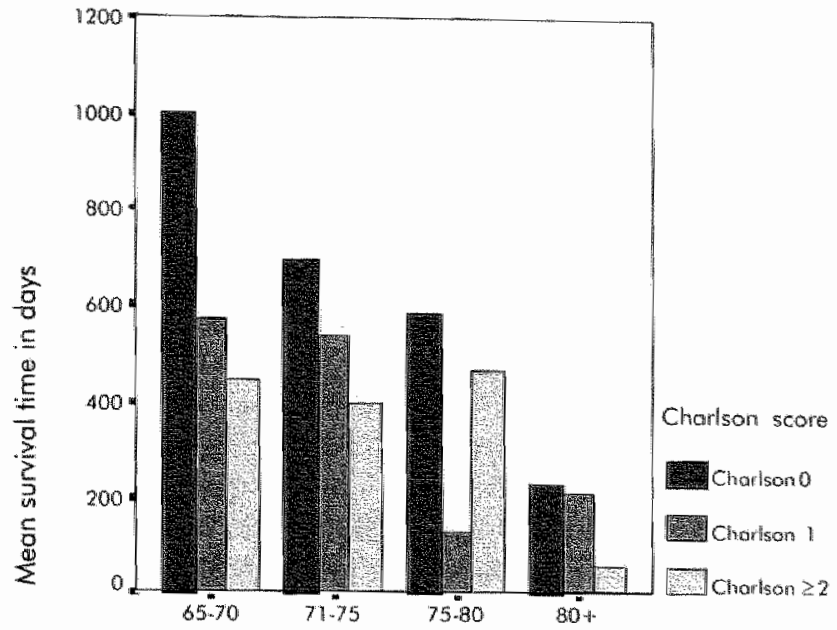

Age groups

Figure 6.7 Survival in relation to Charlson index

Dialysis patients perform worse on mobility and ADL-ability than older control patients. ${ }^{\text {is }}$ Consequently they are in need of more informal and professional help than the control patients and even then the pre-dialysis patients. Especially in male patients, disease lays a heavy burden on the partner. In our data we find more patients living with a partner on RRT in comparison to patients on RRT. Also we find in this group more patients with care provided by the children. Most likely this is due to selection meaning that patients with o solid social basis are more often accepted for RRT. This so-called supportive environment criterion was in use in the past in the United States for entering dialysis treatment before federal funding brought renal replacement therapy in reach for a larger number of patients. "Sometimes even marital status was used as entry criterion. ${ }^{15}$ This criterion is however difficult to apply. There is no general consensus on exactly what environmental factors facilitate effective treatment. Litlle or no evidence from studies is available on the relation of environment and medical benefit. The patient himself cannot be held responsible for his poor environmental conditions. However one has to realise that renal replacement therapy in elderly patients in general, and especially in elderly patients with insufficient support imposes high demands on the dialysis facility. In this respect we want to make strong recommendations that a dialysis facillity takes special measurements to assure that a patient never is rejected because lack of supportive care.

In a logistic regression model using a stepwise backward strategy, we found serum creatinine, the diagnosis of glomerulonephritis, and the need for a urinary catheter as independent factors that favoured treatment. ${ }^{10}$ in our follow- 
up study we found no relation between the value of serum creatinine and the success of the treament. It is conceivable that doctors are impressed by a very high serum creatinine, but this number alone cannot be used as a factor in decision making. The causative diagnosis glomerulonephritis is associated with a relatively good prognosis in patients with end-stage renal disease treated with renal replacement therapy. Most likely is this the result of the fact that these patients have less atherosclerotic lesions in comparison with elderly patients. So in elderly patients with glomerulonephritis RRT should be strongly recommended.

We hardly encountered patients with cognitive deterioration or ovent dementio in our study population. Without doubt this is due to selection. Is it reasonable to exclude patients with cognitive impairment from an intensive treatment as RRT? In this respect the scores on the sickness impact profile we found in dialysis patients are wery important. ${ }^{13}$ Scores of pre-dialysis patients resemble scores of elderly patients without renal disease, where patients stable on RRT had significantly higher scores. Functional observations give no indication of more depressive feelings in RRT patients. A possible cause may be a feeling of no langer being in control when on renal replacement therapy. In favour for this explanation is the relative high score of dialysis patients on the item social behaviour in the SIP68. Also higher scores on mobility control and somatic autonomy can point in this direction. This finding is in sharp contrast with the gemeral feeling that renal replacement therapy is not only prolonging life but also is improving quality of life. This aspect of renal replacement therapy should be thoroughly discussed with a patient before starting RRT. It is our feeling that consent by proxy is not enough to impose a therapy with such an intensity on a patient, but that the decision to undergo this therapy should be made by a patient capable to assess the weight of this decision. So, in our opinion, a major impairment of the cognitive function will make the patient not suitable for RRT.

It is possible that patients on CAPD have a better appreciation of the quality of their life. The mean total SIP68 score is suggestive in this way. But here cognitive impairment will make this kind of renal function replacement therapy impossible because of the technical demands this therapy imposes on the patient.

In generall can be said that following literature CAPD is better endured by elderly patients and a greater effort should be made in the Netherlands to include more elderly patients in CAPD programs.

Based on our findings it is possible to draw an algorithm for decision making in elderly patients with end-stage renal disease (Figure 6.2). It should be noted that this algorithm is based on retrospective and cross-sectional sludies and is not tested in a prospective investigation.

Furthermore the assumption is made that this kind of algorithm is applied in an institution with ample resources for supportive care for elderly patients on RRT and also equipped to offer palliative care for patients with ESRD not on RRT.

Finally we want to emphasize that this algorithm can be only a helpful tool in decision making and never can or will replace the judgement of a skilful doctor who reaches consensus with his or her patient. 
So, in an elderly patient with ESRD and in need of RRT, the first issue which must be answered is whether the patient is able to understand the information given to him by his doctor and to reach a decision.

Renal replacement therapy should be offered to a patient under 80 years of age when the causative diagnosis is glomerulonephritis and/or when mild comorbidity is present (Charlson index 2 or under). A more severe comorbidity or a bad score on the Barthel index $(<15$ but $>5)$ should raise serious questions whether RRT is appropriate for the patient. However, individual arguments can be in favour for a treatment decision. In our opinion no RRT should be offered to patients 65-80 years of age in the presence of a high comorbidity score and a bad performance on the Barthel index.

In patients over 80 years of age RRT is not leading to a better survival. RRT therefore can be offered to patients who are in a very good condition (high scores on the Barthel index and no serious comorbidity), especially when the causative diagnosis is glomerulonephritis.

The better appearance of the pre-dialysis patients is a possible disadvantage for this group of patients. In spite of their better performance on mobility and ADLfests and also on the SIP68, their mean survival, when started on RRT is shorter than that of patients stable on dialysis. In this way these patients confront us with a dilemma. They are feeling better and performing better when not on RRT. On the other hand when started on dialysis they have a mean survival of a little more than one year. During this period as we found the feeling of well-being is diminished. An earlier start of RRT therefore will probably prolong life but at a high price since a loss of the feeling of well-being seems to be associated with RRT.

One must bear in mind that we studied a selected population. It is widely known that elderly patients with ESRD are often not referred to the hospital by the general physician. This phenomenon probably influenced the finding that an acute deterioration of renal function in our population was most often seen in the eldest age group. A slow and gradual loss of renal function in this group is probably accepted as a hallmark of the end of life and does not usually lead to referral. However, survival appears to be influenced by renal history. Patients with a long renal history and, consequently, a more gradual and less aggressive progression of the renal disease, are probably more suited candidates for RRT (Figure 6.1.). It may be concluded that the "wrong" category of elderly patients is usually referred to the hospital, especially in the eldest age group. In future we should try to achieve a situation where elderly patients with a deterioration of their renal function are referred to a specialized institution. Here not only the cause of the renal impairment should be carefully diagnosed, but also should be investigated whether the patient is eligible for RRT, also and propably most important, the right moment to start RRT should be determined. 


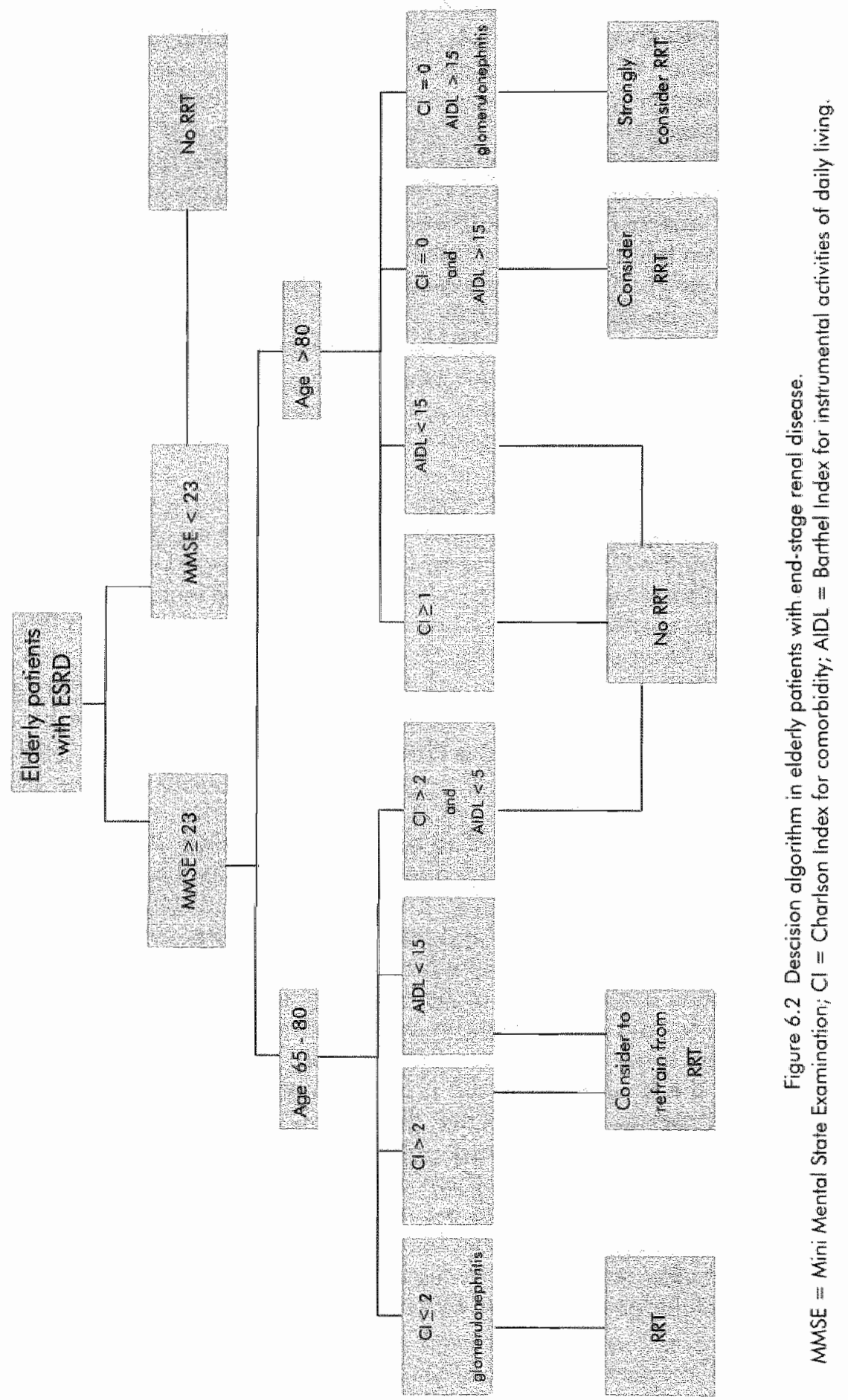




\section{Literature}

1. Schreiner GE. There is a third way. Archives of Internal Medicine 1968;121:463:65.

2 Registratie Nierfunctievervanging Nederland: Statistisch jaamerslag 1998. [Dutch renal replacement Registry. Annual statistical report 19981 stichting Renine Rotterdam, 1998.

3. Elkinton JR. Moral problems in the use of borrowed organs, artificial and transplanted. Annals of internal Medicine 1964;60:309-313.

4. Kilner JF. Who lives? Who dies? : ethical criteria in patient selection Yale University Press New Haven \& London 1990:4.

5. Evans RW. Health Care Thechnology and the Inevitability of resource allocation and rationing decisions (2 parts). JAMA 1983;249:2047-53 and 2208-2019.

6. Aday LA, Andersen RM. Equily of access to medical care: A conceptual and empirical overview. Medical Care 19(suppl): 1981;4-27.

7. Moody HR. Ethics in an aging sociely. The John Hopkins University Press, Battimare Maryland 1992.

8. Mulder WJ, Fiolet JFBM, Leunissen KML, Hillen HFP. Clinical characteristics of elderly patients with end-stage renal disease: a retrospective study in the Dutch population. Submitted for publication.

9. Chandra SM, Schulz J, Lawrence C, Greenwaod RW, Farrington K. Is there a rationale for rationing chronic dialysis? A hospital based cohort study of factors affecting survival and morbidity. BMJ 1999;318:217-223.

10. Mulder WJ, Hillen HFP, Leunissen KML, Fiolet JFBM. Treatment selection criteria and prognostic factors in elderly patients with end-stage renal disease. Submitted for publication.

11. Charlson ME, Pompei P. Ales KA, Mackenzie CR. A new method of classifying prognostic comorbidity in longitudinal studies: Development and validation. J Chron Dis 1987; $40151: 373-383$.

12. Fiolet JFBM. Flankerend geriatrisch beleid Academical thesis. Maastricht, 1995

13. Mulder WJ, Fiolet JFBM, Lewnissen KML, Hillen HFP. The burden of end-stage rend disease in elderly. Submitted for publication.

14. Abram HS, Wadlington W. Selection of patients for artificial and transplanted organs. Annals of Internal Medicine 1968;69(9): 615-620.

15. Kilner JF. Who lives? Wha dies? Elical criteria in patient selection. Yale university press New Haven \& London, 1990. 


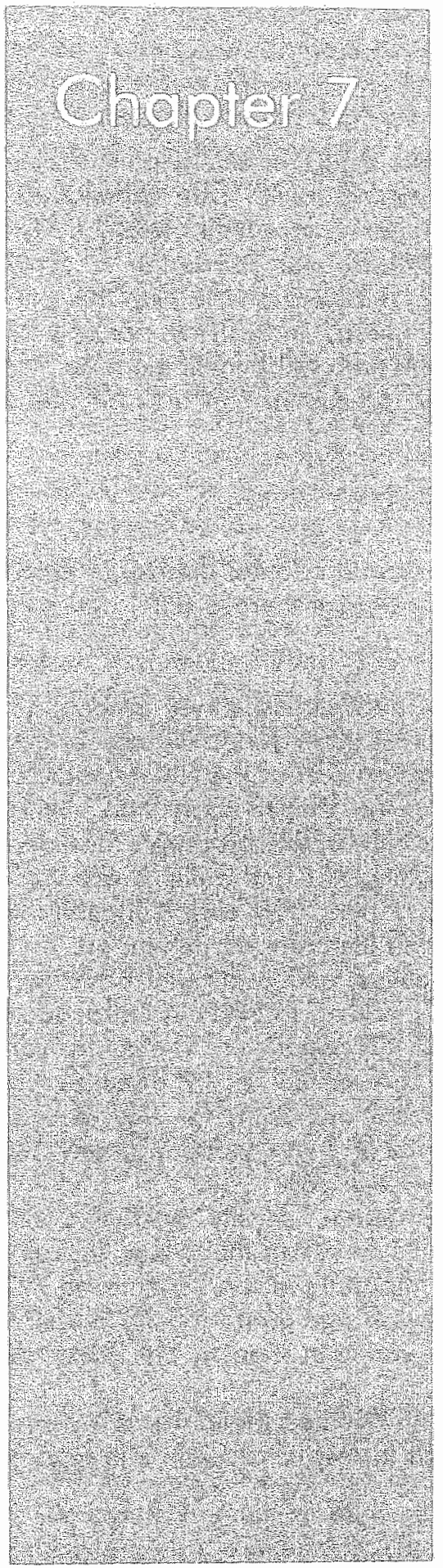

\section{Summary}




\section{Summary}

The topic of this thesis is end-stage renal disease (ESRD) in elderly patients. Due to both patient-related factors and ever-increasing health care expenditures, some kind of selection of elderly patients for renal replacement therapy (RRT) is inevitable. The aim of the studies we undertook was to design a simple algorithm to assist doctors in making treatment decisions and to help them find the best possible match between patients and therapy. In this way, not only can renal replacement therapy be offered to patients who will benefit the most from this treatment, but patients less suited for this procedure can also be spared much suffering.

In chapter 1, a short outline of this thesis is given.

Chapter 2 reviews the literature on renal function and renal disease in elderly people (chapter 2A), as well as on renal replacement therapy (RRT) and renal transplantation in elderly patients (chapter $2 \mathrm{~B}$ ).

In chapter 3 the results are presented of a retrospective survey among 331 elderly patients 165.95 years of age $\mid$ with end-stage renal disease in four hospitals with a dialysis facility in the south-eastern part of the Netherlands. Of interest were the incidence of renal failure in the elderly population, clinical characteristics of these patients, and the accessibility of RRT programs for elderly patients. When including both patients undergoing RRT and patients with ESRD (yet) on RRT, the incidence of renal failure 2.2 per 1000 elderly inhabitants, which is higher than that usually reported in the literature. Hypertension, renal vascular disease, cardiac failure, diabetes mellitus, and post-renal obstruction were the most frequently encountered diseases leading to ESRD in these elderly patients. An extensive comorbidity was found in this population. The comorbidity was classified using the Charlson index, a score based on 19 diseases. The relative risk of death within 1 year after clinical admission for one of these diseases determines the score. A Charlson Index of 1 was found in nearly $30 \%$ of the patients, and a Charlson Index of 2 or more in $16 \%$.

135 patients $(41 \%)$ enrolled in a RRT program, mostly passive center hemodialysis. Seventy of these patients $(52 \%)$ died within the 2-year inclusion period. Age and renal diagnosis proved to be important factors for entering RRT. Most patients entering RRT were from the youngest age group ( $65-70$ years). In the higher age groups acute RRT was more common than in the lower age groups.

Of the 196 patients not treated with RRT, $112(57 \%)$ died within the observation period. This survey did not clearly reveal which factors were taken into account in the treatment decision.

In chapter 4,274 patients are studied who developed ESRD between 1 January 1992 and 31 December 1993. Patients who were admitted to a RRT program, 
as well as those who were not undergoing renal replacement therapy, were studied. A follow-up of these patients was carried out until 31 December 1999. Of these patients, 96 were enrolled in RRT progroms and 178 patients were not. Logistic analysis showed that selection for treatment was significantly associcited with serum creatinine and the causative diagnosis glomerulonephritis. Cardiac and postrenal causes of ESRD as well as incontinence for urine were associated with a smaller chance of being admitted to a RRT program. Mean surwival was calculated of the patients who died. In those patients who underwent RRT aged $65-70$, survival was 570 days; in those aged $71-75$, it was 641 days; in patients $76-80$ years of age survival was 351 days, and in those over 80 years of age it was 102 days. In the group that did not receive RRT, mean survival was also calculated for patients who died. In patients aged 65-70, 71-75, 76-80, and over 80 years, survival was $418,370,322$, and 221 days, respectively. Survival was dependient on age and comorbidity. Acute onset of ESRD in the elderly was accompanied by an increased mortality, where a more gradual onselt was characterized by a better patient survival. Furthermore, comorbidity was of importance in patient survival.

In chapter 5, the effect of RRT on well-being and the quality of life of elderly patients is studied. Elderly patients are often in poor physical condition before the initiation of dialysis treatment. The most common symptoms are anorexia, weight loss, generalized weakness, encephalopathy, nousea, and vomiting. RRT often results in an improvement in their physical condition. We hypothesized that poor physical condition before the initiation of RRT would be reflected in high scores on a sickness impact scale. Improvement in physical condition by being stable on RRT would, in that case, lead to lower scores on the sickness impact profile. Therefore, we compared 16 elderly ESRD patients, selected for, but not yet on, RRT with 107 elderly patients stable on RRT. To assess the degree of improvement in quality of life, we also included 59 consecutive patients, referred to the outpatient facility of the geriatric department, in the comparison. Patients on dialysis scored lower on mobility and ability to perform daily activities (ADL) than pre-dialysis and control patients. The impact of ESRD on elderly pre-dialysis patients was deterioration in their functional capability over a period of 3 months. Nevertheless, the sickness impact profile, measured by the SIP-68, shawed patients stable on RRT as having the highest scores. Thus, in this patient category, improvement in physical condition does not lead to improvement in the feeling of well-being. No signs of depression could be found in these patients. Therefore we speculated that their feeling of no longer being 'in control "was the cause for their high scores on the sickness impact profile of elderly RRT potients.

In chapter 6 we propose a simple algorithm for rationing RRT in elderly patients. In this algorithm, an important item is the cogritive functionality of the patient. RRT has a major impact an the elderly patient. It probably improves his or her physical condition and, in patients under 80 years of age, leading to a better survival. On the other hand, RRT does not improve the feeling of wellbeing and leads to higher scores on the sickness impad profile. Each patient 
must have the right to make his or her decision in this matter. Good and ample information from the doctor, as well as the ability to understand this information and make an independent choice, are essential in this respect. In patients with o severe cognitive impairment, RRT should not be considered becouse the patient is not able to participate in the decision making.

Comorbidity, ADL-ability and the causative diagnosis of ESRD are factors that are also important in making the decision to initiate RRT. In patients aged $65-80$ with no overt cognitive impairment, mild comorbidity, good ADL-ability and the causative diagnosis of glomerulonephritis should be encouraged to start RRT. In contrast patients with extensive comorbidity and a poor ADL-ability should not be encouraged to dose. In patients with intermediate scores on ADL and comorbidity, a more individual approach must be taken before a treatment decision can be made.

In patients over the age of 80 , survival is highly determined by the age. Survival is not better in patients treated by RRT, than in those not treated by RRT. RRT should only be considered when there is no comorbidity and very good ADLability. Again, the causative diagnosis of glomerulonephritis favours treatment in these patients. 


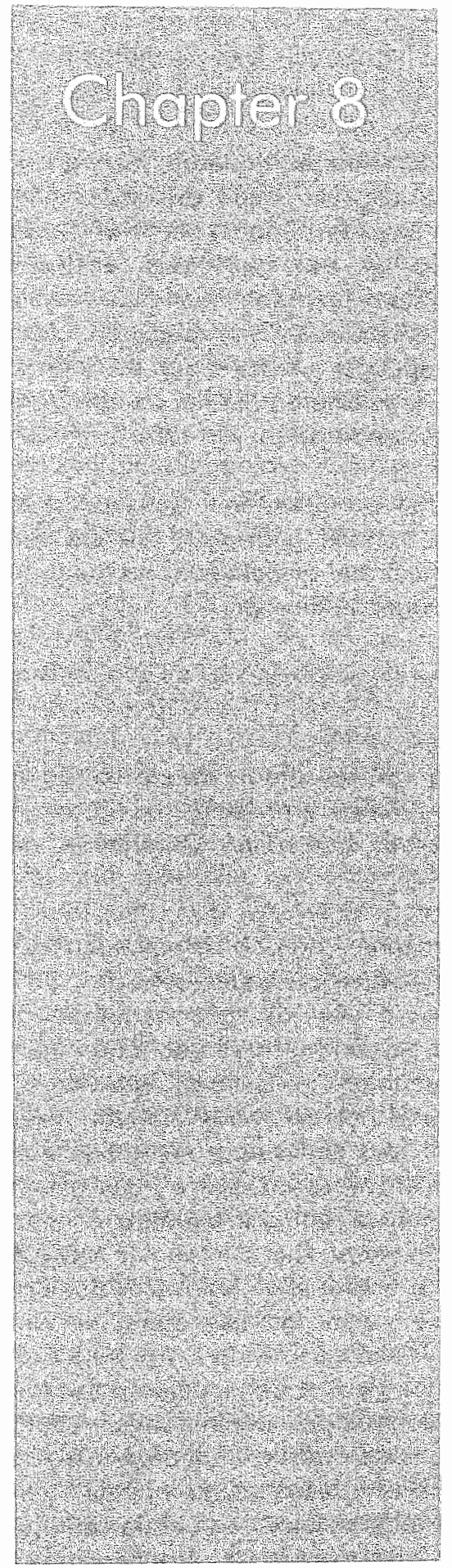

\section{Samenvatting}




\section{Samenvatting}

Dit proefschrift handelf over terminale nierinsufficiëntie bij ouderen. Hiervoor is nierfunctie vervangende therapie (nierdialyse) nodig. Dit is een vaor de patiënt zware behandeling waarvoor hij of zii, meestal meerdere malen per week, naar het ziekenhuis moet komen. Daarnaast is het ook een zeer kostbare behandeling. Het aantal ouderen met eindstadium nierfalen neemt de laatste jaren sterk toe als gevolg van de toename van atherosclerotisch vaatlijden. Deze toename, gevoegd bi hef feit dat er een beperkte ruimte is op de dialyse afdeling, maakt het noodzakelijk die patiënten te selecteren die het meeste baat hebben bij en het beste bestand zijn tegen het andergaan van deze hightech behandeling.

Het doel van het onderzoek beschreven in dif proefschrift is dan ook een simpele beslisboom op te stellen die dokters kunnen gebruiken om op een objectieve manier te bepalen welke oudere patiënt met eindstadium nierfalen in aanmerking moet komen voor nierfunctie vervangende therapie.

In hoofdstuk 1 wordt een beschrijving gegeven van de opzet wan dif proefschrift en de onderzochte patiëntenpopulaties.

In hoofdstuk 2A wordt een overzicht gegeven van de internationale literatuur over de werking van de nier bii ouderen en welke nierziekten biil ouderen voorkomen. In hoofdstuk 2B wordt de literatuur besproken betreffende de behandeling van nierziekten bij ouderen.

In hoofdstuk 3 beschrijven wij de klinische kenmerken van oudere patiënten met eindstadium nierziekte op basis van een retrospectief onderzoek van 331 patiënten. Deze patiënten werden opgespoord via de geautomatiseerde laboratoriumbestanden van vier Limburgse ziekenhuizen, het Laurentius ziekenhuis in Roermond, het Maaslandziekenhuis in Sittard, het Atrium ziekenhuis in Heerlen en het academisch ziekenhuis te Maastricht. Er werd gezocht naar patiënten van 65 jaar en ouder met een serum creatinine van $\geq 400 \mu \mathrm{mol} / \mathrm{l}$ in de jaren 1992 en 1993. Op deze wijze konden wij niet alleen de patiënten die behandeld werden opsporen, maar oak die patiënten vinden die niet voor hun terminale nierziekte behandeld waren met dialyse. Dit maakte het mogelijk een uitspraak te doen over het voorkomen van eindstadium nierziekte bij ouderen. Onze schatting hiervan, een jaarlijks optreden van eindstodium nierziekte bii 2,2 ouderen per 1000 oudere inwoners, viel hoger uit dan de schattingen in de literatuur omdat wii ook de niet behandelde patiënten konden meetellen. Van de in totaal 567 patiënten die aan de criteria voldeden, kon van 331 patiënten een medisch dossier gevonden worden. Uit deze dossiers werden gegevens verzameld betreffende de klinische toestand, de oorzaak van de nierziekte, het tegelijkertijd voorkomen van andere ziektes en het percentage patiënten dat dialyse onderging. Hypertensie, vaatafwijkingen van de nieren, hartfalen, suikerziekte en obstructie van de urinewegen waren de meest 
voorkomende oorzaken van nierfalen bij ouderen. De bijkomende ziekten, de co-morbiditeit, werd vitgedrukt in de Charlson index. Dit scoringssysteem kent een getal toe aan negentien veel voorkomende aandoeningen. Het relatieve risico op overlijden binnen één jaar na een klinische opname voor deze ziekfebeelden bepaalt de hoogle van de score. Wii vonden een Charlson index van 1 bij ongeveer $30 \%$ van de patiënten en een index van 2 of meer bij $16 \%$.

Met nierdialyse werden 135 patiënten (41\%) behandeld. Hiervan overleden er $70(52 \%)$ gedurende de inclusieperiode van twee jaar. De leeftijd en de diagnose betreffende de nierziekte bleken belangrijke factoren voor het al dan niet ondergaan van dialyse. De meeste patiënten die werden opgenomen in een nierfunctie vervangend programma kwamen uit de jongste leeftijdsgroep. Bii patiënten vit de hogere leeftijdsgroepen kwam vaker acute dialyse behandeling voor dan bij de jongere patiënten. Van de 196 patiënten die niet behandeld werden met dialyse overleden er $112(57 \%)$ in de inclusieperiode van twee jaar. Uit de medische dossiers kwam niet duidelijk naar voren welke criteria werden gebruikt om te beslissen of een patiënt wel of niet behandeld werd.

Voor het onderzoek beschreven in hoofdstuk 4 werd in principe dezelfde populatie gebruikt als die in hoofdstuk 3. Alleen werden nu de patiënten bestudeerd die in de inclusie periode hun nierfalen ontwikkelden. Hel klinisch beloop bij deze patiënten werd vervolgd tot 31 december 1999. Van deze 274 patiënten werden er 96 behandeld met nierdialyse en 178 patiënten ondergingen geen nierfunctie vervangende therapie. Logistische regressie analyse toonde aan dat selectie voor dialyse was geassacieerd met de hoogte van het serum creatinine en de diagnose glomerulonefritis. Wanneer de oorzaak van het nierfalen een hartaandoening was of lag in obstructie van de urinewegen, was de kans op behandeling kleiner, evenals bii patiënten die incontinent waren voor urine.

Van de patiënten die overleden tijdens de follow-up kon de gemiddelde overleving berekend worden. Voor de dialyse patiënten bedroeg deze gemiddelde overleving 570 dagen in de leeftijdsgroep 65.70 jaar. In de leeftijdsgroepen $71-75$ jaar, $76-80$ jaar en de groep ouder dan 80 jaar was de gemiddelde overleving van de overleden potiënten respectievelijk 641, 351 en 248 dagen.

Van de niet met dialyse behandelde patiënten die overleden tijdens de follow-up was de gemiddelde overleving per leeftijdscategorie: $418,370,317$ en 222 dagen.

De overleving bleek afhankelijk te ziin van de leeftijd en de co-morbiditeit. Acuut optreden van nierfalen ging gepaard met een hogere mortaliteit dan wanneer er sprake was van een meer geleidelijke ontwikkeling van het nierfalen.

In hoofdstuk 5 is de invloed van dialyse behandeling op hef gevoel van welbevinden en de kwaliteit van leven bij de oudere patiënt het onderwerp van onderzoek. Ouderen zijn vaak in een slechte lichamelijke conditie op het moment dat ze aan dialyse behandeling beginnen. Veelal hebben ze geen eetlust, zijn ze afgevallen en is er sprake van gegeneraliseerde spierzwakte, verwardheid, misselijkheid en braken. Behandeling met dialyse leidt vaak tot 
een sterke verbetering wan hun lichamelifke conditie. Wil veronderstelden dat deze lichamelike verbetering vergezeld zou gaon door een verbetering van gevoelens van welbevinden en lagere scores op een schaal wan sickness impact. Om deze hypothese te bewijzen vergeleken will 16 oudere patiënten vlak woor hun eerste dialyse behandeling met 107 patienten die al langere tiid gedialyseerd werden en stabiel waren. Om de mate van verbetering te kunnen inschatten betrokken wi ook 59 patiënten zonder nierziekte van de polikliniek geriatrie in de vergelijking. In tegenstelling tot wat wij verwachtten scoorden de dialyse patienten lager wat betreft mobiliteit en het vermogen tot het verrichten van ADL handelingen dat de pre-dialyse patiënten en de controle patiènten. Het effect van eindstadium nierziekte bleek bij de pre-dialyse patiënten uit een relatief laag lichaamsgewicht. Daarbii bleek hun functionele capaciteit in een periode van drie maanden achteruit te gaan. De scores op het sickness impact profile, de SIP68 waren het hoogst bii de dialyse patiënten. Deze patienten scoorden laag op een depressie schaal. Op basis van deze bevindingen postuleren wij dat dialyse patiënten zich "ziek" voelen omdat ze niet langer de controle over hun leven in handen hebben, maar afhankelijk zijn wan een chronische en intensieve behandeling.

In hoofdstuk 6 wordt een relatief simpele beslisboom voorgesteld voor het toewizen van dialyse behandeling aan oudere patiënten. In deze beslisboom is cognitieve functionaliteit een belangrijk item. Dialyse behandeling is een zware behandeling met belangrijke consequenties voor de patiënt. De patient heeft het recht hierin zijn eigen beslissing te nemen. Voorwaarde hiervoor is dat hij voldoende en volledig wordt geinformeerd door zijn behandelende arts en hij in staat is deze informatie te begrijpen, om onafhankelijk een beslissing te nemen. Bij patiènten met cognitieve functiestoornissen moet een dialyse behandeling niet gestart worden wanneer ze niet voldoende in staat zijn in de besluitworming te participeren.

Bij oudere patiënten in de leeftijd 65 to 80 jaar zijn vervalgens een beperkte comorbiditeit, een goede ADL functionaliteit en de diagnose glomerulonefritis, argumenten om te beslissen tol nierfunctie vervangende therapie. Bij patiënten in deze leeftijdscategorie met ennstige co-morbiditeit en/of slechte $A D L$ functionaliteit zou afgezien moeten worden van dialyse. Wanneer er sprake is van een minder enstige co-morbiditeit en matige scores wat betreft de $A D L$ functies zal een meer individuele benadering van de patiënt viteindelïk moeten lleiden tot een beslissing over de behondeling.

Bij patiërten ouder dan 80 jaar wordt de overleving in hoge mate bepaald door de leeffijd. Dialyse verlengt de levensverwachting niet. Nierfunctie vervangende therapie moet alleen bij die patiënten overwogen worden wanneer er geen noemenswaardige co-morbiditeit aanwezig is en een vlekkeloze ADL functionaliteit. Ook de aanwezigheid van de diagnose glomerulonefritis is een argument voor behondeling. 


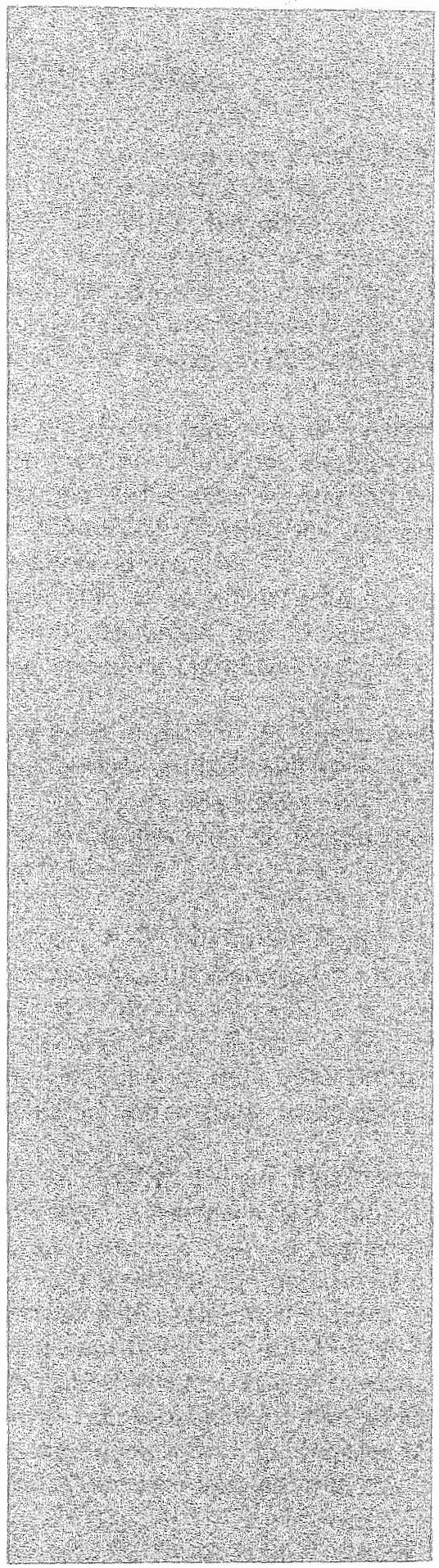

\section{Dankwoord}




\section{Dankwoord}

Het schrijven van een proefschrift is een enorm kanwei. Opvallend vaak wordt het vergeleken mef de fysieke inspanningen die nodig zijn voor het bouwen van een huis. Nu ik het afgelopen jaar zowel het grootste deel van dit boekje heb geschreven en tevens ons huis grondig heb werbouwd kan ik wit eigen ervaring meedelen dat één en ander weinig met elkaar te maken heeft. Wel kan gesteld worden dat "bouwvakken" een goede afleiding is van "schrijven" maar dat je tijdens het werken in de bouw innig kan verlangen naar het rustig achter de PC zitten.

De enige overeenkomst is wellicht dat je tijdens beide werkzaamheden mensen ontmoet met een eigen deskundigheid die enthousiast kunnen praten over hun vak. Zowel het schrijven als het verbouwen geeft een unieke kans deze mensen te ontmoeten en met hen samen te werken en dat heb ik als buitengewoon inspirerend ervaren.

Zonder nu af te willen doen aan de inspanningen van de vele bouwvakkers die ik het afgelopen jaar ontmoette, wil ik in het volgende een aantal mensen bedanken die betrokken waren bij het tot stand komen van dif proefschrift.

Allereerst moet in dit verband genoemd worden Prof.dr. J.A. Flendrig. Hii schetste op een half a-4 tje de eerste opzet van dit proefschrift. Het is opvallend om te zien hoe dicht wii, zoveel jaren later, zijn vitgekomen bij zijn oorspronkelijk idee. Ik betreur het zeer dat hij hiervan geen getuige meer kan zijn.

Prof.dr. A.C. Nieuwenhuijzen Kruseman. Beste Arie, iii hebt mii niet alleen gewezen op hef belang van het doen van onderzoek binnen de academische setting, maar hebt ook een serieuze poging gedaan het starten van mijn onderzoek mogelijk te maken, door te proberen daar tijd voor vrij te maken. Hoewel het voor mijn aanstelling bij het azM niet ongunstig was dat die poging mislukte, heb je zo de basis gelegd voor het onderzoek, warvoor mijn dank.

Prof.dr. H.F.P. Hillen. Beste Harry, iii hebt mii dan toch over de eindstreep gekregen. Overigens niet door mij vrij te stellen van andere werkzaamheden, integendeel zou ik haast zeggen. De nauwe samenwerking van de loatste jaren gaf echter voldoende gelegenheid voor jou om te informeren noar de voortgang en was zodoende de stimulans die ik klaarblijkelijk nodig had. Met betrekking tot de vorm van dit proefschrift heb je een aantal voortreffelijke ideeën gehad die het schrijven in een stroomversnelling hebben gebracht. Uiteindelijk hebben we je oorspronkelijke tijdsplanning slechts drie maanden overschreden. Af en toe heb ik de indruk gekregen dat je aan niets anders dacht dan mijn onderzoek en dat was zeer stimulerend.

Dr. J.F.B.M. Fiolet. Beste Hans, iii hebt mii naar Maastricht gehaald. Tijdens een ltaliaanse maaltijd ontstond de verbondenheid die altijid gebleven is. Jouw 
grenzeloze enthousiasme en tomeloze energie hebben voor mil mogelijkheden gecreeerd die ik elders nooit gekregen zou hebben. Ik deel jouw mening over promoveren, maar die opvatting heeff je toch niet verhinderd mil waar nodig bij te staan en het onderzoek mogelijk te maken, waarvoor mijn dank. Nu moeten alleen nog iets verzinnen waardoor we elkaar vaker zien.

Prof.dr. K.M.L. Leunissen. Beste Karel, iij had als nefroloog de moeiliike taak te participeren in een onderzoek betreffende de 'zachte' aspecten van het hightech vak nefrologie. Ik bewonder je voor de manier waarop iif je van die taak hebt gekweten. De dialyseafdeling is geen sociale werkplaats, wat overigens niet betekent dat er niet voortreffelijk werk verricht wordt. Ik dank je voor de snelle correcties van de verschillende hoofdstukken en voor de vele zeer bruikbare aanwilzingen en tips.

Dr. F. Stevens. Beste Fred, in een fase waarin het onderzoek helemaal vast zat ben iii degene geweest die geprobeerd heeft mij weer op weg te helpen. Niet zozeer door te zeggen hoe iii vond dat het zou moeten, maar door mij te laten formuleren wat ik nou eigenlijk wilde. De gesprekken die wii voerden hadden zo een bijna therapeutisch karakter. Ik hoop dat wij in de toekomst nog eens een project kunnen opzetten.

De beoordelingscommissie. Prof.dr. J.A. Knottnerus, Prof.dr. R.A.M.G. Donckerwolcke, Prof.dr. W.H.L. Hoefnagels. Prof.dr. R.Th. Krediet, Prof.dr. C. Spreeuwenberg. Ik dank $u$ voor de zeer snelle en grondige beoordeling van het manuscript. Een aantal uwer nam daarbii nog de moeite om mii schriftelijk een aantal suggesties te doen om de lijn in het geheel duidelijker te maken. Sir Prof. J. Grimley Evans I would like to thank you for the many useful remarks you have send me after reading the draft version of this thesis.

Drs. E. Pijpers. Beste Evelien, jouw (terug-)komst naar Maastricht bracht de rust, tijd en gelegenheid om serieus aan het schrijven te gaan. Zonder de zekerheid dat de patiëntenzorg in goede handen was, was het nooit gelukt.

Noël Jaegers, hoewel ik me terdege besef dat jouw ambities, op een terrein liggen waar ik je nooit zal kunnen helpen, ben ik je dankbaar voor je onvoonwaardelijke hulp en steun. Ik verklaar hierbii dat als iij ooit de prins van Maastricht wordt ik dat jaar carnaval zal vieren.

Josephin van Lin, onze eerste schreden op het wetenschappelijke pad hebben wii samen gezet. Inmiddels ben iil gepokt en gemazeld in het research gebeuren. ledere onderzoeker zou mogen willen door jou geassisteerd te worden.

Dr. F. de Heer, dr. L.A.M. Frenken en dr. J.J. Wirtz. Beste Frans, Leon en Joris, jullie verleenden mij gastvrijheid in jullie ziekenhuizen en gaven mij inzage in jullie dossiers. Dank voor jullie bereidwilligheid en voor het feit dat jullie steeds opnieuw op zoek wilden gaan naar ontbrekende gegevens. Tevens heb ik bij 
jullie kunnen constateren dat er in de 'periferie' hard gewerkt wordt bii gunstiger secundaire arbeidsomstandigheden.

Een aantal studenten hebben in een wetenschaps-stage een bijdrage geleverd aan het onderzoek; van hen noem ik hier Mascha Spee, Tim Jansen en Sascha de Gast. Ik heb veel plezier beleefd aan de samenwerking. Ik hoop dat het wederzijds geweest is.

Pamela Falger, dank voor de snelle correcties van de hoofdsłukken en de vele verbeteringen in het Engels.

Monique, Lilian en Lilian, jullie hadden de ondankbare taak om mijn rust te bewaken als ik aan het schrijuen was.

Tiny Wouters, hoe vaak heb ik niet jaloers gekeken naar de collegae die door jou werden ingewijd in de essentie van het bewerken van een proefschrift. Jouw oog vaor details en met name het geduld warmee je aan de tekstopmaak bliff sleutelen verdient oneindig meer waardering dan je meestal kriigt. Als er iets is wat promoveren de moeite waard maakt dan is het door jou daarin begeleid te worden. Ik prijs mij zeer gelukkig te weten dat ik ook na deze dag nog bij je welkom ben en reken maar dat ik zo vaak als mogelijk is bij je binnenval.

Lieve Astrid, rust op het thuisfront is een absolute voorwaorde voor een man om iets te bereiken. Jii hebt daar de laatste jaren voor gezorgd op een voortreffelijke manier. Daarmee is dit boekje ook veel meer een product van ons beiden dan de naam op de kaft suggereert.

Peter en Maarten, het proefschrift is af. Dat betekent echter niet dat mijn computer nu collectief bezit is waar straffeloos op gedownload kan worden zonder rekening te houden met reeds aanwezige bestanden. Wel hoop ik nu meer tijd over te houden om me bezig te houden met jullie activiteiten en jullie (langs de lijn) te stimuleren tot grote prestaties. 


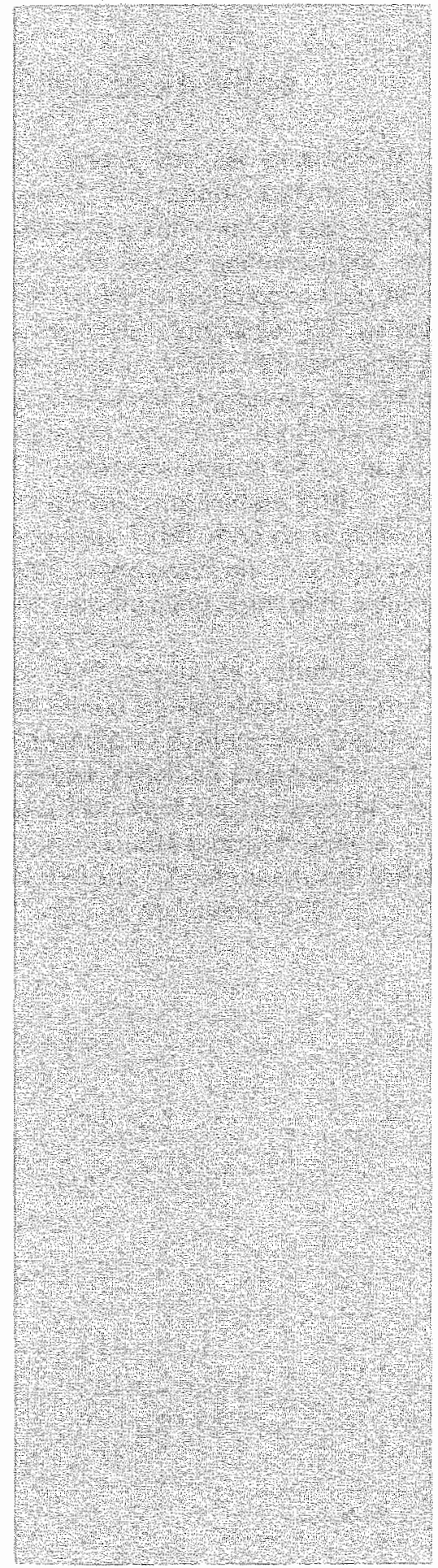

\section{Curriculum vitae}




\section{Curriculum Vitae}

De auteur van dif proefschrift werd geboren in Amsterdam. Na de lagere school, de school met de Bijbel 'Elout van Soetenwoude", behaalde hii het diploma gymnasium-B aan het Christelijk Lyceum Zuid in Amsterdam. Uitgeloot voor de studie geneeskunde, studeerde hij aanvankelijk psychologie aan de subfaculteit psychologie van de Vrije Universiteit te Amsterdam. Aan dezelfde universiteit studeerde hii vervolgens Geneeskunde. Het artsexamen werd afgelegd in 1983. Na een korte periode als agnio werd de specialisatie interne geneeskunde begonnen in het ziekenhuis st. Joannes de Deo in Haarlem (opleider dr. J.A.P. de Fockert). De opleiding werd vervolgd vanaf 1985 in het Academisch Medisch Centrum, het Academisch ziekenhuis bij de Universiteit van Amsterdam (opleiders Prof.dr. A. van Leeuwen en Prof.dr. J. Vreeken). Op 1 augustus 1988 vond de registratie tot internist plaats. Vervolgens werd hij in het AMC aangesteld als specialist patiëntenzorg en was onder andere betrokken bii de ontwikkeling van een polikliniek voor vetstofwisselings-stoornissen in dit ziekenhuis.

In 1992 volgde de verhuizing naar Maastricht waar hij tijdelijk werd aangesteld als staflid bii de afdeling Interne Geneeskunde (Hoofd Prof.dr. J.A. Flendrig) in de werkgroep Algemeen Interne Geneeskunde. Binnen deze werkgroep is zijn aandachtsgebied de geriatrie.

In 1994 werd hii aangesteld als staflid in vaste dienst bii de afdeling Interne Geneeskunde (hoofd Prof.dr. A.C. Nieuwenhuijzen-Kruseman).

In 1985 is hii getrouwd met Astrid Spee. Zij hebben samen twee kinderen: Peter (1987) en Maarten (1989). 